\title{
Vulnerability factors in panic disorder patients and their first-degree relatives : inquiries into carbon dioxide vulnerability, anxiety sensitivity, and respiratory pathology
}

Citation for published version (APA):

van Beek, N. (2003). Vulnerability factors in panic disorder patients and their first-degree relatives : inquiries into carbon dioxide vulnerability, anxiety sensitivity, and respiratory pathology. [Doctoral Thesis, Maastricht University]. Universiteit Maastricht. https://doi.org/10.26481/dis.20031017nb

Document status and date:

Published: 01/01/2003

DOI:

$10.26481 /$ dis.20031017nb

Document Version:

Publisher's PDF, also known as Version of record

Please check the document version of this publication:

- A submitted manuscript is the version of the article upon submission and before peer-review. There can be important differences between the submitted version and the official published version of record. People interested in the research are advised to contact the author for the final version of the publication, or visit the DOI to the publisher's website.

- The final author version and the galley proof are versions of the publication after peer review.

- The final published version features the final layout of the paper including the volume, issue and page numbers.

Link to publication

\footnotetext{
General rights rights.

- You may freely distribute the URL identifying the publication in the public portal. please follow below link for the End User Agreement:

www.umlib.nl/taverne-license

Take down policy

If you believe that this document breaches copyright please contact us at:

repository@maastrichtuniversity.nl

providing details and we will investigate your claim.
}

Copyright and moral rights for the publications made accessible in the public portal are retained by the authors and/or other copyright owners and it is a condition of accessing publications that users recognise and abide by the legal requirements associated with these

- Users may download and print one copy of any publication from the public portal for the purpose of private study or research.

- You may not further distribute the material or use it for any profit-making activity or commercial gain

If the publication is distributed under the terms of Article $25 \mathrm{fa}$ of the Dutch Copyright Act, indicated by the "Taverne" license above, 


\title{
Vulnerability Factors in Panic Disorder Patients
}

\author{
and Their First-degree Relatives
}




\section{Promotor:}

prof. dr. E.J.L. Griez

\section{Co-promotor:}

dr. K. Schruers

\section{Beoordelingscommissie:}

prof. dr. M.A. van den Hout (voorzitter)

prof. dr. M. Maes

prof. dr. J. van Os

prof. dr. G. Perna (San Raffaele Hospital, Milaan)

prof. dr. Ph. Spinhoven (Universiteit Leiden) 


\section{Contents}

1 Introduction

2 Reactivity to a $35 \% \mathrm{CO}_{2}$ challenge in healthy first-degree relatives of patients with panic disorder

3 Does age or sex influence anxiety sensitivity?

4 Anxiety sensitivity in first-degree relatives of patients with panic disorder

5 Anxiety sensitivity in children of panic disorder patients

6 Anxiety sensitivity and modulation of the serotonergic system in patients with panic disorder

7 Prevalence of respiratory disorders in first-degree relatives of panic disorder patients

8 Vulnerability to $35 \% \mathrm{CO}_{2}$ of panic disorder patients with a history of respiratory disorders

9 Concluding remarks

References

Summary

Samenvatting

Dankwoord

Curriculum vitae 



\section{Chapter 1}

\section{Introduction}

\section{Panic disorder}

A 30-year old women had her first panic attack while shopping. Afterwards she could not force herself to go to the same supermarket. The next panic attack occurred while driving a car. A sense of intense fear flooded over her and she pulled over at the side of the road and stepped out of her car, where she felt an immediate relief. From then on, the fear of another attack made it impossible to drive or go shopping.

For some people, anxiety takes the form of panic disorder (PD). Like the case described above, persons suffering from PD experience panic attacks. Panic attacks often come without warning or obvious cause and are marked by fear and symptoms like palpitations, dyspnea, chest pain and dizziness. People may worry about having a future panic attack. Repeated panic attacks lead to anticipatory anxiety. The person starts to fear and avoid places where panic attacks could occur or where help will not be available should panic recur. Panic attacks occur frequently and are sometimes linked to specific situations, such as driving a car as described in the above case. Several criteria must be met for the diagnosis to be applied (see box 1 and 2). 


\section{Box 1 Panic attack according to DSM-IV}

A discrete period of intense fear or discomfort, in which four (or more) of the following symptoms developed abruptly and reached a peak within 10 minutes:

1. palpitations, pounding heart, or accelerated heart rate

2. sweating

3. trembling or shaking

4. sensations of shortness of breath or smothering

5. feeling of choking

6. chest pain or discomfort

7. nausea or abdominal distress

8. feeling dizzy, unsteady, lightheaded, or faint

9. derealization (feelings of unreality) or depersonalization (being detached from oneself)

10. fear of losing control or going crazy

11. fear of dying

12. paresthesias (numbness or tingling sensations)

13. chills or hot flushes

Box 2 Panic disorder with agoraphobia according to DSM-IV

- Recurrent unexpected panic attacks

- At least one of the attacks has been followed by 1 month (or more) of one (or more) of the following:

- persistent concern about having additional attacks

- worry about the implications of the attack or its consequences (e.g., losing control. having a heart attack, "going crazy")

- a significant change in behavior related to the attacks

- The presence of agoraphobia:

- Anxiety about being in places or situations from which escape might be difficult (or embarrassing) or in which help may not be available in the event of having an unexpected or situationally predisposed panic attack or panic-like symptoms. Agoraphobic fears typically involve characteristic clusters of situations that include being outside the home alone; being in a crowd or standing in a line; being on a bridge: and travelling in a bus, train, or automobile. Note: Consider the diagnosis of specific phobia if the avoidance is limited to one or only a few specific situations, or social phobia if the avoidance is limited to social situations.

- The situations are avoided (e.g., travel is restricted) or else are endured with marked distress or with anxiety about having a panic attack or panic-like symptoms, or require the presence of a companion.

- The anxiety or phobic avoidance is not better accounted for by another mental disorder.

- The panic attacks are not due to the direct physiological effects of a substance (e.g., a drug of abuse, a medication) or a general medical condition (e.g., hyperthyroidism).

- The panic attacks are not better accounted for by another mental disorder, such as social phobia (e.g., occurring on exposure to feared social situations), specific phobia (e.g., on exposure to a specific phobic situation), obsessive-compulsive disorder (e.g., on exposure to dirt in someone with an obsession about contamination), posttraumatic stress disorder (e.g., in response to stimuli associated with a severe stressor), or separation anxiety disorder (e.g., in response to being away from home or close relatives). 


\section{Epidemiology of panic}

Panic attacks in the general population are quite frequent. The lifetime prevalence is estimated at $7 \%$ to $15 \%$. The lifetime prevalence of PD is between $1.5 \%$ and $2.5 \%$. Twelve month prevalence of PD rates around $1 \%$ (Overbeek, Vermetten, \& Griez, 2001). PD occurs almost twice as much in women than in men. The peak of onset for developing PD is generally around the age of 25 (Wittchen \& Essau, 1993; American Psychiatric Association, 1994). Co-occurrence of PD and depression is very common. Thirty to $60 \%$ of PD patients have a comorbid depression (Weissman et al., 1997). PD is also comorbid with other anxiety disorders (Goisman et al., 1994), as well as in other general medical conditions, such as cardiovascular diseases (Fleet, Lavoie, \& Beitman, 2000; Griez et al., 2000) and respiratory disorders (Perna, Bertani, Diaferia, Arancio, \& Bellodi, 1994; Spinhoven, Ros, Westgeest, \& Van der Does, 1994; Zandbergen et al., 1991).

It has been repeatedly shown that a strong genetic component is present in PD (e.g., Hettema, Neale, \& Kendler, 2001). Consistent with this hereditary component is the presence of other cases of PD in affected families (Coryell, 1997; Crowe, Noyes, Pauls, \& Slymen, 1983; Goldstein, Wickramaratne, Horwath, \& Weissmann, 1997; Hettema et al., 2001; Maier, Lichtermann, Minges, Oehrlein, \& Franke, 1993). The high rate of PD among offspring of a parent with PD suggests that there may be underlying psychological or biological vulnerability factors to PD. The factor $\mathrm{CO}_{2}$ sensitivity may identify subjects with a predisposition to develop panic. Therefore, we examined in the present thesis whether $\mathrm{CO}_{2}$ sensitivity is a marker of a vulnerability to PD. Furthermore, the psychological factor anxiety sensitivity and the physiological factor respiratory pathology are hypothesized to be important factors that might be transmitted in PD families. Hence, the focus of this thesis is to investigate whether anxiety sensitivity and respiratory pathology are vulnerability factors to PD.

\section{Carbon dioxide and panic}

Panic attacks are the core phenomenon in the clinical picture of PD. Historically, one was looking for a method to reduce panic attacks in PD patients by using an inhalation of $\mathrm{CO}_{2}$ enriched air as exposure to internal stimuli. But instead, an experimental model emerged building on the unexpected finding of $\mathrm{CO}_{2}$ enriched 
air inducing rather than decreasing anxiety symptoms. In experiments, subjects inhaled different percentages of $\mathrm{CO}_{2}$ enriched air, like the 5\% (Gorman et al., 1984 ) or the $7 \% \mathrm{CO}_{2}$ condition (Gorman et al., 1988). At the same time, Griez and Van den Hout also worked with carbon dioxide inhalation. They used a single breath inhalation of $35 \% \mathrm{CO}_{2}$ and $65 \% \mathrm{O}_{2}$. To their surprise they found that $35 \% \mathrm{CO}_{2}$ appeared to trigger anxiety symptoms rather than reducing it (Griez, Lousberg, Van den Hout, \& Van der Molen, 1987; Van den Hout \& Griez, 1984). Over the years it has become clear that $35 \% \mathrm{CO}_{2}$ induces panic-like symptoms and does not block anxious feelings as previously believed (Verburg, Perna, \& Griez, 2001). Inhalation of $35 \% \mathrm{CO}_{2}$ induces physical symptoms that mimic a panic attack, and in susceptible patients leads to subjective anxiety as well. Through a self-administration mask, subjects receive one vital capacity inhalation of $35 \%$ $\mathrm{CO}_{2}$ and $65 \% \mathrm{O}_{2}$ which triggers a very short-lived panic attack in the laboratory. Therefore, the $\mathrm{CO}_{2}$ challenge has been used as a laboratory model to study PD (Verburg et al., 2001).

This $\mathrm{CO}_{2}$ model for panic could give more insight into the mechanisms that cause anxiety in vulnerable individuals. Several studies have been carried out to examine this idea. In one study, $12 \mathrm{PD}$ patients and 11 healthy controls inhaled one vital capacity of $35 \% \mathrm{CO}_{2}$. It was found that PD patients were more anxious and experienced more panic symptoms than controls (Griez et al., 1987). Others have found the same result (Fyer et al., 1987; Perna et al., 1994). The $\mathrm{CO}_{2}$ vulnerability of PD patients was not a matter of an already present high baseline anxiety (Griez, De Loof, Pols, Zandbergen, \& Lousberg, 1990).

A next step was to investigate whether the challenge differentiates PD patients from other anxiety disorder patients. It has been shown that PD patients were more vulnerable to a $35 \% \mathrm{CO}_{2}$ challenge than patients with obsessive compulsive disorder (Griez et al., 1990; Perna, Bertani, Arancio, Ronchi, \& Bellodi, 1995), generalized anxiety disorder patients (Verburg, Griez, Meijer, \& Pols, 1995a), and subjects with animal phobia (Verburg, Griez, \& Meijer, 1994). Also, PD patients are more reactive to a $35 \% \mathrm{CO}_{2}$ challenge than patients with mood disorder (Perna, Barbini, Cocchi, Bertani, \& Gasperini, 1995) and other psychiatric disorders (Griez, Zandbergen, Pols, \& De Loof, 1990). Yet, persons with for example fear of heights or fear of thunderstorms (situational/natural phenomena phobics) were more vulnerable to the challenge than controls. Their increase in anxiety was comparable to that of PD patients (Verburg et al., 1994). Furthermore, social phobics seem to be 
$\mathrm{CO}_{2}$-sensitive as well (Caldirola, Perna, Arancio, Bertani, \& Bellodi, 1997). Although social phobics experience significantly more panic symptoms than normal controls, they were not more anxious (Verburg, Perna, Bellodi, \& Griez, 1998). It seems that the $\mathrm{CO}_{2}$ sensitivity in social phobics is in between that of healthy volunteers and PD patients (Schuers et al., personal communication). Besides, others found that $\mathrm{PD}$ patients were more sensitive to $\mathrm{CO}_{2}$ than patients with social phobia or normal subjects (Papp et al., 1993). Overall, the $35 \% \mathrm{CO}_{2}$ challenge appears to be a specific marker for a spectrum of conditions related to panic.

It is still unknown how $\mathrm{CO}_{2}$ inhalation exactly induces panic. It was thought that hyperventilation played a role. Obviously, an inhalation of $35 \% \mathrm{CO}_{2}$ a hypercapnic gas, induces a strong hyperventilatory response. Hyperventilation can be defined as rapid and deep breathing in excess of the metabolism resulting in a decrease of $\mathrm{CO}_{2}$ in the blood and increased blood acid level $(\mathrm{pH})$. Hyperventilation results in a state of respiratory alkalosis. The role of hyperventilation as a causal factor for panic has been investigated in several experiments. The rationale is, that if hyperventilation causes panic attacks by inducing respiratory alkalosis, then $\mathrm{CO}_{2}$ inhalation should not induce panic, because $\mathrm{CO}_{2}$ administration increases ventilation but does not induce alkalosis. This was investigated in PD patients. It was shown that PD patients did not panic after forced hyperventilation. However, $5 \% \mathrm{CO}_{2}$ for 20 minutes did induce panic (Gorman et al., 1984). Furthermore, it was found that hypocapnia resulting from forced hyperventilation failed to induce any clinically significant anxiety in PD patients or controls (Griez, Zandbergen, Lousberg, \& Van den Hout, 1988; Zandbergen, Lousberg, Pols, De Loof, \& Griez, 1990). In conclusion, hyperventilation does not causally induce panic. Not hypocapnia, but an increased $\mathrm{CO}_{2}$ concentration can induce a panic attack (Griez \& Verburg, 1995). Moreover, it is suggested that hyperventilation is a response to panic instead of a causal mechanism (Griez \& Verburg, 1995; Hornsveld, Garssen, Fieldeldij Dop, Van Spiegel, \& De Haes, 1996).

\section{Familial loading for PD}

The above mentioned studies show that the $35 \% \mathrm{CO}_{2}$ challenge induces panic in PD patients. This knowledge gave rise to a new experimental approach of PD. Family and twin studies were conducted using the $\mathrm{CO}_{2}$ challenge as a probe to explore the predisposition to $\mathrm{CO}_{2}$ vulnerability (Bellodi et al., 1998; Coryell, 1997; 
Perna, Bertani, Caldirola, \& Bellodi, 1996). Results suggest that $35 \% \mathrm{CO}_{2}$ hypersensitivity may be a marker of familial loading to PD (Chapter 2).

It has been established that genetic and familial influences play a role in the development of PD (Crowe et al., 1983; Goldstein et al., 1994; Kendler, Heath, Martin, \& Eaves, 1986; Skre, Onstad, Torgersen, Lygren, \& Kringlen, 1993; Torgersen, 1983, 1988; Weissman, 1993). For example, in one study, $17 \%$ of the first-degree relatives of PD patients had PD compared to $2 \%$ of the first-degree relatives of controls (Crowe et al., 1983). In another study it was found that first-degree relatives of PD patients had an increased risk for developing PD (Goldstein et al., 1994). Specifically, it seems that children of PD parents may be particularly prone to develop PD later in life. This is supported by other findings. Firstly, children of PD patients are at higher risk of having anxiety disorders than children of healthy control parents (Turner, Beidel, \& Costello, 1987). Secondly, during childhood, children of PD parents had significantly more often internalizing anxiety disorders than children of parents with animal phobia or healthy control parents (Unnewehr, Schneider, Florin, \& Margraf, 1998). And thirdly, in prospective studies most children with an anxiety disorder still suffer from an anxiety disorder later in adulthood (Newman et al., 1996; Pine, Cohen, Gurley, Brook, \& Ma, 1998). Given a relation between PD of parents and their offspring, it might be suggested that PD parents transmit a diathesis for PD. One diathesis for the development of PD might be high anxiety sensitivity. This is discussed in the next section.

\section{Anxiety sensitivity}

Anxiety sensitivity (AS) refers to individual differences in the fear of anxietyrelated sensations and the expectation that such sensations can have harmful consequences (Reiss, 1997; Reiss \& McNally, 1985). Just as some people are afraid of spiders, some individuals fear the sensations that accompany anxiety. This construct AS can be measured with the Anxiety Sensitivity Index (ASI) (Peterson \& Reiss, 1992; Reiss, Peterson, Gursky, \& McNally, 1986). AS has been proposed as a risk factor for the development of anxiety disorders, specifically PD (Reiss, 1991).

Besides AS, trait anxiety is also regarded as a vulnerability factor for the de- 
velopment of anxiety disorders. While AS and trait anxiety are intercorrelated (Muris, Schmidt, Merckelbach, \& Schouten, 2001), both constructs can be seen as conceptually different (McNally, 2002). Trait anxiety is a higher order construct that denotes a general tendency to react fearfully to stressors, whereas AS is a lower order construct that is viewed as a specific tendency to react fearfully to one's own anxiety symptoms (McNally, 1999). Some see AS as a facet of trait anxiety (McNally, 1999).

Several times it has been found that elevated ASI scores and PD are strongly associated (McNally, 2002). Research in adult populations has provided evidence that AS is elevated in patients with PD (Reiss, 1991; Taylor, Koch, \& McNally, 1992). In this respect, high AS would be considered as a consequence of a person having had panic attacks. On the other hand, elevated ASI levels were found in nonclinical subjects (Donnell \& McNally, 1990). This indicates that AS can be acquired from sources other than through direct experience with panic attacks. Misinformation about for example heart diseases may increase AS in an individual, as may observational learning. If the fear of anxiety-related symptoms can be acquired prior to any experience with panic, then AS can be a predisposing factor for the development of PD. Prospective studies have addressed this idea. Young nonclinical adults with high ASI scores were five times more likely to develop an anxiety disorder than young adults with low ASI scores during a 3-year followup. Three out of four subjects who had their first panic attack later on were in the high ASI group. Moreover, initial ASI scores predicted the frequency and intensity of panic attacks during the follow-up period (Maller \& Reiss, 1992). In another study, it was evaluated whether AS predicted the development of anxiety pathology. A large sample of nonclinical subjects was followed over a 5-week highly stressful period of time (i.e. military basic training). AS was found to be predictive of the development of spontaneous panic attacks after controlling for a history of panic attacks and trait anxiety (Schmidt, Lerew, \& Jackson, 1997). Taken together, these studies suggest that elevated AS is a vulnerability factor for developing panic.

Prospective studies of AS in nonclinical samples can evaluate the initial incidence of anxiety pathology. The role of AS in the long-term course of anxiety pathology can be examined in longitudinal studies of clinical samples. In this respect, reduction in AS levels due to treatment should be associated with clinical improvement. In Chapter 3 to 6 , the role of AS will be further discussed. 


\section{Respiratory disorders}

Obviously, elevated AS may not be the only risk factor for the development of PD. Other factors, such as respiratory disorders are also linked to PD. Superficial evidence in favor of a relation between PD and respiratory disorders is that symptoms of panic attacks show overlap with symptoms seen in patients with respiratory disorders (Smoller, Pollack, Otto, Rosenbaum, \& Kradin, 1996). On the other hand it is possible that, suffering from pulmonary disorders may increase the risk of developing PD. Consistent with this hypothesis, the rate of PD was found to be significantly higher in patients with chronic obstructive pulmonary diseases than in the general population (Karajgi, Rifkin, Doddi, \& Kolli, 1990; Yellowlees, Alpers, Bowden, Bryant, \& Ruffin, 1987). Moreover, PD patients were found to have suffered significantly more from lifetime respiratory disorders than other populations (Perna et al., 1994; Spinhoven et al., 1994; Zandbergen et al., 1991). Not only in adults have associations between PD and respiratory disorders been documented. A study in youth, aged 9-17 years, demonstrated that among anxiety disorders the strongest association was found between allergy and PD (Kovalenko et al., 2001). Furthermore, adults who develop PD later in life had a higher childhood prevalence of respiratory diseases than did obsessive compulsive and eating disorder patients (Zandbergen et al., 1991). Even more important, besides the above mentioned studies on high comorbidity of PD and respiratory disorders, respiratory diseases were associated with an increased risk for panic attacks in a large sample of adults in the general population. This association even persisted after controlling for sociodemographic characteristics, and comorbidity of physical and mental disorders (Goodwin \& Pine, 2002). Therefore, respiratory disorders may be a vulnerability factor for the development of PD. Increased awareness of respiratory disorders, like asthma, as a potential risk factor, is important, because asthma is one of the most common health problems, with an increasing prevalence in most developed countries (Steerenberg et al., 2000). Therefore, improving our understanding of the relation between respiratory pathology and PD is needed. Especially when considered the facts that both PD (see section familial loading for PD) and respiratory disorders, like asthma (e.g., Hopper, Hannah, Macaskill, \& Mathews, 1990), run in families. This might have clinical implications. Therefore, in Chapter 7 the link between PD and respiratory disorders in families will be further discussed. It is conceivable that both disorders are the expression of a third 
factor that runs in families and predisposes to PD. A familial association between $\mathrm{PD}$ and $\mathrm{CO}_{2}$ hypersensitivity has already been suggested (Coryell, 1997; Perna et al., 1996) and an inhalation of $35 \% \mathrm{CO}_{2}$ has a strong effect on the respiratory system. Thus, the study in Chapter 8 presents data on the possible link between respiratory pathology, $\mathrm{CO}_{2}$ vulnerability and $\mathrm{PD}$.

\section{Outline of the thesis}

With the above mentioned frame of reference in mind, the present thesis aims to elucidate three risk factors to PD. On that account, seven studies were performed in patients with PD and their first-degree relatives. In Chapter 2 the factor $\mathrm{CO}_{2}$ vulnerability will be discussed. In the following chapters, two factors possible connected to $\mathrm{CO}_{2}$ vulnerability were examined. First, the cognitive factor AS was studied (Chapter 3 to 5). Second, the role of the physiological factor respiratory disorders was investigated (Chapter 7 to 8 ).

As has been mentioned in the previous sections, the $35 \% \mathrm{CO}_{2}$ challenge is used to provoke paniclike symptoms in a laboratory. It is known that PD patients are more vulnerable to $35 \% \mathrm{CO}_{2}$ than other populations. Also, $\mathrm{PD}$ runs in families. If there is a link between $\mathrm{CO}_{2}$ sensitivity and familial loading for PD, then first-degree relatives of PD patients should be more reactive to $\mathrm{CO}_{2}$ than control participants. Therefore, the hypothesis that first-degree relatives of PD patients are more reactive to the $\mathrm{CO}_{2}$ challenge than control participants is tested in Chapter 2. It was found that being a first-degree relative of a PD patient is an important factor in $\mathrm{CO}_{2}$ hypersensitivity. The results suggest that $\mathrm{CO}_{2}$ hypersensitivity may be a marker of a familial vulnerability to PD. However, the nature of this vulnerability remains unclear. Therefore, possible factors that could be associated with $\mathrm{CO}_{2}$ sensitivity are investigated in the next chapters. First, in Chapter 3 to 5 the factor AS will be studied.

AS has been proposed as a cognitive risk factor for the development of PD. Moreover, it is suggested that AS itself has a strong hereditary component. Therefore, persons who are reactive to the $\mathrm{CO}_{2}$ challenge, i.e. PD patients and their first-degree relatives, could be highly anxiety sensitive. It has been repeatedly shown that PD patients have high AS levels. Contrarily, to our knowledge, AS in first-degree relatives of PD patients has not been investigated. Before turning to 
this issue, we examined factors playing a role in being highly anxiety sensitive, like age and sex. For example, older women could be more afraid of feeling palpitations than young men. Hence, in Chapter 3, it was investigated whether sex and age influence AS. In Chapter 4, AS in first-degree relatives of PD patients was studied. Results showed that first-degree relatives of PD patients were more anxiety sensitive than control subjects. This particular group of first-degree relatives was relatively old (mean age of 50 years). Since the peak of onset for PD is around 25 , these first-degree relatives will most likely not develop a PD. Under the assumption that high AS is a risk factor for developing PD, it would be interesting to know if children of PD patients, who are still at risk for developing PD, are highly anxiety sensitive. Thus, we elaborate on the theme AS in children in Chapter 5. As a side issue, to further explore AS, SSRI treatment effects on AS in PD patients were studied in Chapter 6, which is the final chapter on AS in this thesis.

Second, we now elaborate on the physiological factor respiratory pathology. As reported in the previous section on respiratory disorders, the association between PD and respiratory disorders has been well documented in several studies. For example, PD patients have more childhood respiratory disorders than other populations. Hence, respiratory pathology could be a vulnerability factor for the development of PD. Furthermore, as noted before, an association between geneticfamilial vulnerability to PD and respiration seems to exist. To further explore the relation between respiratory disorders and familial loading for PD, we investigated in Chapter 7 if the lifetime prevalence of respiratory disorders in first-degree relatives of PD patients is higher than in first-degree relatives of patients with another anxiety disorder than PD.

The inhalation of $35 \% \mathrm{CO}_{2}$ has consistently been shown to provoke panic in PD patients, as reported in the section carbon dioxide and panic. However, not all PD patients are equally vulnerable to $\mathrm{CO}_{2}$. Therefore, in Chapter 8 the hypothesis that specifically PD patients with a history of respiratory disorders are more vulnerable than PD patients without such a history. More general, a possible physiological mechanism underlying $\mathrm{CO}_{2}$ vulnerability in PD patients was investigated.

In the final Chapter 9, the findings will be summarized and discussed. In sum, this thesis focuses on whether $\mathrm{CO}_{2}$ sensitivity is a marker of the vulnerability to PD, and whether AS and respiratory pathology are vulnerability factors in PD patients and their first-degree relatives. 


\section{Chapter 2}

\section{Reactivity to a $35 \% \mathrm{CO}_{2}$ challenge in healthy first-degree relatives of patients with panic disorder}

Background: The effects of a $35 \% \mathrm{CO}_{2}$ challenge were examined in healthy firstdegree relatives of panic disorder patients and in healthy control subjects matched for age and gender.

Methods: One single inhalation of a $35 \% \mathrm{CO}_{2} / 65 \% \mathrm{O}_{2}$ challenge was administered to 50 first-degree relatives of panic disorder patients and 50 control subjects. Results: The first-degree relatives were more reactive to the $35 \% \mathrm{CO}_{2}$ challenge than the control subjects.

Conclusions: These findings indicate that being a member of a family with a panic disorder patient is, in itself, an important factor in $\mathrm{CO}_{2}$ hypersensitivity among subjects who have never experienced a panic attack. Both panic disorder patients and their first-degree relatives have a tendency to be more reactive to the $\mathrm{CO}_{2}$ challenge.

van Beek, N., \& Griez, E. (2000). Reactivity to a $35 \% \mathrm{CO}_{2}$ challenge in healthy first-degree relatives of patients with panic disorder. Biological Psychiatry, 47, 830-835. 


\section{Introduction}

It has been established that panic attacks can be experimentally elicited by $\mathrm{CO}_{2}$ inhalation (Griez \& Verburg, 1995). The $\mathrm{CO}_{2}$ challenge appears to be sensitive and specific as regards the induction of panic in panic disorder (PD) patients (Griez et al., 1990, 1990; Perna et al., 1994). One single vital capacity inhalation of a 35\% $\mathrm{CO}_{2}$ mixture in oxygen provokes a brief, immediate paniclike episode in patients with PD but does not in control subjects (Griez et al., 1990; Perna et al., 1994). Thus, $\mathrm{PD}$ patients seem to be hypersensitive to $\mathrm{C}_{2}$ inhalation. Carbon dioxide seems to activate specific mechanisms and that may be what predisposes them to the development of panic (Griez et al., 1990).

As far as predisposing factors are concerned, several studies provide evidence that familial factors play an important role in PD (Coryell, 1997; Crowe et al., 1983; Goldstein et al., 1997; Maier et al., 1993). Others suggest a genetic factor in PD (Torgersen, 1983). It is known that PD runs in families and that PD patients have a certain tendency to react hypersensitively to $\mathrm{CO}_{2}$. If there is a link between familial loading for PD and hypersensitivity to $\mathrm{CO}_{2}$, first-degree relatives may also have a tendency to be hypersensitive to $\mathrm{CO}_{2}$. Our aim, therefore, was to determine whether first-degree relatives of PD patients are, in fact, more reactive to a $35 \%$ $\mathrm{CO}_{2} / 65 \% \mathrm{O}_{2}$ challenge than healthy control subjects.

\section{Method}

\section{Subjects}

Fifty healthy first-degree relatives of PD patients were included in this study (29 men and 21 women; mean age $=30.8$ years; $S D=12.08$; range $16-63$ years), as were 50 control subjects ( 29 men and 21 women; mean age $=30.56 ; \mathrm{SD}=$ 12.31; range 16-63 years). At the time of the challenge, all subjects were healthy and none had taken any medication that could influence their mental state. The subjects met the inclusion criteria.

Inclusion criteria were age between 16 and 63 years, absence of any present or past psychiatric illness, a state of good physical health, and no prior experience with the $\mathrm{CO}_{2}$ challenge. For PD patients, an additional criterion was a DSM III-R diagnosis panic disorder, with or without agoraphobia, by at least two experienced clinicians. 
A clinical interview about the family was carried out and a clinical history ascertained in search of the following exclusion criteria: important cardiovascular history or suspicion of infarct, cardiomyopathy, cardiac failure, transient ischemic attack, angina pectoris, cardiac arrythmias or cerebrovascular accident; important respiratory history, including asthma and lung fibrosis; personal or familial history of cerebral aneurysm; hypertension with systolic pressure of $>180 \mathrm{mmHg}$ or diastolic pressure of $>100 \mathrm{mmHg}$; pregnancy; epilepsy; and noninvalidating chronic obstructive pulmonary disease. First-degree relatives were also excluded if they had ever had a panic attack or a hyperventilation attack. Control subjects were also excluded if they had a first-degree relative with an anxiety disorder or a depression. At the time of the challenge, none of the subjects had taken any central acting drugs, including $\beta$-blockers; an occasional exception was made for incidental use of low doses of benzidiacepines (i.e., single doses equivalent to 5 $\mathrm{mg}$ of diazepam) in the past 2 weeks. Subjects were asked to refrain from alcohol for at least 36 hours, from beverages containing xanthine for at least 8 hours, and from eating or smoking for at least 2 hours before the test.

\section{Apparatus}

For the $\mathrm{CO}_{2}$ challenge, two different gas mixtures were used: compressed air (placebo) and a mixture of $35 \% \mathrm{CO}_{2} / 65 \% \mathrm{O}_{2}$. Both gases were inhaled through the same self-administration mask. The respirometer connected to the self-administration mask measured the gas volume delivered at each inhalation.

Self-administered questionnaires that the subjects filled out included the StateTrait Anxiety Inventory (STAI-1) (Spielberger, Gorsuch, \& Lushere, 1970) for anxiety state, the Visual Analogue Scale for Anxiety (VAS-A) (Perna et al., 1994) for subjective anxiety, and the Panic Symptom List, DSM III-R (PSL III-R) (Pols, Zandbergen, De Loof, \& Griez, 1991) for panic symptoms.

\section{Procedure}

Control subjects were recruited either by word of mouth or through advertisements placed throughout the city of Maastricht. They received a questionnaire that they filled out before the experiment in order to give the investigators an impression of their health. If the subject was not healthy, he or she was excluded. The firstdegree relatives were selected from among PD patients referred to the Academic 
Anxiety Center Maastricht for treatment. Because subjects with a psychiatric disorder (axis I), panic attacks, or hyperventilation attacks were excluded, the firstdegree relatives were interviewed by an experienced psychiatrist, and the control subjects by a mental health scientist who used the Mini International Neuropsychiatric Interview, version 4.3 (Sheehan et al., 1994). A panic attack was defined as a period of intense fear or discomfort and at least four symptoms described in DSM III-R. A hyperventilation attack was defined as the suspicion that the breathing pattern was fast, deep, disregulated and not related to the physical activity of the subject. All subjects were tested in a double-blind, random, cross-over design (with half of the subjects inhaling $\mathrm{CO}_{2}$ first and the other half air) and they were matched for age and gender. Before the challenge, informed consent was obtained from the subjects. All subjects were paid for participating in the challenge. Briefly, subjects were informed beforehand that they would inhale two different gas mixtures containing different percentages of $\mathrm{CO}_{2}$ and $\mathrm{O}_{2}$, and that during the challenge they might experience some discomfort, ranging from a few physical symptoms to a definite sensation of anxiety. The possibility of a panic attack was not mentioned.

Vital capacity was measured and baseline anxiety assessed with the STAI-1. The subject then received one vital capacity inhalation of $35 \% \mathrm{CO}_{2} / 65 \% \mathrm{O}_{2}$ or compressed air in a randomly assigned order, with an interval of 10 min between the two inhalations. The researcher made sure that the gas mixture was inhaled for a period of $4 \mathrm{sec}$. The test was considered valid only if the subject had inhaled at least $80 \%$ of the previously measured vital capacity. For safety reasons blood pressure was measured before and after each inhalation. Immediately before and after each inhalation (air or $\mathrm{CO}_{2}$ ), anxiety was assessed via the VAS-A and panic symptoms via the PSL III-R.

\section{Data analyses}

The baseline scores of the first-degree relatives, assessed by the STAI-1 and the VAS-A prior to the first inhalation, were compared with those of the control subjects by means of Student's t-test. Linear regression analysis was performed to evaluate if baseline anxiety, assessed by the STAI-1, is a predictor of anxiety response (i.e., VAS-A score $\geq 25$ post- $\mathrm{CO}_{2}$ ).

To determine whether the $\mathrm{CO}_{2}$ inhalation, in general, induces more panic 
symptoms than the air inhalation and whether the first-degree relatives report more panic symptoms (PSL III-R) after inhalation of $\mathrm{CO}_{2}$ than after inhalation of air compared with control subjects, a multivariate analysis of variance (MANOVA) was applied, with group (first-degree relatives vs. control subjects) as betweensubjects factor and moment of inhalation (pre- vs. post-inhalation) and procedure $\left(\mathrm{CO}_{2}\right.$ vs. air) as within-subjects factors. The same analysis was used for subjective anxiety.

A post- $\mathrm{CO}_{2}$ score of 25 assessed by the VAS-A seemed to be the score that best discriminated PD patients from control subjects (Verburg et al., 1998). A Chi-square analysis was applied to determine whether more first-degree relatives had a higher or an equal score on the VAS-A after $\mathrm{CO}_{2}$ inhalation compared with control subjects.

A $\mathrm{CO}_{2}$-induced panic attack was defined by an increase of anxiety (VAS-A $\geq 25$ ) combined with an increase in panic symptomatology. This definition is comparable to the one used in previous studies on $\mathrm{CO}_{2}$-induced panic (Pols, Verburg, Hauzer, Meijer, \& Griez, 1996; Woods, Charney, Delgado, \& Heninger, 1990).

\section{Results}

\section{Baseline anxiety}

Table 2.1 shows baseline anxiety scores of the subjects.

Table 2.1 Baseline anxiety of the subjects before the first inhalation

\begin{tabular}{lcc}
\hline Baseline anxiety & First-degree relatives & Control subjects \\
\hline STAI-1 & $29.7 \pm 6.2$ & $26.9 \pm 5.0$ \\
VAS-A pre-CO & $2.4 \pm 4.8$ & $3.2 \pm 5.5$ \\
VAS-A pre-air & $3.5 \pm 5.9$ & $3.6 \pm 7.0$ \\
\hline
\end{tabular}

Results are expressed as mean \pm SD. STAI-1, State-Trait Anxiety Inventory-1; VAS-A. Visual Analogue Scale for Anxiety.

The mean baseline anxiety score of the first-degree relatives on the STAI-1 was 29.7 ( $\mathrm{SD}=6.2$ ) versus $26.9(\mathrm{SD}=5.0)$ for the control subjects. This represents a significant difference between the two groups $(t(98)=2.42, p<0.025)$. The first-degree relatives showed more anxiety than the control subjects before the first inhalation as assessed with the STAI-1. Yet, no significant difference was found 
in anxiety before the first inhalation between the first-degree relatives and the controls as assessed with the VAS-A. The mean VAS-A score before the $\mathrm{CO}_{2}$ inhalation was $2.4(\mathrm{SD}=4.8)$ for the first-degree relatives versus $3.2(\mathrm{SD}=5.5)$ for the control subjects ( $\mathrm{t}(98)=-0.76, \mathrm{p}=\mathrm{NS}$ ). The mean score before the air inhalation was $3.5(\mathrm{SD}=5.9)$ for the first-degree relatives versus $3.6(\mathrm{SD}=7.0)$ for the control subjects $(\mathrm{t}(98)=-0.06, \mathrm{p}=\mathrm{NS})$.

Linear regression analysis revealed that baseline anxiety, using the STAI-1, did not predict differences between first-degree relatives and control subjects on the VAS-A score of $\geq 25$ post- $\mathrm{CO}_{2}\left(\mathrm{R}^{2}=0.073, \mathrm{~F}(2,31)=1.23, \mathrm{p}=\mathrm{NS}\right)$.

\section{Panic symptoms}

Table 2.2 Panic symptoms of the subjects

\begin{tabular}{lcc}
\hline Panic symptoms & First-degree relatives & Control subjects \\
\hline PSL pre-CO $\mathrm{CO}_{2}$ & $0.7 \pm 1.2$ & $0.2 \pm 5.2$ \\
PSL post-CO & $8.0 \pm 7.5$ & $5.4 \pm 5.2$ \\
PSL pre-air & $1.0 \pm 1.7$ & $0.6 \pm 1.2$ \\
PSL post-air & $1.1 \pm 1.7$ & $0.6 \pm 1.2$ \\
\hline
\end{tabular}

Results are expressed as mean \pm SD, PSL, Panic Symptom List.

Table 2.2 shows the results of the challenges. A three-way MANOVA showed a significant main effect for group $(\mathrm{F}(1,98)=5.0, \mathrm{p}<0.05)$, procedure $(\mathrm{F}(1,98)=$ 108.3, $\mathrm{p}<0.001)$ and moment of inhalation $(\mathrm{F}(1,98)=111.5, \mathrm{p}<0.001)$. A significant interaction effect was found for procedure $\times$ moment of inhalation $(\mathrm{F}(1,98)$ $=94.3, \mathrm{p}<0.001$ ), indicating that the $\mathrm{CO}_{2}$ inhalation induced significantly more panic symptoms than the air inhalation. There were no significant interactions for group $\times$ procedure $(F(1,98)=3.9, p=0.051)$, group $\times$ moment of inhalation $(\mathrm{F}(1,98)=3.6, \mathrm{p}=0.061)$, and group $\times$ procedure $\times$ moment of inhalation $(\mathrm{F}(1,98)=2.6, \mathrm{p}=0.055)$, although group $\times$ procedure and group $\times$ procedure $\times$ moment of inhalation are almost significant. The latter interaction shows that the $\mathrm{CO}_{2}$ inhalation induced more panic symptoms in the first-degree relatives than in the control subjects.

\section{Subjective anxiety}

Results are displayed in Table 2.3. 
Table 2.3 Subjective anxiety of the subjects

\begin{tabular}{lcc}
\hline Subjective anxiety & First-degree relatives & Control subjects \\
\hline VAS-A pre- $\mathrm{CO}_{2}$ & $2.4 \pm 4.8$ & $3.2 \pm 5.5$ \\
VAS-A pre-air & $3.5 \pm 6.0$ & $3.6 \pm 7.0$ \\
VAS-A post-CO & $23.8 \pm 26.1$ & $16.5 \pm 21.7$ \\
VAS-A post-air & $3.3 \pm 5.8$ & $3.9 \pm 6.9$ \\
\hline
\end{tabular}

Results are expressed as mean \pm SD. VAS-A, Visual Analogue Scale for Anxiety.

A significant main effect was found for procedure $(\mathrm{F}(1,98)=53.7, \mathrm{p}<0.001)$ and moment of inhalation $(\mathrm{F}(1,98)=54.7, \mathrm{p}<0.001)$. No significant effect was found for group $(\mathrm{F}(1,98)=0.7, \mathrm{p}=\mathrm{NS})$ group $\times$ procedure $(\mathrm{F}(1,98)=2.8, \mathrm{p}$ $=$ NS), or group $\times$ moment of inhalation $(F(1,98)=2.6, p=N S)$. Significant interactions were found for procedure $\times$ moment of inhalation $(F(1,98)=52.7, p<$ $0.001)$ and group $\times$ procedure $\times$ moment of inhalation $(\mathrm{F}(1,98)=3.3, \mathrm{p}<0.05)$. This indicates that the $\mathrm{CO}_{2}$ inhalation induced more subjective anxiety than the air inhalation, and the last-mentioned interaction shows that the $\mathrm{CO}_{2}$ inhalation induced more subjective anxiety in the first-degree relatives than in the control subjects.

\section{VAS-A post score}

Results are shown in Table 2.4.

Table 2.4 Anxiety score $\geq 25$ on the VAS-A post- $\mathrm{CO}_{2}$ inhalation

\begin{tabular}{lcc}
\hline Anxiety score & First-degree relatives & Control subjects \\
\hline VAS-A $\geq 25($ mean \pm SD) & $\begin{array}{c}49.7 \pm 17.4 \\
\text { range 25-91 }\end{array}$ & $\begin{array}{l}49.5 \pm 18.7 \\
\text { range 29-80 }\end{array}$ \\
$\begin{array}{l}\text { Number of subjects who } \\
\text { scored } \geq 25 \text { on the VAS-A }\end{array}$ & $22(44 \%)$ & $12(24 \%)$ \\
\hline VAS-A, Visual Analogue Scale for Anxiety & &
\end{tabular}

A significant difference was found in the VAS-A score post- $\mathrm{CO}_{2}$ inhalation between the first-degree relatives and the control subjects $\left(\chi^{2}=4.46, \mathrm{df}=1, \mathrm{p}<\right.$ $0.05)$. 


\section{$\mathrm{CO}_{2}$-induced panic attacks}

A significant difference was found in $\mathrm{CO}_{2}$-induced panic attacks between the firstdegree relatives and the control subjects $\left(\chi^{2}=4.46, \mathrm{df}=1, \mathrm{p}<0.05\right)$. Twenty-two first-degree relatives $(44 \%)$ and 12 controls $(24 \%)$ had a panic attack.

\section{Discussion}

The results of our study support the idea that first-degree relatives of PD patients are more responsive to the $\mathrm{CO}_{2}$ challenge than control subjects. Carbon dioxide reactivity of first-degree relatives was assessed in three different ways. First, an increase on the VAS-A was measured, indicating $\mathrm{CO}_{2}$-induced subjective anxiety. Second, PSL III-R symptoms were measured, roughly indicating $\mathrm{CO}_{2}$-induced autonomic panic symptoms. Also, the number of subjects who had a score higher than 25 on the VAS-A post- $\mathrm{CO}_{2}$ inhalation was counted. Finally, the number of panic attacks was registered. Whatever measurement we took, first-degree relatives clearly appeared more vulnerable to the $\mathrm{CO}_{2}$ challenge than control subjects. It therefore seems that both PD patients and their first-degree relatives share some specific vulnerability to inhalation of $\mathrm{CO}_{2}$.

It may be speculated that the first-degree relatives' stronger reaction to the $\mathrm{CO}_{2}$ challenge compared with the healthy control subjects might have been the result of a higher baseline anxiety. One way to assess baseline anxiety is to use the STAI-1. Indeed, the first-degree relatives had a higher STAI-1 score at baseline. However, baseline anxiety may also be inferred from the VAS-A scale, which was filled in immediately before the first inhalation. Using the VAS-A, no difference could be seen between the first-degree relatives and control subjects. In any case, earlier findings of our group and others have demonstrated that a high baseline anxiety is not a sufficient condition for $\mathrm{CO}_{2}$-triggered anxiety in PD (Perna et al., 1994), even though it might be a necessary one (Griez et al., 1990). We also found that linear regression analysis revealed that baseline anxiety did not predict $\mathrm{CO}_{2}-$ induced anxiety.

It may be argued that our first-degree relatives might have experienced isolated panic attacks earlier in their life, even if they failed to meet the diagnosis of PD. Indeed, healthy subjects who experience sporadic panic attacks have been reported to be $35 \% \mathrm{CO}_{2}$-reactive compared with control subjects without a lifetime history 
of panic attacks (Perna, Gabriele, Caldirola, \& Bellodi, 1995). However, in order to eliminate this type of bias in our study first-degree relatives were very carefully screened. Any suspicion of a lifetime panic-like or hyperventilation attack was an explicit criterion for exclusion. It is thus very unlikely that our results can be explained by unnoticed, subthreshold PD.

Other studies have already suggested that healthy relatives of PD patients may be more vulnerable to panic-inducing procedures than controls. Balon and colleagues (1989) infused with lactate 45 subjects who had no PD or any other mental illness. Ten subjects experienced panic attacks in response to lactate infusion. Eight of 10 subjects with lactate-induced panic attacks and 26 of 35 without panic attacks were interviewed about family history. A higher prevalence of anxiety disorders was found among first-degree relatives of subjects with lactate-induced panic attacks than among relatives of subjects who did not panic. It was suggested that individuals with a family history of anxiety disorders might be vulnerable to lactate-induced panic attacks (Balon et al., 1989).

To test the hypersensitivity to $\mathrm{CO}_{2}$ inhalation as a possible trait marker for PD, Coryell (1997) recruited two high-risk groups for PD and affective disorder, respectively, and a low-risk control group. Eleven subjects at high-risk for PD had at least one first-degree relative who had been treated for PD. Those subjects were compared with a group of 13 individuals who were at high risk for affective disorder. The low-risk controls had no first-degree relatives with either affective disorder or PD. All of the subjects took the $\mathrm{CO}_{2}$ challenge. Five of the subjects at high risk for $\mathrm{PD}$, but none of the controls or any of the individuals at high risk for affective disorder, experienced a panic attack following the $\mathrm{CO}_{2}$ challenge. These results confirm an association between hypersensitivity to excessive $\mathrm{CO}_{2}$ and familial vulnerability to PD (Coryell, 1997).

Perna et al. (1995) tested the sensitivity to $35 \% \mathrm{CO}_{2}$ in healthy first-degree relatives of PD patients. The procedure they used was similar to ours. Eightyfour patients with PD, 23 first-degree relatives of PD patients, and 44 healthy controls with no family history of PD inhaled $35 \% \mathrm{CO}_{2} / 65 \% \mathrm{O}_{2}$. Fifty-one percent of the PD patients compared to $22 \%$ of the first-degree relatives and $2 \%$ of the healthy controls experienced $\mathrm{CO}_{2}$-provoked panic attacks. They found that the first-degree relatives reacted significantly more strongly to the $35 \% \mathrm{CO}_{2}$ challenge than healthy controls and significantly less strongly than the PD patients (Perna et al., 1995). 
One difference with the above-mentioned studies of Coryell and Perna et al. is that our sample is matched for age and gender to exclude possible influences of it on the results. Perna, Coryell and we all found that first-degree relatives have more $\mathrm{CO}_{2}$-induced panic attacks than controls $-22 \%, 45 \%$ and $44 \%$ respectively. But a striking difference in our study and the two earlier studies is in the proportion of controls with $\mathrm{CO}_{2}$-induced panic attacks: $2 \%$ (Perna), $0 \%$ (Coryell) and $24 \%$. Both above-mentioned studies used different criteria in defining panic attacks, using the PSL III-R. To be as conservative as possible we chose to take a very low threshold of assessing panic attacks, using the VAS-A and PSL III-R. This might explain the high score of panic attacks in control subjects. It is suggested that the VAS-A the easiest way is to measure effects of the $\mathrm{CO}_{2}$ challenge and that the rating of panic symptoms, assessed by the PSLIII-R, does not have any discriminative value (Verburg et al., 1998). Differences in the assessments and thresholds used to score panic attacks may contribute to the differences in the amount of panic attacks. It is a common problem in defining exactly how to assess panic attacks, which makes comparing studies difficult (Pols, Verburg, \& Griez, 1994).

Finally, Perna et al. (1996) also investigated the relationship between hypersensitivity to $\mathrm{CO}_{2}$ and familial-genetic risk for PD in patients with PD. Twohundred patients with PD were challenged with $35 \% \mathrm{CO}_{2}$. Of the PD patients, 157 $(77 \%)$ were $35 \% \mathrm{CO}_{2}$-sensitive. The morbidity risk for PD was calculated for families of the patients with PD. The morbidity risk was significantly higher for the subjects who were hypersensitive to $35 \% \mathrm{CO}_{2}$ than for those with normal sensitivity to $\mathrm{CO}_{2}$. Subjects who were hypersensitive to $35 \% \mathrm{CO}_{2}$ seemed to have a clear familial-genetic vulnerability to PD (Perna et al., 1996). The same group conducted a twin study and found a significantly higher concordance rate for $35 \%$ $\mathrm{CO}_{2}$-induced panic attacks among monozygotic than dizygotic twins. The authors suggest a role of genetic factors in sensitivity to $\mathrm{CO}_{2}$ inhalation (Bellodi et al., 1998). $\mathrm{CO}_{2}$ hypersensitivity may be due to a particular genetic dysfunction and can play a role in genetic studies as a possible phenotypical marker of panic vulnerability.

All of the above-mentioned studies indicate an association between panic vulnerability triggered by lactate or $\mathrm{CO}_{2}$ and a constitutional predisposition to PD that runs in families. Using experimental panic provocation in the largest group of first-degree PD relatives ever, our study confirms the above results.

Two different explanations for the reactivity to the $\mathrm{CO}_{2}$ challenge have been 
proposed. Some authors suggest a key role of yet undefined biological abnormalities. For example, a hypersensitive reaction to $\mathrm{CO}_{2}$ fits the false suffocation alarm hypothesis developed by Klein (1993). Klein hypothesizes that $\mathrm{CO}_{2}$ hypersensitivity is due to a deranged suffocation alarm monitor. Since it is argued that subjects with panic attacks have an oversensitive suffocation detector, first-degree PD relatives may have such a disrupted detector too, which may explain their hypersensitive reaction to $\mathrm{CO}_{2}$. However, respiratory indices of a false suffocation monitor were not assessed in the present study. In line with the false suffocation theory is the study of Horwath et al. (1997). If smothering symptoms are a marker for a hypersensitive suffocation detector, and if this hypersensitivity is familial, then first-degree relatives of PD patients with smothering symptoms would have higher rates of panic than first-degree relatives of PD patients without smothering. This was confirmed (Horwath et al., 1997).

Others explain the specific reactivity to $\mathrm{CO}_{2}$ challenges on the basis of psychological factors. $\mathrm{CO}_{2}$-induced panic is supposed to be a consequence of cognitive misinterpretation of the induced bodily symptoms. Subjects undergoing a $\mathrm{CO}_{2}$ challenge perceive these bodily sensations as much more dangerous than they really are (Clark, 1986; Sanderson, Rapee, \& Barlow, 1989). Our data can not exclude a possible role of cognitive factors, since specific cognitive patterns may run in families. Interestingly, a recent study by Stein and colleagues (1999) investigated the role of a psychological factor that predisposes one to panic. The authors examined the heritability of anxiety sensitivity in a group of 179 monozygotic and 158 dizygotic twin pairs. This study suggests that anxiety sensitivity has a strong heriditary component (Stein et al., 1999).

In sum, the present findings indicate that being a member of a family with a PD patient is, in itself, an important factor in $\mathrm{CO}_{2}$ hypersensitivity, even for subjects who have never experienced a panic attack. This suggests that first-degree relatives of PD patients have an apparent vulnerability to $\mathrm{CO}_{2}$ which, in turn strongly suggests that $\mathrm{CO}_{2}$ hypersensitivity may be a marker of a familial vulnerability to PD. The nature of this vulnerability, however, remains unclear. It is known that PD runs in families and anxiety sensitivity has been proposed as a risk factor for the development of PD. It is be possible that first-degree relatives of PD patients have an increased anxiety sensitivity that may cognitively mediate the response during the $\mathrm{CO}_{2}$ challenge. Further work is needed to characterize the potential role of anxiety sensitivity as a vulnerability factor in PD. An evaluation of anxi- 
ety sensitivity in first-degree relatives of PD patients may more fully elucidate the relationship between $\mathrm{CO}_{2}$ reactivity and $\mathrm{PD}$.

Acknowledgement The authors thank Thea Overbeek for her help in screening the subjects. 


\section{Chapter 3}

\section{Does age or sex influence anxiety sensitivity?}

Objective: We investigated the role of sex and age on anxiety sensitivity in patients with panic disorder.

Method: One hundred and sixteen patients with panic disorder filled out the Anxiety Sensitivity Index (ASI). Analyses of age and sex were performed on the ASI scores of the patients.

Results: ASI scores did not differ on the basis of sex. Nor was any age-related difference in ASI scores found. Moreover, age did not differ with sex, although there was a tendency for younger women to have higher ASI scores than men.

Conclusions: We did not find a clear relation between sex and anxiety sensitivity. We suggest that anxiety sensitivity was similar across age groups. The influence of sex or age on ASI calls for further documentation.

van Beek, N., Schruers, K. \& Griez, E. (submitted). Does age or sex influence anxiety sensitivity? 


\section{Introduction}

The construct of trait anxiety refers to individual differences in anxiety proneness. However, people vary not only in how prone they are to experience anxiety symptoms, but also in their fear of those symptoms (McNally, 1999). Some individuals tend to regard the sudden pounding of their heart as life-threatening, whereas others experience this as merely unpleasant. The construct of anxiety sensitivity (AS) deals with these individual differences in the fear of anxiety (Reiss \& McNally, 1985). More specifically, AS refers to fears of anxiety-related sensations based on beliefs that these sensations have harmful consequences (Reiss \& McNally, 1985). The Anxiety Sensitivity Index (ASI; Reiss et al., 1986; Peterson \& Reiss, 1992) has been the most commonly used instrument to measure AS. The ASI is a questionnaire assessing how much the subject is concerned when experiencing symptoms commonly associated with anxiety, such as fear of physical sensations, fear of loss of cognitive control, and fear of publicly observable symptoms (Taylor, Koch, Woody, \& McLean, 1996; Zinbarg, Barlow, \& Brown, 1997).

A small number of studies have assessed sex differences in ASI scores. One report mentions higher ASI scores for female students in a large sample of 818 university students (Stewart, Taylor, \& Baker, 1997). However, as stressed by the author, in this particular population, social desirability response bias may have played a role. Male students tend to underreport their actual fears, which explains their lower scores relative to female students. The same reasoning may apply to a recent investigation reporting higher scores in female native American Indian and Alaskan college students (Zvolensky, McNeil, Porter, \& Stewart, 2001). One study addressed a clinical population. This investigation assessed AS in 61 female and 27 male panic disorder (PD) patients. There was a significant difference between the sexes, with higher ASI values in female patients (Schmidt \& Koselka, 2000). To our knowledge, this is the only report addressing sex differences on AS in a population with pathological anxiety.

There are factors other than sex that may influence ASI scores. One of them is age. Currently, there is little or no evidence for a possible effect of age on ASI scores. Previous studies with the ASI either used subjects who did not differ in age (Ball, Otto, Pollack, Uccello, \& Rosenbaum, 1995) or subjects matched for this variable (Asmundson \& Stein, 1994). It is, however, conceivable that a 50 -year-old may be more worried by palpitations than a 20 -year-old. The only 
study we are aware of measured AS in a group with a limited age range. The sample was divided into two groups, one that included subjects aged 40 to 60 years and one aged 60 to 93 years. Contrary to what might be expected, the younger than 60 group had significantly higher ASI scores than those over 60 (Owens, Hadjistavropoulos, \& Asmundson, 2000).

There is support for high AS as a risk factor for the development of anxiety disorders, PD in particular (Reiss, 1991), and the ASI is widely used in anxiety research. In view of the above, additional investigation into the role of age and sex on AS seemed warranted. We sought to confirm the findings that women report higher ASI scores than men in a broader sample of participants with a clinical diagnosis of PD. This sample was also an opportunity to further document the influence of age on AS.

\section{Method}

\section{Participants}

One hundred and sixteen $\mathrm{PD}(\mathrm{A})$ patients participated in the present study. All participants were 18 years and over (range $18-66$, mean $=39.9, \mathrm{SD}=11.5$ ). The sample consisted of 49 male $(42.2 \%)$ and 67 female (57.8\%) participants. Age was normally distributed. To divide the total sample into two age groups, we conducted a median split, resulting in a 'younger' group (aged 18 to 40) and an 'older' group (aged 41 to 66 ).

\section{Assessment}

All participants were given the Mini International Neuropsychiatric Interview (MINI) to confirm their diagnosis, and they filled out the ASI. The MINI is a short, structured diagnostic interview for DSM-IV psychiatric disorders, developed by psychiatrists and clinicians in the U.S. and Europe. The MINI has been found to be a reliable and valid instrument (Lecrubier et al., 1997; Sheehan et al., 1997). The ASI is a 16-item self-report questionnaire to assess fear of anxiety-related symptoms on a 5 -point Likert-type scale $(0=$ no anxiety to $4=$ maximum anxiety) (Reiss et al., 1986). Each item assesses concern about the possible negative consequences of anxiety symptoms (Schmidt et al., 1997). An individual's AS score is the sum of the scores on the 16 items. The results of a factor analysis 
of the ASI (Zinbarg et al., 1997) imply good internal reliability for the scale as a whole. Maller and Reiss (1992) reported a test-retest reliability of 0.71 for college students over 3 years (Maller \& Reiss, 1992). Schmidt (1997) reported a 5-week test-retest correlation of 0.65 , although participants had undergone a highly stressful military training in between (Schmidt et al., 1997). These results suggest that AS is a stable construct and that the ASI is a reliable measure of AS.

\section{Data analyses}

A Pearson correlation was calculated between age and ASI score. A 2 (age: younger or older $) \times 2$ (sex: male or female) ANOVA was performed on the ASI scores. All independent variables were between subject variables.

\section{Results}

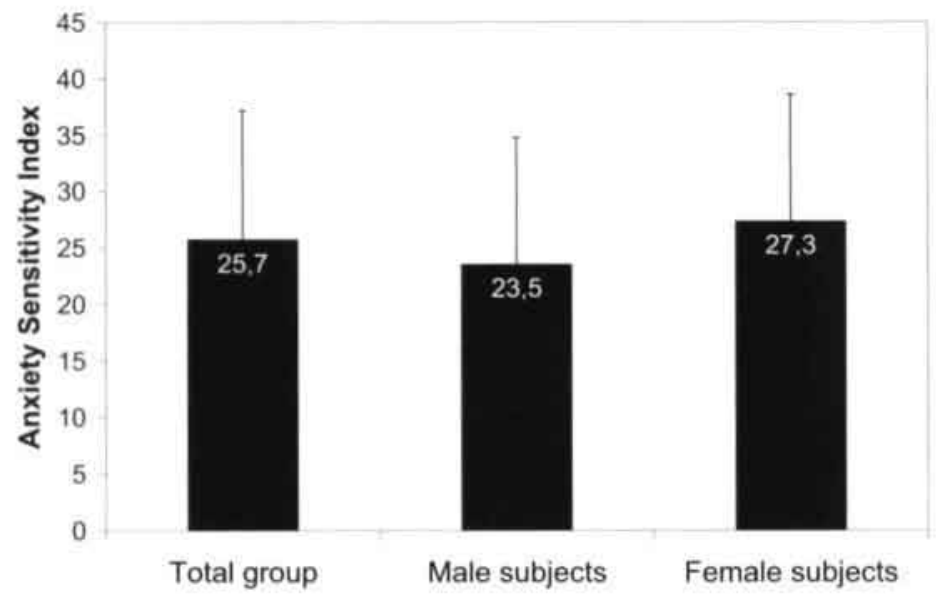

Figure 3.1 Mean ASI scores (+SD) for the entire sample and per sex

\section{Correlational analyses}

The mean of ASI scores was $25.7(\mathrm{SD}=11.5)$ for the total sample (Figure 3.1) and the mean age was $39.9(\mathrm{SD}=11.5)$. No significant correlation was found between age and ASI $(r=-0.12)$. 


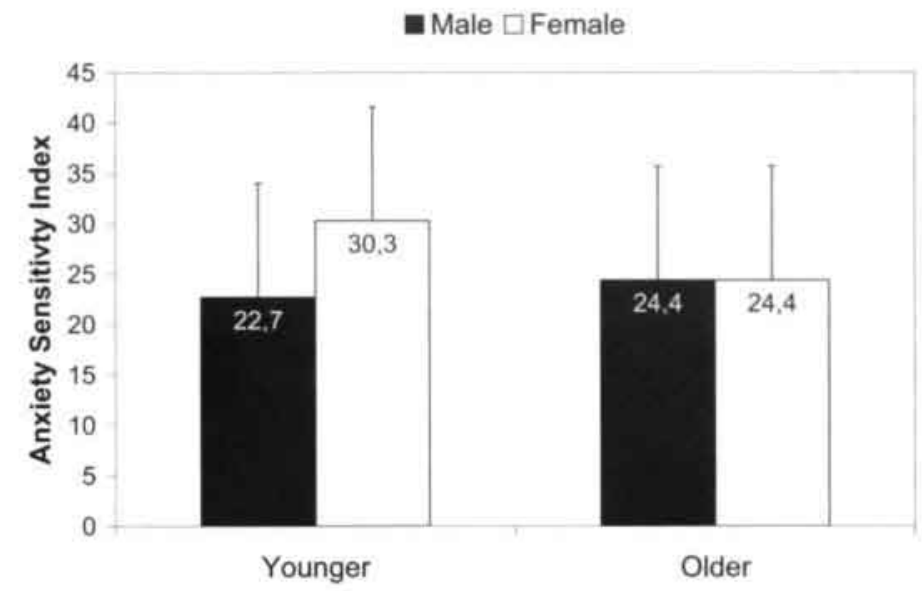

Figure 3.2 Mean ASI scores (+SD) for men and women in function of age groups

\section{Analysis of variances}

The mean ASI score of the male participants was $23.5(\mathrm{SD}=11.3)$ and it was 27.3 $(\mathrm{SD}=11.3$ ) for the female participants (Figure 3.2). No significant main effect was found for sex on ASI $(F(1,112)=3.2, p=0.076)$. No significant difference was found between the younger group (mean ASI 26.5, SD = 11.3) and the older group (mean ASI 24.4, $\mathrm{SD}=11.5)(\mathrm{F}(1,112)=0.9, \mathrm{p}=0.33)$.

Furthermore, age did not significantly interact with $\operatorname{sex}(\mathrm{F}(1,112)=3.2, \mathrm{p}=$ 0.076) (Figure 3.2). To further explore the interaction effect, a post-hoc Tukey HSD for unequal $\mathrm{N}$ was performed. This did not reveal any significant differences, although younger women tended to score higher on the ASI than younger men.

\section{Discussion}

In the present study we found no influence of sex or age on anxiety sensitivity in patients with panic disorder. Contrary to both previously mentioned studies of Stewart and Zvolensky, in which female participants scored significantly higher than male participants on the ASI (Stewart et al., 1997; Zvolensky et al., 2001), we found no significant effect of sex on AS. It should, however, be borne in mind that both of those studies addressed a specific population of college students; in Zvolensky's case, the population was even more specific, including native Alaskan 
and American Indian students. The possible cultural bias in this subpopulation, male subjects possibly tending to underreport their fears, may help to explain the difference between Stewart's and Zvolensky's studies, on the one hand, and the present study, on the other. Yet, still another factor may play a role. Both previous studies investigated a normal healthy population. We addressed patients referred for treatment to a specialized clinic. The mean ASI score in our sample was 25.7, almost twice that found in Stewart's participants. Our patients suffered from severe anxiety associated with physical symptoms that are typical for PD. They may have been more prone to report their fears as such than individuals with a less pronounced, subclinical symptomatology, regardless of whether they were male or female. Alternatively, AS may increase after people start experiencing panic attacks and certainly after they develop PD with its prominent physical symptoms. It may be that pre-existing sex differences in AS in nonclinical samples are levelled out when developing a PD. It is possible that a risk factor, i.e., AS, may act differently as a premorbid risk than as a pathoplastic risk, that is, after the disorder is manifest. On the other hand, one paper reported significant sex differences on the ASI between 61 female and 27 male PD patients (Schmidt \& Koselka, 2000). Although, at first sight, this finding seems to be at odds with our results, a closer examination of our data show that sex tended to interact with age. In line with the above-mentioned study in patients (Schmidt \& Koselka, 2000), we found that younger women tended to be more anxiety sensitive than younger men.

In the present study we found no relation between age and ASI scores. According to our findings, older persons are no more concerned than young people about possible harmful consequences of discomfort related to anxiety. In other words, the higher the age does not necessarily mean the higher the AS. Interestingly, others have found that not only ASI as a whole, but also its internal structure seem to be similar across age groups. When looking at the structure of AS in older adults (aged 65 to 97 years, with a mean of 75) compared to younger people, factor analysis revealed that the ASI construct had a highly similar structure in both age groups (Mohlman \& Zinbarg, 2000). Unfortunately, no absolute ASI scores were mentioned in this study. Another study, also examining an older population, did report ASI scores. They found that people under 60 scored higher on the ASI than those over 60 (Owens et al., 2000).

In sum, in spite of our sample, which was larger than that in the previously mentioned study with patients (Schmidt \& Koselka, 2000), we failed to find clear- 
cut differences between AS and sex in this particular sample of PD patients. Moreover, the present study suggests that AS is similar across age groups. Therefore, given the previous findings, further studies on the influence of sex or age on ASI appear to be warranted. 



\section{Chapter 4}

\section{Anxiety sensitivity in first-degree relatives of patients with panic disorder}

Anxiety sensitivity has been proposed as a risk factor for the development of panic disorder. Strong familial-genetic influences in panic disorder have been reported. Anxiety sensitivity may be familial too. The current study therefore examined whether first-degree relatives of panic disorder patients are more anxiety sensitive than normals. Twenty-three first-degree relatives of panic disorder patients, 38 panic disorder patients and 30 normals were given the Anxiety Sensitive Index and the Body Sensations Questionnaire. It was found that the first-degree relatives were, indeed, more anxiety sensitive than the normals, but less so than the panic disorder patients, suggesting that anxiety sensitivity runs in families.

van Beek, N., \& Griez, E. (2003). Anxiety sensitivity in first-degree relatives of patients with panic disorder. Behaviour Research and Therapy, 41(8), 949-957. 
asthma or bronchitis, and had never experienced a panic attack according to the DSM-IV. All PD patients were diagnosed according to the DSM-IV criteria by two experienced psychiatrists.

\section{Procedure}

Self-administered questionnaires that the subjects filled out included the ASI (Reiss et al., 1986) and BSQ 1 and 2 (Chambless et al., 1984). The ASI is a 16-item self-report questionnaire to assess fear of anxiety-related symptoms on a 5-point Likert-type scale ( $0=$ no anxiety to $4=$ maximum anxiety) (Reiss et al., 1986). Each item assesses concern about the possible negative consequences of anxiety symptoms (Schmidt et al., 1997). An individual's AS score is the sum of the scores on the 16 items. The BSQ is a 17-item questionnaire that measures fear of bodily symptoms that are common to autonomic arousal on a 5-point Likert-type scale ( $1=$ not at all afraid to $5=$ very much afraid). Two versions, each containing 17 items, were used: the BSQ1 measures how afraid people are of bodily feelings and BSQ2 measures how often these feelings occur (Chambless et al., 1984).

\section{Data analysis}

To determine whether the first-degree relatives were more anxiety sensitive, as assessed by the ASI, than the normals, a non-parametric analysis (Kruskal-Wallis) was applied, because the within-group variances are unequal. The same analysis was used for the BSQ. Additional Student t-tests were used to determine group differences between PD patients and normals, between PD patients and first-degree relatives, and between first-degree relatives and normals on the ASI and BSQ scores. Welch t-tests were used instead of Student t-tests if the variances in the two groups were significantly different.

\section{Results}

The mean score on the ASI was $26.2(\mathrm{SD}=10.2)$ for the PD patients, $9.2(\mathrm{SD}=$ 7.3) for the first-degree relatives, and $5.2(\mathrm{SD}=3.0)$ for the normals (Fig. 4.1). The mean score on the BSQ1 was $46.3(\mathrm{SD}=13.2), 27.9(\mathrm{SD}=8.0), 24.1(\mathrm{SD}=$ 6.0 ) for the PD patients, the first-degree relatives, and normals, respectively (Fig. 4.2). On the BSQ2, the scores were 45.0 ( $\mathrm{SD}=10.7$ ) for the PD patients, 27.0 


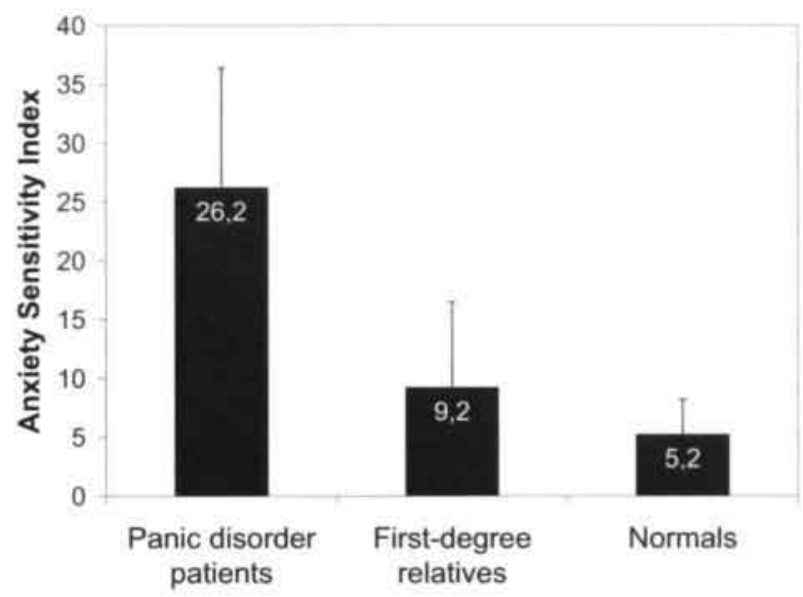

Figure 4.1 ASI scores (+SD) of panic disorder patients, first-degree relatives and normals

$(\mathrm{SD}=7.4)$ for the first-degree relatives, and $26.3(\mathrm{SD}=5.2)$ for the normals. No significant difference was found in gender between the three groups $\left(\chi^{2}=2.8\right.$, df $=2, \mathrm{p}=\mathrm{NS})$, but age significantly differed between the three groups $(\mathrm{H}=27.7$, df $=2, \mathrm{p}<0.001$ ).

Significant differences were found for ASI scores $(\mathrm{H}=58.4, \mathrm{df}=2, \mathrm{p}<0.001)$, BSQ1 scores $(\mathrm{H}=50.5, \mathrm{df}=2, \mathrm{p}<0.001)$, and BSQ2 scores $(\mathrm{H}=48.1, \mathrm{df}=2$, $\mathrm{p}<0.001$ ). t-tests indicated that the ASI and BSQ1 and BSQ2 were significantly different between normals and PD patients, respectively (Welch $\mathrm{t}(45)=-12.1, \mathrm{p}$ $<0.0001$; Welch $\mathrm{t}(54)=-9.2, \mathrm{p}<0.0001$; Welch $\mathrm{t}(56)=-9.5, \mathrm{p}<0.0001)$ and between first-degree relatives and PD patients (Student $\mathrm{t}(59)=-7.0, \mathrm{p}<0.0001$; Welch $\mathrm{t}(59)=-6.8, \mathrm{p}<0.0001$; Welch $\mathrm{t}(58)=-7.7, \mathrm{p}<0.0001)$. The scores on the ASI were significantly different between normals and first-degree relatives (Welch $\mathrm{t}(28)=2.5, \mathrm{p}<0.01$ ), but those on the BSQ1 (Student $\mathrm{t}(51)=2.0, \mathrm{p}=\mathrm{NS}$ ) and BSQ2 (Student $\mathrm{t}(51)=0.5, \mathrm{p}=\mathrm{NS}$ ) were not.

\section{Discussion}

As assessed by the ASI and in line with our hypothesis, we found that first-degree relatives of PD patients were more anxiety sensitive than normals. In contrast, PD relatives had no increased ratings on the BSQ. 


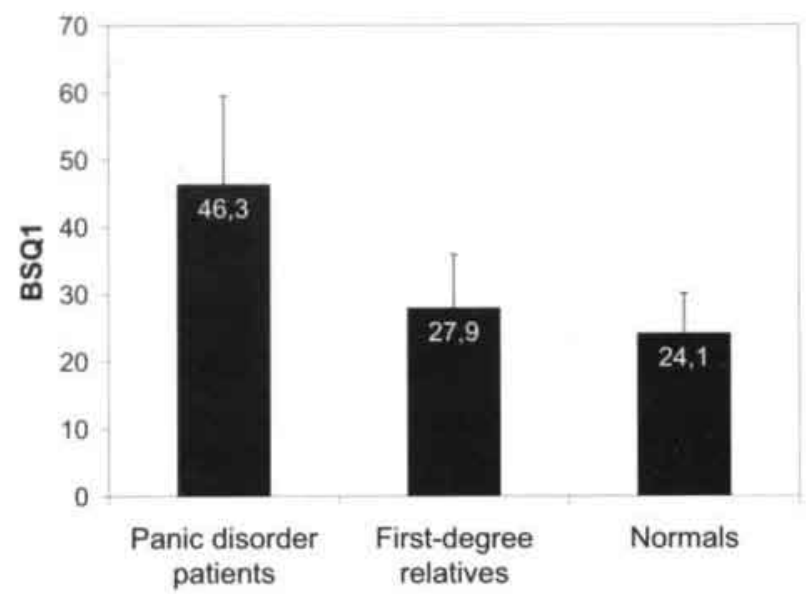

Figure 4.2 BSQ1 scores (+SD) of panic disorder patients, first-degree relatives and normals

While both questionnaires clearly yield augmented scores in the patient' population, the discrepancy in outcome between the ASI and the BSQ in the group of first-degree relatives is noteworthy. It may indicate that the ASI is a more sensitive measure than the BSQ. Possibly, a larger sample is needed to find group differences on the BSQ. Alternatively, the present results may support the view that the ASI and the BSQ do not measure exactly the same concept. The BSQ was introduced on the premise that physical symptoms of panic attacks may themselves become conditioned signals of fear (Goldstein \& Chambless, 1978). On the contrary, the ASI was designed to assess the fear of becoming anxious, i.e., a cognitive pattern that is assumed to favor the development of panic attacks (Reiss \& McNally, 1985). It was subsequently stressed that the construct assessed by the ASI may comprise both the cognitive pattern predisposing to, and the conditioned fear resulting from, the panic experience (Reiss, 1987). In fact, factor analyses have shown the ASI to contain several dimensions (Stewart et al., 1997; Taylor, 1996). Although one investigation in agoraphobics found a good correlation between the ASI and the BSQ (McNally \& Lorenz, 1987), this correlation was rather poor in another study (Asmundson et al., 1996). Thus, there are several arguments that support the ASI's potential to encompass both a cognitive risk that predisposes to panic and the fears that are the result of panic attacks, while the BSQ assesses only the latter dimension. Logically, both those having the risk factor only (the 
PD patients' relatives) and those having the risk as well as the consequences (the PD patients) will be discriminated from normals by the ASI, while the BSQ will discriminate only those suffering from the psychological consequence. That is exactly the pattern we observe in the present study. Assuming that the ASI score is a composite construct, reflecting both antecedents and consequences of panic, it seems only logical that, of the three groups, the PD patients had the highest scores, while much lower values were found in their first-degree relatives.

As for our main hypothesis, we had put forward that high AS may run in firstdegree relatives of PD subjects. The results are consistent with our hypothesis. When the concept of AS was first proposed, the authors posited that genetic factors might be involved (Reiss \& McNally, 1985). In fact, until recently, little was known about the origin of the complex construct represented by AS. The earlier mentioned study by Stein et al. (1999) revealed that there is a definite hereditary component in the transmission of AS, the correlation of the total AS score, for instance, being 0.47 between monozygotic twins and 0.17 between dizygotic twins. In particular, factor 1 of the ASI, related to the beliefs about harmfulness of physical sensations, seems to contain a strong genetic component: additive genetic factors accounted for $35 \%$ for factor 1 and for $45 \%$ of the total variance on the ASI score. Moreover, Stein's study strongly suggests that scores in the high range of the ASI, typically found in PD patients, and scores in the subclinical range, encountered in nonsymptomatic subjects, share the same common genetic basis (Stein et al., 1999).

In the past, investigators have hypothesized that not only specific genetic factors, but also specific learning experiences may influence specific factors of AS, e.g. how much one learns about the danger of cardiac symptoms may determine one's fear of those sensations (Taylor \& Cox, 1998). In particular, Ehlers (1993) examined the relationship between specific childhood learning experiences and the degree of fear of anxiety-related symptoms in panickers. She suggested significant associations between levels of fear of anxiety-related symptoms in adulthood and anxiety-specific learning experiences in childhood and adolescence (Ehlers, 1993). Contradicting Ehlers findings, Watt, Stewart, and Cox (1998) found that the learning experiences reported by high anxiety sensitive individuals (although not clinically ill) were not specifically related to anxiety symptoms, but rather involved parental reinforcement of sick role behavior in general. It was suggested that it is learning to catastrophize about the occurrence of bodily discomfort in 
general, rather than anxiety-related symptoms in particular, that leads to higher than normal levels of AS (Watt, Stewart, \& Cox, 1998). Thus, the exact function of distinctive patterns of environmental influences on specific AS factors remains unclear.

Besides the influences mentioned above, gender differences may play a role in AS. Some studies found females to be more anxiety sensitive than males (Schmidt \& Koselka, 2000; Stewart et al., 1997; Zvolensky et al., 2001). We had a slightly higher proportion of females than males in the first-degree relatives group. However, the gender difference both across and within the three groups failed to reach statistical significance. Admittedly, our groups significantly differed in age. Yet, there was no reason to match the subjects for age. Age does not seem to modulate ASI scores (Mohlman \& Zinbarg, 2000). As far as age and gender are concerned, it is worth mentioning that a recent study by our group failed to find a definite global effect of age on ASI in a clinical sample of 116 PD patients (Van Beek, Schruers, \& Griez, submitted for publication).

Increased AS is obviously not a sufficient condition to develop a PD. AS may be part of a large complex etiological picture where a variety of psychological and (neuro)biological factors must be taken into account. No one in our sample of first-degree relatives had ever developed a PD, because we explicitly excluded first-degree relatives with a lifetime history of PD. Moreover, most of the firstdegree relatives studied will probably never develop a PD, considering that the mean age of our sample is $50.0 \mathrm{yr}$, well above the peak age of onset for PD i.e. 25 yr (DSM-IV; American Psychiatric Association, 1994). It may be argued that only those with an ASI score in the high range are at risk for PD, while the scores of our first-degree relatives are only moderately increased, although significantly higher than those of normals. However, Donnell and McNally (1990) found that two-thirds of a group of high anxiety sensitive subjects had never experienced a spontaneous panic attack (Donnell \& McNally, 1990). More prospective studies are needed to test to what extent AS is a predictor of the development of PD.

In previous studies, both we and others have shown that first-degree relatives of PD patients have an enhanced sensitivity to $\mathrm{CO}_{2}$ (Coryell, 1997; Perna et al., 1995, 1996; Van Beek \& Griez, 2000). Enhanced $\mathrm{CO}_{2}$ sensitivity is known to affect individuals suffering from panic attacks and/or situational phobias (Battaglia \& Perna, 1995; Griez \& Schruers, 1998; Verburg et al., 1998), in sharp contrast to individuals with other anxiety disorders or to normals. Therefore, $\mathrm{CO}_{2}$ vul- 
nerability may identify subjects with a constitutional predisposition to developing panic. The present results show that first-degree relatives of PD subjects also have an increased AS. It may be tempting to make a link between high $\mathrm{CO}_{2}$ vulnerability and increased AS. Some authors have posited that high AS may explain high vulnerability to biological challenges (Forsyth, Palav, \& Duff, 1999). Yet, in a well-controlled study including both normals and PD patients, cognitive manipulation failed to influence the results of a $\mathrm{CO}_{2}$ challenge (Welkowitz, Papp, Martinez, Browne, \& Gorman, 1999). Moreover, analysis of $35 \% \mathrm{CO}_{2}$ challenges in PD subjects recently showed that $\mathrm{CO}_{2}$-elicited anxiety was not significantly predicted by ASI scores, although ASI scores predicted the symptomatological reaction to $\mathrm{CO}_{2}$ (Perna, personal communication). Furthermore, in another study the total ASI scores did not correlate with post- $\mathrm{CO}_{2}$ scores (Koszycki \& Bradwejn, 2001). On the other hand, a small study in PD did find a correlation between ASI and the response to $\mathrm{CO}_{2}$ (Shipherd, Beck, \& Ohtake, 2001).

Assuming that $\mathrm{CO}_{2}$ vulnerability is not merely a consequence of high AS, it is conceivable that both $\mathrm{CO}_{2}$ vulnerability and high AS are the expression of a third factor that runs in families and predisposes to panic. Alternatively, AS and $\mathrm{CO}_{2}$ vulnerability may identify two independent factors that operate separately in two different subtypes of PD. Recent findings with the $35 \% \mathrm{CO}_{2}$ challenge have supported the idea that $\mathrm{CO}_{2}$ vulnerability may vary across subtypes of $\mathrm{PD}$ (Biber \& Alkin, 1999). It remains to be established whether the same applies to AS and, if so, whether the same subtypes are defined by both high $\mathrm{CO}_{2}$ susceptibility and enhanced AS.

To summarize, we have found that healthy first-degree relatives are significantly more anxiety sensitive than normals, suggesting that high AS runs in families. This finding may imply that first-degree relatives have a certain cognitive attitude that may contribute to the development of PD. However, future research is required to clarify the exact role of AS as a predictor of PD. 



\section{Chapter 5}

\section{Anxiety sensitivity in children of panic disorder patients}

Background: Anxiety sensitivity, which refers to the tendency to interpret anxietyrelated bodily sensations as having potentially harmful somatic, psychological or social consequences, has been proposed as a vulnerability factor for the development of panic disorder. The current study examined the anxiety sensitivity levels in children of parents with panic disorder.

Methods: Children of panic disorder patients $(n=68)$ and children of healthy parents $(n=68)$ filled out the Childhood Anxiety Sensitivity Index, while parents completed the Anxiety Sensitivity Index.

Results: Children of parents with panic disorder did not display higher levels of anxiety sensitivity than children of healthy parents. Furthermore, no association between anxiety sensitivity levels of parents with panic disorder and their children was found.

Conclusions: Anxiety sensitivity is not clearly manifest in children of parents with panic disorder and might be a developing vulnerability factor that may increase towards late adolescence or early adulthood.

van Beek, N., Perna, G., Schruers, K., Muris, P., Griez, E. (submitted). Anxiety sensitivity in children of panic disorder patients. 


\section{Introduction}

Anxiety sensitivity (AS) refers to the extent to which an individual fears anxietyrelated sensations based on the expectation that such sensations can have harmful consequences (Reiss, 1997; Reiss \& McNally, 1985). Research findings show that adults with high AS are more likely to develop a panic disorder (PD) than those with low AS (Maller \& Reiss, 1992; Reiss, 1991). Conversely, PD subjects have been found to score higher on AS than healthy individuals, and in general than people with other anxiety disorders (Taylor et al., 1992). It has therefore been suggested that AS predisposes to the development of anxiety disorders, in particular PD.

Increased AS has been documented in adult first-degree relatives of PD patients, who have never experienced a panic attack (Van Beek \& Griez, 2003). This suggests that high AS may run in PD families. Strikingly, a twin study indicated that AS may have a strong hereditary component (Stein et al., 1999).

Considering the familial-genetic influences involved in the development of PD (Coryell, 1997; Crowe et al., 1983; Goldstein et al., 1997; Torgersen, 1983), the above finding of high AS in PD families, and the possible heritability of AS, one would expect to find increased AS in children of PD patients. If AS operates in a similar way in children as it does in adults (i.e., as a risk factor for the development of panic attacks), high AS in children may be of practical relevance for primary prevention. Thus, research on AS in children may be warranted for a better understanding of the development of PD. Despite the broad interest in AS in adults, AS has been relatively understudied in children.

AS can be measured with a specially developed questionnaire for children, the Childhood AS Index (CASI) (Silverman, Fleisig, Rabian, \& Peterson, 1991), which is a modified version of the adult AS Index (ASI; Reiss et al., 1986). The CASI has good internal consistency and test-retest reliability (Silverman et al., 1991; Van Widenfelt, Siebelink, Goedhart, \& Treffers, 2002). In a sample of 280 children, aged 6 to 17 years, it was found that the CASI showed incremental validity, meaning that the CASI predicted a significant amount of additional variance in fear beyond that predicted by trait anxiety (Weems, Hammond-Laurence, Silverman, \& Ginsburg, 1998).

In most studies, the CASI differentiated children with anxiety disorders from normal control subjects (Rabian, Peterson, Richters, \& Jensen, 1993; Vasey, Dalei- 
den, Williams, \& Brown, 1995). However, AS may not differentiate among a clinical population, as children with an anxiety disorder were not more anxiety sensitive than children with an externalizing disorder (i.e., ADHD or conduct disorder). PD as such was, however, not represented in this particular study (Rabian et al., 1993). Another investigation did take PD into account, and showed that children with PD scored significantly higher on the CASI than those with other anxiety disorders (Kearney, Albano, Eisen, Allan, \& Barlow, 1997). Furthermore, AS in adolescents was significantly related to panic symptoms (Lau, Calamari, \& Waraczynski, 1996; Muris et al., 2001). Adolescents with a lot of panic attack symptomatology reported significantly higher levels of AS than the non-panickers (Lau et al., 1996).

Although on a cross sectional basis the CASI may differentiate between anxious children and others, the prediction of panic attacks by high CASI scores in follow-up studies has been hardly examined. Nevertheless, there is some evidence demonstrating that high AS predicted panic attacks assessed over a 4-year period in high school students (Hayward, Killen, Kraemer, \& Taylor, 2000; Weems, Hayward, Killen, \& Taylor, 2002). However, in another study, earlier levels of AS did not predict the occurrence of panic symptoms six months later after controlling for initial levels of panic (Ginsburg \& Drake, 2002). Thus, there are several issues where available findings are not consistent. In the present study, we investigated whether children of PD patients display higher levels of AS on the CASI than children of healthy controls. Because parents may pass on AS, either via a genetic pathway or via observational learning, we additionally examined, in a subsample of our participants, whether there is a correlation between the parents' and their offspring's AS.

\section{Method}

\section{Participants}

One-hundred-thirty-six children, aged 6-17 years (mean age $=11.9$ years, $\mathrm{SD}=$ 2.9) participated in the present study. Sixty-four $(47.1 \%)$ children were recruited in the Netherlands (Maastricht) and $72(52.9 \%)$ in Italy (Milan). The total group consisted of 75 boys $(55.1 \%)$ and 61 girls $(44.9 \%)$.

Sixty-eight children of PD patients (PD child group) ( mean age $=11.7$ years, 
$\mathrm{SD}=3.2,35$ boys $(51.5 \%), 33$ girls $(48.5 \%))$ were recruited among patients treated at clinics in Maastricht $(n=31)$ or Milan $(n=37)$. Sixty-eight children of healthy subjects without a family history positive for PD (control child group) (mean age $=12.2$ years, $\mathrm{SD}=2.6,40$ boys $(58.8 \%), 28$ girls $(41.2 \%)$ ) were recruited among the hospital staff and among friends of the members of the research teams. Thirtythree control children participated in Maastricht and 35 in Milan.

Data of AS in parents were collected in Maastricht. Sixteen parents with PD (mean age $=42.7$ years, $\mathrm{SD}=3.8,4$ males $(25 \%), 12$ females $(75 \%)$ ) and 33 healthy parents of the control group (mean age $=41.8$ years, $\mathrm{SD}=4.2,6$ males (18.2\%), 27 females (81.8\%)) filled out the Anxiety Sensitivity Index (ASI) (Reiss et al., 1986). We attempted to match the proportion of males and females between the PD parents and the control parents.

\section{Procedure}

The study was approved by the local medical ethics committee. All parents with PD in Maastricht and Milan were diagnosed according to DSM-IV criteria by experienced psychiatrists using the Mini International Neuropsychiatric Interview (MINI) (Sheehan et al., 1997). The MINI is a short structured diagnostic interview measuring psychiatric disorders on axis 1 of the DSM-IV. One Dutch PD parent had a comorbid dysthymia and one a comorbid major depressive disorder. Parents of the control children in Maastricht and Milan were also interviewed with the MINI (Sheehan et al., 1997) to exclude anxiety disorders on axis I according to DSM-IV. These parents were indeed free of psychiatric disorders.

All children filled out the CASI (Silverman et al., 1991). Complementary information on the children's emotional status was available in Maastricht from the Screen for Child Anxiety Related Emotional Disorders (SCARED: Birmaher et al., 1997; Muris, Merckelbach, Schmidt, \& Mayer, 1999). In Milan the children were interviewed by a child psychiatrist using the Diagnostic Interview for Children and Adolescents (Herjanic \& Campbell, 1977). Additional to the screening, the parents in both centers were interviewed about their children with a specially developed checklist concerning the exclusion criteria. Exclusion criteria for all children were important medical diseases (important cardiovascular diseases, respiratory disorders, epilepsy, attention deficit hyperactivity disorder Silverman et al., 1991), significant traumatic experiences, evidences of mental retardation, significant school 
difficulties. From this information, it appeared that children in both centers did not suffer from severe health or mental problems, except for one child in the PD group in Maastricht who had diabetes, but scored within the range of this group on the CASI.

\section{Assessment}

As mentioned previously, the CASI (Silverman et al., 1991) is a specially developed instrument for assessing AS in the youth (aged 6-17 years). The CASI is an 18-item self-rating scale that requires children to rate their fear of anxiety-related sensations, using a 3 -point scale (none $=1$, some $=2$, a lot $=3$ ). CASI total scores range from 18 to 54 . The CASI assesses fears of the same types of anxiety-related sensations as its adult counterpart, the ASI (Reiss et al., 1986).

The ASI (Reiss et al., 1986) is a 16-item self-report questionnaire to assess fear of anxiety-related symptoms on a 5-point Likert-type scale $(0=$ no anxiety to $4=$ maximum anxiety). Each item assesses concern about the possible negative consequences of anxiety symptoms. An individual's AS score is the sum of the scores on the 16 items.

\section{Data analyses}

Gender and age differences between the PD child group and the control child group were tested by means of Chi-square test and Student t-test, respectively. Differences in CASI scores between the PD child group and control child group were analyzed by means of a Student t-test (two-tailed). The relation between AS of the parents and their children was examined by computing a Pearson correlation. To examine if PD parents were more anxiety sensitive than the healthy parents a Welch t-test was applied (two-tailed).

\section{Results}

The two groups of children did not differ in gender or age. The mean score on the CASI was $28.2(\mathrm{SD}=5.3)$ for the PD child group and $27.8(\mathrm{SD}=5.5)$ for the control child group. This difference was not statistically significant.

In the subsample where parents also were assessed, the parents with PD had a mean ASI score of $15.9(\mathrm{SD}=9.7)$, whereas their offspring scored $26.9(\mathrm{SD}=$ 
5.6) on the CASI. The healthy parents scored on average $5.8(\mathrm{SD}=3.9)$ on the ASI and their children scored $25.3(\mathrm{SD}=4.7)$ on the CASI. Note that parents with PD were significantly more anxiety sensitive than healthy parents $(\mathrm{t}(17)=4.0$; $\mathrm{p}<$ 0.001 ), whereas no significant differences emerged in their children. Correlations between AS scores of children (CASI) and their parents (ASI) were .04 in PD families, and .15 in healthy families. Thus, no statistically significant association between parents' and children's level of AS was found.

\section{Discussion}

As expected, parents with PD displayed higher levels of AS than healthy parents. However, the results of the present study also demonstrate that children of PD parents are not more anxiety sensitive than children of healthy parents. Accordingly, no link was found between AS scores of PD parents and their offspring.

It was hypothesized that parents with PD would predispose their children to high AS. However, PD parents do not seem to pass on high AS to their children. Since completing our study, we learned that Mannuzza and colleagues (2002) recently conducted a study on the same topic. These researchers compared CASI scores of children who had parents with PD, other anxiety and/or mood disorders, and no psychiatric disorder, and also found no differences among these groups (Mannuzza et al., 2002). It is also important to note, that the mean CASI scores of children with PD parents in the present study (28.2) and in Mannuzza et al.'s study (27.2) were highly comparable to the mean scores of normal children (27.8 in our study versus 27.9 in Manuzza et al.'s study). Thus, the above results appear to be quite robust and seem to indicate that high AS in PD parents does not necessarily predispose their offspring to be highly anxiety sensitive. Yet, results of our previous study show that adult first-degree relatives of PD patients displayed increased AS levels compared to controls (Van Beek \& Griez, 2003).

The failure to detect a difference between children of PD parents and healthy parents may be due to a lack of sensitivity of the CASI. It has been suggested, that the CASI is possibly still in need of some refinement to assess AS in children more accurately (Lau et al., 1996). In a nonclinical population, it was found that even children with sporadic panic attacks did not differ in CASI scores compared to nonpanickers (Calamari et al., 2001). Nevertheless, the CASI has a proven record of discriminating between children with anxiety disorders and control children. It 
is therefore more likely that the present study, like Mannuzza et al.'s (2002), truly reflects a normal level of AS in children of PD patients. It should be noted that our sample of children, like that of Mannuzza et al., was quite young, with mean ages of 11.9 and 11.5 years, respectively. It is possible that, AS is a developing vulnerability factor that may increase as children get older; high AS only becoming manifest beyond a certain age. Commenting on the failure of earlier studies to find increased AS levels in anxious children (Rabian et al., 1993; Silverman et al., 1991), Lau and colleagues (1996) pointed at the young age of the children in these studies, and wondered whether AS in childhood may increase over time (Lau et al., 1996). Recent research indeed demonstrates that there seem to be consistent patterns of AS changes during childhood. In a 4-year longitudinal study of AS in high school students, Weems et al. (2002) identified groups of adolescents with stable low AS, stable high AS, or escalating AS. Most importantly, results showed that youth with stable high AS or escalating AS were at increased risk for panic attacks (Weems et al., 2002). It may well be the case that children of PD parents belong to the group of youth with escalating AS levels. Stressors have been demonstrated to elevate AS levels. In particular, the experience of spontaneous panic attacks increases AS levels, especially when occurring during low levels of general distress (Schmidt, Lerew, \& Joiner, 2000). Although panic attacks do occur in a sizeable proportion of normal adolescents (Lau et al., 1996), it is well-conceivable that children of PD parents are particularly prone to suffer from either limited symptoms or full blown attacks. In this view, children of parents with PD will show gradually increasing levels of AS during childhood, a hypothesis that clearly warrants further research. This would also imply that only in late adolescence and early adulthood, high levels of AS should be considered as a significant risk factor for PD, which may nicely fit the clinical observation that the peak age of onset for $\mathrm{PD}$ is 25 years (American Psychiatric Association, 1994).

In conclusion, the results from the present study show that high AS, which is considered as an important risk factor for PD, is not present in children of PD parents, at the age of 11 years. AS in children of parents with PD might be an underlying vulnerability factor, which is not clearly manifest until late adolescence or early adulthood. Only further longitudinal studies will demonstrate whether these children display escalating AS levels towards their early adulthood and subsequently are more prone to develop PD themselves. 
Acknowledgment This study was supported in part by travel grant from the Netherlands Organisation for Scientific Research (NWO). The authors thank Linda Zwambag for her help with data collection. 


\section{Chapter 6}

\section{Anxiety sensitivity and modulation of the serotonergic system in patients with panic disorder}

Anxiety sensitivity, i.e., the fear of anxiety-related bodily sensations, is one of the most studied cognitive variables in panic disorder. However, the effects of selective serotonergic antipanic agents on this variable have not yet been investigated. The present study examines the effects of 6 weeks of treatment with citalopram on anxiety sensitivity in patients with panic disorder. Twenty patients entered the study. On day 0 , before starting drug treatment, after 1 week and after 6 weeks of treatment, each patient was evaluated with the Anxiety Sensitivity Index (ASI); the severity of clinical symptomatology was assessed with standardized psychometric scales. Results showed a significant reduction of anxiety sensitivity after 6 weeks of treatment. There was a significant correlation between decrease of anxiety sensitivity and anticipatory anxiety, while no correlations were found between panic attacks and agoraphobic avoidance. These results suggest that antipanic drug treatment decreases anxiety sensitivity.

Romano, P., van Beek. N., Cucchi, M., Biffi, S. \& Perna, G. (in press). Anxiety sensitivity and modulation of the serotonergic system in patients with PD. Journal of Anxiety Disorders 


\section{Introduction}

Anxiety sensitivity (AS) is a dispositional cognitive variable that reflects the fear of anxiety-related bodily sensations that arise from beliefs that these sensations have harmful consequences (Taylor, 1999). For example, subjects with high AS may believe that a rapid heart rate signifies an impending heart attack, whereas subjects with low AS will merely regard this as unpleasant (McNally, 1994). AS is a construct conceptually distinct from trait anxiety (McNally, 1996; Rapee \& Medoro, 1994) and may be a cognitive risk factor for developing panic disorder (PD) (McNally, 1994; McNally \& Lorenz, 1987; Schmidt, Lerew, \& Jackson, 1999). AS can be measured by the Anxiety Sensitivity Index (ASI) (Peterson \& Reiss, 1992; Reiss et al., 1986).

AS may be a predictor of the maintenance of PD in patients who remain untreated (Ehlers, 1995). Consequently, treating PD may have an impact on the level of AS. Reductions in ASI scores of patients with PD following cognitive/behavioral treatment (CBT) have already been reported (McNally \& Lorenz, 1987; Shear, Pilkonis, Cloitre, \& Leon, 1994; Telch et al., 1993). These studies indicate that exposure and cognitive restructuring interventions reduces AS. However, it is not clear if an explicit focus on fear of anxiety is necessary for the modification of AS. Other treatments, such as pharmacotherapy, may also lead to significant changes in AS. It is possible that fear of anxiety sensations is maintained by presence of panic attacks. If so, any treatment that controls these attacks might correspondingly diminish the fear of anxiety sensations. Alternatively, cortical serotonin changes might change cognitions directly, i.e., without psychological mediation, as some studies on depression have highlighted (Imber et al., 1990; Simons, Garfield, \& Murphy, 1984).

Few studies have examined the effects of pharmacotherapy on ASI scores; all of these found a decrease of AS (Mavissakalian, Perel, Talbott-Green, \& Sloan, 1998; Otto, Pollack, Sachs, Rosenbaum, \& Fava, 1991). Otto et al. (1991) reported a reduction of ASI scores from a mean of 31.3 at baseline to 22.2 after 6 months of drug treatment ( $67 \%$ of the sample with benzodiazepines alone, $8 \%$ with antidepressants alone and $25 \%$ with a combination of the two drugs). Mavissakalian et al. (1998) found that mean ASI scores decreased from 33.6 to 12.5 after 24 weeks of treatment with imipramine, with the mean score lower than 20 by 8 weeks. These studies suggest that fear of the consequences of anxiety-related bod- 
ily sensation can be normalized by biological treatments. Among the main brain systems, several experimental evidences suggest that the serotonergic one plays a key role in the pathogenetic mechanism of anxiety disorders, PD in particular (Coplan, Gorman, \& Klein, 1992; Gorman, Kent, Sullivan, \& Coplan, 2000; RoyByrne \& Cowley, 1998), and the efficacy of selective serotonergic agents in the treatment of PD supports the idea of an important role of the modulation system in the treatment of PD (Kent, Coplan, \& Gorman, 1998; Perna, Bertani, Caldirola, Smeraldi, \& Bellodi, 2001). We hypothesize that modulation of the serotonergic system is able to improve not only the core symptoms of PD, but also the catastrophic misinterpretation of anxiety symptoms. To test this idea, we have evaluated effects of 6 weeks of treatment with citalopram, the most selective drug for blocking serotonin reuptake, on AS in a sample of patients with PD. In addition, since citalopram decreased anxious hypereactivity to inhalation of carbon dioxide (a biological marker of PD) as rapidly as the first week of treatment (Bertani, Caldirola, Bussi, Bellodi, \& Perna, 2001), we measured AS after 1 week (testing the idea that cognition could change before clinical improvement).

\section{Method}

\section{Subjects}

Twenty-two outpatients with PD were recruited over 12 months at the Anxiety Disorders Clinical and Research Unit of the Department of Neuropsychiatric Sciences from the San Raffaele Hospital in Milan. All patients were agoraphobics. Two patients were withdrawn for poor tolerability and therefore were excluded from the analysis. Twenty patients $(6$ males and 14 females; mean age $=28$ years, $\mathrm{SD}=9.6$; mean age at onset $=21$ years, $\mathrm{SD}=5.4$ ) completed the study. Diagnostic assessments were made by a senior psychiatrist of this study using the Schedule for Affective Disorders and Schizophrenia, lifetime version, modified for the study of Anxiety Disorders (SADS-LA-IV) (Fyer, 1995). Exclusion criteria for all subjects included psychiatric disorders other than PD, significant medical diseases, pregnancy, and epilepsy. Exclusions were made as a result of direct physical examination and careful collection of the medical history. Each patient gave informed consent after a detailed explanation of the experimental procedure, carried out in accordance with the Declaration of Helsinki, 1964, and its amendments (Tokyo, 
1975, Venice, 1983, and Hong Kong, 1989).

\section{Drug treatment}

Patients were treated with citalopram for 6 weeks. At the beginning of treatment patients were given a daily dose of $10 \mathrm{mg}$ for 1 week, $20 \mathrm{mg}$ from day 8 to day $11,30 \mathrm{mg}$ from day 12 to day 14 , and $40 \mathrm{mg}$ from day 15 to the end of the trial. No concomitant psychotropic drugs or psychotherapeutic interventions of any kind were allowed during the trial.

\section{Assessments}

The psychometric scales were administered on days 0 , the day of beginning medication, 7 , and 42 by experienced psychiatrists. The raters were others than the authors and blind to the aim of the study and to the drug treatment. The same rater evaluated each patient over time. The following scales were used:

- The Panic Associated Symptoms Scale (PASS) a self-administered scale to assess frequency of panic attacks, level of anticipatory anxiety, and phobic avoidance. Those yielded a global score (PASS-TOT), subscores for panic attacks (PASS-AP), phobic avoidance (PASS-FOB), and anticipatory anxiety (PASSAA) (Argyle et al., 1991).

- The Fear Questionnaire (FQ) a self-administered scale assessing to value the entity of the avoidant behavioral. A global score was obtained, with subscores for agoraphobia (FQ-AGO), blood-injury phobia (FQ-BI), and social phobia (FQ-SP) (Marks \& Mathews, 1979).

- Anxiety Sensitivity Index (Peterson \& Reiss, 1992) is a self-administered scale developed to measure the fear of anxiety sensations on a five-choice continuum $(0=$ no anxiety to $4=$ maximum anxiety $)$. The mean score of the ASI in healthy subjects was $18.4 \pm 8.5$ (Peterson \& Reiss, 1987) and, according to the score's distribution, subjects were classified into three groups: with high (ASI score > 27), medium ( $10<$ ASI score $<26$ ) and low (ASI score $<9$ ) AS.

- State Trait Anxiety Inventory (STAI) (Spielberger et al., 1970) is a self-administered scale to assess the state anxiety where subjects rate how they generally feel on a four-point scale ( 1 = almost always $)$. 


\section{Data analyses}

Fractional ranks was performed on the raw data before doing the analysis. To assess the significances of any differences in continuously distributed variables across the trial (days 0, 7, and 42) Friedman ANOVA tests and post-hocWilcoxon matched pairs tests with Bonferroni's corrections were applied. For each variable, the response to treatment was calculated as score (score on day 0 minus score on day 42). Correlations between variables were analysed by Spearman rank correlation tests.

\section{Results}

Citalopram was well tolerated by patients who completed the study $(91 \%)$. The two patients who withdrew the study reported nervousness, somnolence, gastrointestinal distress.

Table 6.1 reports scores on the psychometric scales before treatment, after 1 week and after 6 weeks of treatment with citalopram. Friedman tests showed a significant decrease of scores for panic attacks, anticipatory anxiety and phobic avoidance on the PASS scale, and for agoraphobia and blood-injury phobia subscales of the FQ. Post-hoc Wilcoxon tests showed significant decreases of these variables only after 42 days of treatment, while the decreases were not significant after 7 days.

Table 6.1 Psychometric scores during treatment with citalopram

\begin{tabular}{lcccll}
\hline & $\begin{array}{c}\text { Day 0 } \\
\text { mean } \pm \mathrm{SD}\end{array}$ & $\begin{array}{c}\text { Day } 7 \\
\text { mean } \pm \mathrm{SD}\end{array}$ & $\begin{array}{c}\text { Day 42 } \\
\text { mean } \pm \mathrm{SD}\end{array}$ & $\begin{array}{l}\text { Friedman ANOVA } \\
(\mathrm{N}=20, \mathrm{df}=2)\end{array}$ \\
\hline ASI & $26.6 \pm 8.7$ & $23.2 \pm 9.5$ & $17.2 \pm 7.7$ & $\chi^{2}=19.7$ & $\mathrm{p}<0.00005$ \\
STAI & $52.6 \pm 12.6$ & $50.4 \pm 13.2$ & $38.4 \pm 12.9$ & $\chi^{2}=15.3$ & $\mathrm{p}<0.0004$ \\
PASS-AP & $4.2 \pm 2.6$ & $3.6 \pm 1.9$ & $1.5 \pm 1.8$ & $\chi^{2}=16.2$ & $\mathrm{p}<0.0003$ \\
PASS-AA & $3.3 \pm 1.8$ & $2.6 \pm 1.5$ & $1.3 \pm 1.0$ & $\chi^{2}=16.8$ & $\mathrm{p}<0.0002$ \\
PASS-FOB & $1.1 \pm .1$ & $0.95 \pm .1$ & $0.50 \pm .9$ & $\chi^{2}=6.4$ & $\mathrm{p}<0.04$ \\
PASS-TOT & $8.7 \pm 4.0$ & $7.2 \pm 3.2$ & $3.3 \pm 3.3$ & $\chi^{2}=20.6$ & $\mathrm{p}<0.00003$ \\
FQ-AGO & $15.2 \pm 12.2$ & $15 \pm \pm 11.3$ & $8.4 \pm 9.2$ & $\chi^{2}=11.1$ & $\mathrm{p}<0.002$ \\
FQ-BL & $19.8 \pm 11.7$ & $20.5 \pm 11.3$ & $15.7 \pm 9.8$ & $\chi^{2}=9.6$ & $\mathrm{p}<0.008$ \\
FQ-SOC & $10.4 \pm 8.3$ & $10.3 \pm 8.1$ & $9.4 \pm 10.0$ & $\chi^{2}=0.8$ & $\mathrm{p}=\mathrm{NS}$ \\
\hline
\end{tabular}

ASI scores on days 0,7 , and 42 are also reported in Table 6.2. Before treatment, 
10 patients (50\%) had high ASI scores and 10 medium scores, while none had low scores. The mean ASI scores before treatment were higher than those reported in a sample of Italian normal controls (11.2 \pm 6.4 ) (Saviotti et al., 1991). Friedman tests showed a significant decrease of ASI scores across the trial. A post-hoc Wilcoxon test with Bonferroni's correction showed a significant decrease from day 0 to day 42 and from day 7 to day 42 , while no significant decrease of ASI scores was found from day 0 to day 7 .

Table 6.2 Anxiety Sensitivity Index scores across treatment with citalopram

\begin{tabular}{lccc}
\hline & Day 0 & Day 7 & Day 42 \\
\hline Subject 1 & 42 & 34 & 22 \\
Subject 2 & 26 & 36 & 23 \\
Subject 3 & 14 & 9 & 12 \\
Subject 4 & 19 & 16 & 17 \\
Subject 5 & 42 & 27 & 17 \\
Subject 6 & 28 & 20 & 12 \\
Subject 7 & 14 & 15 & 12 \\
Subject 8 & 32 & 31 & 20 \\
Subject 9 & 27 & 31 & 27 \\
Subject 10 & 31 & 26 & 11 \\
Subject 11 & 23 & 1 & 1 \\
Subject 12 & 25 & 22 & 4 \\
Subject 13 & 12 & 28 & 28 \\
Subject 14 & 26 & 41 & 21 \\
Subject 15 & 23 & 20 & 19 \\
Subject 16 & 17 & 15 & 11 \\
Subject 17 & 28 & 26 & 27 \\
Subject 18 & 32 & 17 & 14 \\
Subject 19 & 37 & 23 & 19 \\
Subject 20 & 33 & 26 & 28 \\
\hline
\end{tabular}

The Spearman rank correlation test showed a significant correlation between ASI and PASS-AA $(r=.48, p<0.04)$ and ASI and FQ-BF $(10 ; r=.61, p<$ 0.005 ), while no significant correlations were found between ASI and PASSAP, PASS-FOB, FQ-AGO, FQ-SOC, and STAI. No significant correlations were found between ASI scores before treatment and all the scores of the PASS, FQ, and STAI scales. 


\section{Discussion}

This is the first study examining the effects of a serotonin reuptake inhibitor on AS in patients with PD. The results suggest that citalopram might decrease fear of bodily sensations in patients with PD. Some significant limitations should be taken into account when interpreting these results. This study was a simple pre-post design, not placebo controlled. Therefore, given the importance of a placebo effect in the treatment of patients with PD, we cannot exclude this bias in the explanation of our results, although citalopram has been repeatedly demonstrated to be more effective that placebo in the reduction of phobic symptoms (Leinonen, Lepola, Turtonen, Wade, \& Letho, 1990; Lepola, Leinonen, \& Turtoten, 1994; Lepola et al., 1998) and ASI scores are stable over time (Maller \& Reiss, 1992; Reiss et al., 1986; Schmidt et al., 1999). The clinical utility of this study is limited from the utilization of fixed dosages and the exclusion of individuals with episodes of major depression. Moreover, the sample examined was not large enough to exclude the possibility of Type II errors, and thus replication with larger samples is warranted. Finally, since we have studied a sample of panic patients with agoraphobia, we cannot exclude a different result in those without agoraphobia.

The main finding of the present study is the evidence that treatment with a selective serotonergic agent improves not only the core somatic manifestations of $\mathrm{PD}$, but also the tendency to make misinterpretations of them. This finding gives rise to two implications. First, the decrease of AS after drug treatment alone, consistent with the two previous studies examining the effect of antipanic medications on AS (Mavissakalian et al., 1998; Otto et al., 1991), challenges the idea that the decrease of AS is selectively mediated by cognitive/behavioral treatment (Clark et al., 1994). Second, since citalopram is a selective serotonergic compound, decrease of AS suggests that the serotonergic mechanism might be involved in modifying this cognitive aspect of PD. The serotonergic system, by decreasing activity of the amygdala, could influence both cortical sites involved in the interpretation of sensory information, and diminishes the activity of brainstem centers that activate somatic symptoms during panic attacks (Gorman et al., 2000). The double modulation might yield a therapeutic effect on both the somatic and cognitive aspects of PD. Modulation of the serotonergic system might also be one mechanism through which psychotherapy, in particular the cognitive/behavioral approach, could exert a therapeutic effect in improving both somatic and cognitive aspects of PD (Baer, 
1996).

AS only decreased significantly after 6 weeks of citalopram treatment, whereas the decrease after 1 week was not significant. This finding parallels the delay of the improvement of core symptoms of PD panic attacks, agoraphobic avoidance and anticipatory anxiety during drug treatment and suggests that the decrease in panic symptoms might not be secondary to an immediate decrease of AS. However, only an evaluation of these components at short intervals during the trial could provide a definitive answer. Moreover, the absence of a significant correlation between the decrease of AS and the decrease of panic attacks or agoraphobic avoidance after 1 week argues against a direct relationship between improvement of panic symptoms and cognitive fear of bodily-related symptoms. The positive correlations between the decrease of AS (i.e., fear of anxiety-related bodily sensations), and of both anticipatory anxiety (i.e., fear of having panic attacks) and blood-injury phobia suggest that treatment with serotonergic drugs might influence a fear system specifically involved in the emotional interpretation of bodily sensations.

Finally, in our sample, AS was not able to predict a decrease in any of the psychometric measures of the severity of PD, suggesting that fear of anxiety-related bodily sensations is not related to the response to serotonergic antipanic drugs.

Future research should include a placebo control group and a non-PD group to investigate the specificity of our finding. Moreover, it might also be interesting to investigate whether treatment with effective antipanic agents other than citalopram would result in a similar decrease in AS.

In conclusion, the results of our study indicate that serotonergic antipanic compounds might decrease AS. The decrease of AS seems to be related to the decrease of anticipatory anxiety as there were no correlations with a decrease in panic attacks and agoraphobic avoidance. 


\section{Chapter 7}

\section{Prevalence of respiratory disorders in first-degree relatives of panic disorder patients}

Panic disorder patients often report a history of respiratory pathology, such as asthma. Also, it has been repeatedly demonstrated that panic disorder is highly prevalent amongst patients with respiratory disorders. It is known that both panic disorder and respiratory disorders, like asthma, run in families. A common diathesis for panic disorder and respiratory disorders may be present both in panic disorder patients and their first-degree relatives. We examined whether the lifetime prevalence of respiratory disorders is higher in first-degree relatives of panic disorder patients than in first-degree relatives of patients with other anxiety disorders. The lifetime history of respiratory pathology was assessed in 379 first-degree relatives of patients with an anxiety disorder by means of a questionnaire. We found the first-degree relatives of panic disorder patients $(n=258)$ to report significantly more chronic obstructive pulmonary diseases (COPD) in general and asthma specifically than the control group $(n=121)$. Our findings are consistent with and extend previous studies by showing that a specific association between COPD, asthma in particular, and panic disorder may exist.

van Beek, N., Schruers, K. \& Griez, E. (submitted). Prevalence of respiratory disorders in firstdegree relatives of panic disorder patients. 


\section{Introduction}

There is an obvious overlap in symptomatology between panic and respiratory disorders. Both disorders have dyspnea, smothering sensations and choking in common. Furthermore, anxiety, a predominant symptom of panic disorder (PD), frequently occurs in asthmatic patients (Carr, 1999; Smoller et al., 1996). However, the link between both types of pathology seems to go beyond a mere phenomenological resemblance. Research has now repeatedly demonstrated that PD is highly prevalent amongst patients with asthma and other chronic obstructive pulmonary diseases (Carr, 1998; Karajgi et al., 1990; Nascimento et al., 2002; Pollack et al., 1996; Yellowlees et al., 1987; Yellowlees, Haynes, Potts, \& Ruffin, 1988).

Conversely, we (Zandbergen et al., 1991) and others (Perna et al., 1994; Spinhoven et al., 1994) have repeatedly found adult PD patients to report a significantly higher lifetime and childhood prevalence of respiratory disorders than control groups. The prevalence of respiratory disorders before the onset of the anxiety disorder was found to be as high as $42.7 \%$ in PD patients contrasting with only $16.2 \%$ in controls (Verburg, Griez, Meijer, \& Pols, 1995b). Congruently with these findings, a recent large scale epidemiological study showed asthma, chronic bronchitis, or emphysema to be related to an increased risk of developing panic attacks in adulthood (Goodwin \& Pine, 2002).

Investigating the lifetime history of atopic disorders in the offspring of PD parents, a recent study suggested an increased rate of asthma in children of PD patients (Slattery et al., 2002). Both PD (Crowe et al., 1983; Goldstein et al., 1997; Maier et al., 1993; Torgersen, 1983) and atopic disorders, such as asthma (Hopper et al., 1990; Postma \& Kips, 1999) have been known to rely on a constitutional predisposition which runs in families. PD patients and their first-degree relatives may share a diathesis that predisposes them to both types of pathology. If that is the case, one would predict the lifetime prevalence of respiratory disorders, atopic disorders such as asthma in particular, to be higher in first-degree relatives of PD patients than in first-degree relatives of patients with other anxiety disorders. This hypothesis was investigated in the present study. 


\section{Method}

\section{Participants}

Three hundred seventy nine first-degree relatives of patients with an anxiety disorder referred to our Academic Anxiety Center in Maastricht agreed to participate in the present study. Amongst them, 258 were relatives of patients with a DSMIV diagnosis of PD and 121 of patients with another DSM-IV anxiety disorder. All patients' diagnoses were made by experienced clinicians on basis of the Mini International Neuropsychiatric Interview (Sheehan et al., 1997). First-degree relatives of patients not fulfilling the criteria for one of the anxiety disorders according to DSM-IV; having PD and a comorbid anxiety disorder; and only having agoraphobia were excluded from the study. Since our main interest was in the relation between asthma and PD, one could consider asthma in patients as a confounder. Therefore, we excluded the family members of patients who ever reported asthma both in the PD and non-PD group.

\section{Procedure}

After having obtained the informed consent from both the patient and his or her relative, all participants completed a specially developed questionnaire, either on basis of a telephonic interview or by returning the mailed questionnaire. As far as children younger than 16 were concerned, data were collected with the parents' collaboration.

The questionnaire globally assessed the lifetime prevalence of any type of significant respiratory disorder, excluding trivial affections, such as common cold. The questionnaire specifically assessed the following categories: asthma, bronchitis, emphysema, and 'other disturbances affecting the respiratory system'. Each category on the questionnaire was scored as present ('ever suffered from') or absent ('never had this type of disease') on a lifetime basis.

\section{Data analyses}

We organized the data in three different ways with increasing specificity: 'any type of dysfunction affecting the respiratory apparatus' (which meant any positive answer in whatever category of the questionnaire), 'chronic obstructive pulmonary 
diseases' (COPD: i.e., asthma, bronchitis, emphysema (Goodwin \& Pine, 2002)), and finally the discrete categories of asthma, bronchitis and emphysema. Presence or absence of a score in each of the above categories was assessed in first-degree relatives of PD patients versus those of patients with other anxiety disorders. Finally, data from children under the age of 16 were specifically addressed. Data was analyzed using a Chi-square test with Yates' continuity correction, except when the assumptions for a Chi-square test were not met, a Fisher exact test was used.

\section{Results}

The total group of first-degree relatives of PD patients $(n=258$, mean age $=32.5$ years, $\mathrm{SD}=22.5$ ) did not differ in age from the total group of first-degree relatives of other anxiety disorder patients $(n=121$, mean age $=34.8$ years, $S D=21.8)$ $(\mathrm{t}(374)=-.95, \mathrm{p}=\mathrm{NS})$. The children of PD patients $(\mathrm{n}=95)$ had a mean age of 9.4 years $(\mathrm{SD}=4.1)$ and the other child group $(\mathrm{n}=37)$ scored 8.9 years $(\mathrm{SD}=$ 4.2). This difference was not statistically significant $(\mathrm{t}(130)=.66, \mathrm{p}=\mathrm{NS})$.

Ninety-five of the 258 first-degree relatives of PD patients (36.8\%) versus 37 of the 121 first-degree relatives of other anxiety disorder patients $(30.6 \%)$ reported a lifetime prevalence of any respiratory disorder. This difference did not reach statistical significance $\left(\chi^{2}=1.2, \mathrm{p}=\mathrm{NS}\right)$. Sixty-four of the 258 first-degree relatives of PD patients (24.8\%) reported a lifetime prevalence of COPD compared to 16 of the 121 control first-degree relatives $(13.2 \%)$. This difference on COPD was statistically significant $\left(\chi^{2}=6.0, \mathrm{p}<0.05\right)$. To further refine the subcategory COPD, we calculated the prevalence of asthma, bronchitis and emphysema. Asthma occurred in 27 of the 258 first-degree relatives of PD patients (10.5\%) versus only in 4 of the 121 first-degree relatives of other anxiety disorder patients (3.3\%). This difference on asthma was also statistically significant $\left(\chi^{2}=4.71, \mathrm{p}<0.05\right)$ (Figure 7.1 ). Although the prevalence of bronchitis (13.2\% vs. $9.1 \%$ ) or emphysema $(1.2 \%$ vs. $0.8 \%)$ in the first-degree relatives of PD patients was higher than that in those of other anxiety disorder patients, the differences were not statistically significant.

Thirty-nine of the 95 children of PD patients $(41 \%)$ and 12 of the 37 children of other anxiety disorder patients $(32.4 \%)$ had any respiratory disorder $\left(\chi^{2}=.51\right.$, $\mathrm{p}=$ NS). Twenty-two out of the 95 children of PD patients $(23.2 \%)$ reported a lifetime prevalence of COPD versus 6 of the 37 children of other patients $(16.2 \%)$ 


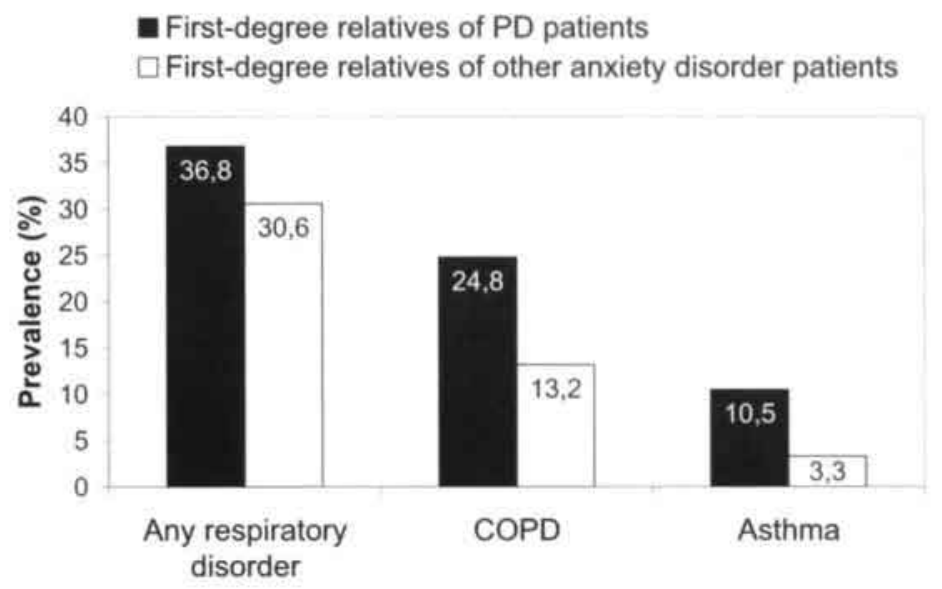

Figure 7.1 Prevalence (\%) of respiratory disorders in first-degree relatives

$\left(\chi^{2}=.41, \mathrm{p}=\mathrm{NS}\right)$. On the subcategory asthma, a lifetime occurrence was reported by 13 of the 95 children of PD patients (13.7\%) compared to 4 of the 37 controls $(10.8 \%)(p=$ NS, Fisher exact test) (Figure 7.1). The children groups did not differ in prevalence of bronchitis ( $9.5 \%$ vs. $5.4 \%$ ) or emphysema ( $0 \%$ vs. $0 \%$ ).

\section{Discussion}

Whether expressed as the global occurrence of any type of respiratory pathology in general, or as the pooled occurrence of asthma, bronchitis and emphysema, the lifetime prevalence of diseases affecting the respiratory system was higher in first-degree relatives of PD patients than in first-degree relatives of other anxiety disorder patients. The differences between these two groups reached statistical significance for the pooled COPD category as well as for asthma specifically.

The difference between the first-degree relatives of PD patients and the control group however, did not reach statistical significance on the prevalence of respiratory pathology in general. In this regard, it should be noted that this global measure included the category 'other disturbances affecting the respiratory system' in our self designed questionnaire, resulting in a very rough approach of respiratory pathology. Under the broad formulation of this latter category, participants appeared to report such various conditions as infectious diseases, for in- 
stance acute pneumonia, and mechanical incidents of false deglutition causing a suffocation-like experience. Thus, it may be supposed that the global evaluation of respiratory diseases, as assessed by our questionnaire, took into account very heterogeneous conditions, some of them being only loosely linked to respiratory physiology. Therefore, as far as 'respiratory pathology in general' is concerned, we suspect background noise to have masked a statistically significant difference between the first-degree relatives of PD patients and the control group.

Narrowing the diagnostic focus on COPD, we found the data to be consistent with our expectations. First-degree relatives of PD patients had a significantly higher lifetime prevalence of obstructive respiratory diseases than family members of other anxiety disorder patients. This result is consistent with, and extends repeated findings of a series of earlier studies reporting an association between PD and COPD (Perna et al., 1994; Verburg et al., 1995b; Yellowlees et al., 1987; Zandbergen et al., 1991).

Considering the fact that a more specific link between PD and asthma in particular has been suggested by others (Carr, 1999; Perna, Bertani, Politi, Colombo, \& Bellodi, 1997) and that the prevalence of asthma has doubled in ten years in Western Europe (Steerenberg et al., 2000), we paid special attention to the discrete category of asthma. Similarly to COPD in general, there was a significant difference in the prevalence of asthma between PD families and families of other anxiety patients. Eleven percent of the first degree relatives of PD patients reported a lifetime history of asthma while only $3 \%$ of comparison family members did so.

Regarding the children under the age of 16, the figures are in general remarkably comparable to those observed in the groups of adult first-degree relatives. However, the differences between children of PD patients and those of parents with other anxiety disorders failed to reach statistical significance, probably due to a limited number of participants in the latter group. Nevertheless, compared to those of other anxiety disorders parents, children of PD parents suffer twice as often from bronchitis. Also, the prevalence of asthma we found in children of PD patients was over twice as high the prevalence of $6 \%$ in a Dutch sample of school children (Rijcken, Schouten, \& Kerkhof, 1999). This might suggest that being a child of a PD parent makes one especially vulnerable to develop respiratory conditions, like bronchitis and asthma.

The above findings indicate a common familial aggregation of some types of respiratory diseases and PD. Conclusions about the sequence of onset of respira- 
tory disorders and PD cannot be drawn from our data, let alone about any link of causality between respiratory and affective pathology. Beside the hypothesis of a shared diathesis, predisposing both to PD and obstructive respiratory pathology, it is possible that some types of respiratory conditions predispose to the development of PD. A strong argument in favor of this idea is the finding that asthma and other obstructive conditions do represent an increased risk of panic attacks (Goodwin \& Pine, 2002). Moreover, personal experience with trivial wheeze and asthma at age 15 increased the risk for PD in females, just as a positive history for asthma at age 18 increased the risk for $\mathrm{PD}$ in more emotionally reactive males (Craske, Poulton, Tsao, \& Plotkin, 2001). It is worth noting that asthma or other obstructive respiratory conditions involve the presences of relatively prolonged respiratory dysfunction with dyspnea as a prominent feature. Panic has been conceived as the consequence of an oversensitive biological suffocation alarm (Klein, 1993). One might speculate that a chronic obstructive respiratory condition presenting in the early childhood induces a lowering of this putative suffocation alarm threshold via a process of long-term sensitization. However, as long as the exact sequence of onset has not been established in large scale prospective longitudinal studies, the nature of the relation between both types of pathologies will remain speculative. A particular focus of interest should be the population of children of PD parents who are suffering with asthma or bronchitis, since, according to the above speculations, those subjects are expected to be at high risk for the development of PD later in life.

While either a shared diathesis, or a simple causal link between PD and COPD may be an obvious, albeit speculative, hypothesis, one could think of other factors entering into play. Passive smoking is known to be of importance in the development of asthma during childhood (Rijcken et al., 1999). PD patients smoke more cigarettes than persons in the general population and individuals with other anxiety disorders (Zvolensky, Schmidt, \& Stewart, 2003). Therefore, close relatives of PD patients are at higher risk than others to be exposed to the pathogenic effects of passive smoking, at least those first-degree relatives living together with the PD patient. Moreover, it has been suggested that cigarette smoking itself contributes to the development of PD (Zvolensky et al., 2003). Findings of a large epidemiological study indicate that daily smoking was associated with an increased risk for first-time occurrence of panic attacks and PD (Breslau \& Klein, 1999). In addition, heavy cigarette smoking during adolescence was found to be associated with 
an increased risk for PD during early adulthood (Johnson et al., 2000). Therefore, the factor of smoking may be a good candidate to explain an aggregation of PD and (childhood) asthma in the same families.

Some limitations of the present study should be mentioned. First, the data on respiratory disorders relies on retrospective self-reports. At best, this is likely to represent a crude approximation of the exact history of respiratory disorders. To reduce the effect of a possible recollection bias, we used only rough diagnostic categories. Patients are likely to remember if they ever have had any respiratory disorder, but they may be expected to have difficulty remembering exactly what kind of diagnosis was made. This crude approach introduced diagnostic imprecision and prevents refined analysis. On the other hand, self-reports are the most commonly used form of assessment of physical diseases in large surveys, which allows for comparison of prevalence rates (Goodwin \& Pine, 2002). Second, our PD patients were assumed to contact first-degree family members who were not under psychiatric treatment. However, the participating relatives did not undergo formal psychiatric assessment and therefore it cannot be excluded that they were free of any psychiatric disorder.

Despite the above limitations, we found quite strong evidence that first-degree relatives of PD patients have a higher prevalence of respiratory pathology, in particular COPD, than those of patients with other anxiety disorder. This finding adds to the suspicion that a link may exist between COPD, namely asthma, and PD. Future studies that further examine affected families and analyze the sequence of onset of both types of diseases will help improving our understanding of this comorbidity.

Acknowledgement The authors thank Cindy Debie and Janneke van Drunen for their help with data collection. 


\section{Chapter 8}

\section{Vulnerability to $35 \% \mathrm{CO}_{2}$ of panic disorder patients with a history of respiratory disorders}

Patients with panic disorder often report a history of respiratory pathology. Furthermore, panic disorder patients are vulnerable to $\mathrm{CO}_{2}$ challenges. The increased $\mathrm{CO}_{2}$ vulnerability displayed by panic disorder patients may be related to lifetime respiratory pathology. We examined whether panic disorder patients with a history of respiratory disorders are more vulnerable to a $35 \% \mathrm{CO}_{2}$ challenge than those without such a history. Ninety-six patients with panic disorder were interviewed about their lifetime respiratory status (asthma, bronchitis and various other respiratory conditions) and underwent the challenge. Immediately before and after the $\mathrm{CO}_{2}$ inhalation, the patients filled out the Visual Analogue Scale for Anxiety (VAS-A) and the Panic Symptom List (PSL). We found no differences between the two panic disorder groups on anxiety (VAS-A), panic symptoms (PSL) or panic attacks after the $\mathrm{CO}_{2}$ challenge. Our results support that having a panic disorder is an important factor in $\mathrm{CO}_{2}$ vulnerability independent of a history of respiratory disorders.

van Beek, N., Perna, G., Schruers, K.. Verburg, K., Cucchi, M., Bellodi, L., \& Griez, E, (in press). Vulnerability to $35 \% \mathrm{CO}_{2}$ of panic disorder patients with a history of respiratory disorders. Psychiatry Research. 


\section{Introduction}

Several studies suggest a link between panic and respiratory disorders. Panic disorder patients, either with or without agoraphobia (PD), more often report a history of respiratory disorders compared to other populations (Perna et al., 1994; Spinhoven et al., 1994; Zandbergen et al., 1991). The lifetime prevalence of respiratory diseases was significantly higher in PD than in obsessive compulsive disorder and eating disorder patients (Zandbergen et al., 1991). Conversely, a higher prevalence of PD was found in patients with chronic obstructive pulmonary diseases than in the general population (Karajgi et al., 1990; Yellowlees et al., 1987). Asthma is associated with a high risk of panic attacks and panic symptoms (Carr, 1999). Furthermore, symptoms of panic attacks overlap with the respiratory distress seen in some pulmonary diseases (Smoller et al., 1996).

Experimentally, PD patients are hyperreactive to inhalation of hypercapnic gas mixtures, while $\mathrm{CO}_{2}$ is a well-known key factor in respiratory regulation. Specifically, PD patients are more vulnerable to a $35 \% \mathrm{CO}_{2}$ challenge than healthy subjects (Griez et al., 1987; Fyer et al., 1987; Perna et al., 1994), patients with mood disorder (Perna et al., 1995), obsessive compulsive disorder (Griez et al., 1990; Perna et al., 1995), generalized anxiety disorder (Verburg et al., 1995a), and other psychiatric disorders (Griez et al., 1990; Papp et al., 1993). Particularly, it is hypothesized that PD patients have an abnormally low suffocation alarm threshold and that panic attacks may be the equivalent of a false alarm triggered in an oversensitive suffocation monitor (Klein, 1993).

However, not all PD patients are equally vulnerable to $35 \% \mathrm{CO}_{2}$. Depending on the criteria used, up to $52 \%$ of them fail to report a panic attack in response to a $35 \% \mathrm{CO}_{2}$ challenge (Gorman et al., 1990; Perna et al., 1994, 1995). $\mathrm{CO}_{2}$ vulnerability is not equally distributed across the PD population and may vary across subtypes of PD. When PD patients were divided into a 'respiratory' and a 'non respiratory' subtype according to the symptom profile of their panic attacks, the 'respiratory' group was significantly more sensitive to $\mathrm{CO}_{2}$ than the 'non respiratory' group (Biber \& Alkin, 1999).

Overall, the increased $\mathrm{CO}_{2}$ vulnerability seen in PD patients may be related to respiratory pathology. We therefore investigated whether PD patients with a history of respiratory disorders are more vulnerable to a $35 \% \mathrm{CO}_{2}$ challenge than PD patients without such a history. 


\section{Method}

\section{Subjects}

Ninety-one patients with PD (with or without agoraphobia) participated in the present study ( 49 men and 42 women; mean age $=35.9$ years, $\mathrm{SD}=11.0$, range 18-64 years). Forty-four patients were recruited at the Academic Anxiety Center in Maastricht (the Netherlands) and 47 at the Anxiety Disorders Clinical and Research Unit, San Raffaele Hospital in Milan (Italy).

Inclusion criteria were: age between 16 and 65 years, no prior experience with the $\mathrm{CO}_{2}$ challenge, a DSM-IV diagnosis panic disorder with or without agoraphobia. Diagnoses were made in good agreement by at least two experienced clinicians using a structured interview (Mini International Neuropsychiatric Interview; Sheehan et al., 1997). Exclusion criteria were: any comorbidity on axis I; significant history of cardiovascular or cerebrovascular pathology; any current respiratory disorders, including asthma and lung fibrosis; personal or familial history of cerebral aneurysm; hypertension with systolic pressure $>180 \mathrm{mmHg}$ or diastolic pressure $>100 \mathrm{mmHg}$; pregnancy; epilepsy. At the time of the challenge, none of the subjects were on any centrally acting drugs.

\section{Procedure}

The study was approved by the local medical ethics committees both in Maastricht and in Milan. After complete description of the study to the subjects, their informed consent was obtained. The individual history of respiratory disorders was assessed by means of a checklist. The checklist contained the items asthma and bronchitis, and various other respiratory conditions (e.g., tuberculosis, recurrent upper respiratory tract infections, and emphysema). On a positive answer, patients were asked when the disorder occurred, if and how it was treated, and if there were any further particularities. A patient was considered having a history of respiratory disorders if he reported having suffered from any of the respiratory conditions. We used this composite measure to reduce the effect of a possible recollection bias. Patients are likely to remember if they had suffered from a respiratory disorder, but they may have difficulty remembering exactly which diagnosis was made.

In both Maastricht and Milan the same $\mathrm{CO}_{2}$ inhalation procedure was used (Verburg et al., 2001). A gas mixture of $35 \% \mathrm{CO}_{2}$ and $65 \% \mathrm{O}_{2}$ was used. The 
gas was inhaled through a self-administration mask. The respirometer connected to the self-administration mask measured the gas volume delivered at each inhalation to ensure that at least $80 \%$ of the subject's vital capacity volume would be inhaled. Subjects were informed that they would inhale a physiologically harmless gas mixture, but also that during the challenge they might experience some discomfort, ranging from a few neurovegetative symptoms to strong anxiety-like symptoms. The term 'panic attack' itself was not mentioned. A single vitalcapacity breath of the $35 \% \mathrm{CO}_{2} / 65 \% \mathrm{O}_{2}$ gas mixture was inhaled, and exhaled after 4 seconds.

Self-administered questionnaires that the subjects rated immediately before and after the inhalation were a Visual Analogue Scale for Anxiety (VAS-A) for subjective anxiety, ranging from 0 to 100 , and a 13 items Panic Symptom List (PSL) referring to the DSM-IV criteria, each item being assessed on a 5-point scale.

\section{Data analyses}

To determine whether the $\mathrm{CO}_{2}$ inhalation induces more subjective anxiety (VASA) and panic symptoms (PSL) between the respiratory group and the non respiratory group a repeated measures analysis of variance (ANOVA) was used with history of respiratory disorders (Group) as between-subjects factor and the effects of the challenge (Moment; pre or post) as within-subjects factor.

A $\mathrm{CO}_{2}$-induced panic attack was defined by an increase of anxiety (VAS-A post $\mathrm{CO}_{2} \geq 25$ ) combined with an increase in panic symptomatology (Pols et al., 1996; Woods et al., 1990). A Chi-square analysis with Yates' continuity correction was applied to determine if more PD patients with a respiratory disorder had more $\mathrm{CO}_{2}$-induced panic attacks than those without respiratory disorders.

\section{Results}

\section{History of respiratory disorders}

Fifty-seven PD patients (62.6\%) had a history of respiratory disorders (respiratory group; 31 men, 26 women, mean age $=35.4$ years, $S D=9.4$ ) and 34 patients $(37.4 \%$ ) did not (non respiratory group; 18 men, 16 women, mean age $=36.9$ years, $\mathrm{SD}=13.4)$. The respiratory group did not significantly differ in age $(\mathrm{t}(52.6)$ 
$=-.59, \mathrm{p}=\mathrm{NS})$ or gender $\left(\chi^{2}\right.$ with Yates' continuity correction $\left.=.01, \mathrm{p}=\mathrm{NS}\right)$. Nineteen patients had bronchitis, five patients had asthma, 13 had pneumonia and 66 had other respiratory conditions like, allergy or tuberculosis.

\section{Subjective anxiety}

The scores on the VAS-A are shown in figure 8.1. A significant main effect was found for moment $(\mathrm{F}(1,89)=174.5, \mathrm{p}<0.0001)$, meaning that a difference is found in subjective anxiety pre and post the $\mathrm{CO}_{2}$ challenge for the entire group. No significant main effect was found for group. No significant interaction effect was found for group $\times$ moment.

mpre $\mathrm{CO} 2 \square$ post $\mathrm{CO} 2$

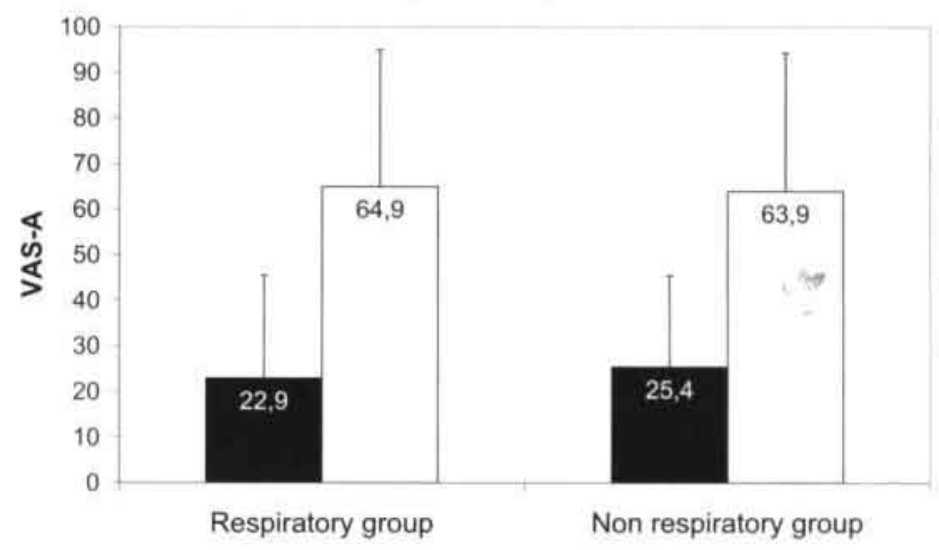

Figure 8.1 Scores (+SD) on the Visual Analogue Scale for Anxiety (VAS-A) on the $35 \% \mathrm{CO}_{2}$ challenge in panic disorder patients with (Respiratory) and without a history of respiratory disorders (Non respiratory)

\section{Panic symptoms}

The scores on the PSL are shown in figure 8.2. A significant main effect was found for moment $(\mathrm{F}(1,89)=148.0, \mathrm{p}<0.0001)$, meaning that a difference is found in panic symptoms pre and post the $\mathrm{CO}_{2}$ challenge for the entire group. No 
significant main effect was found for group. No significant interaction effect was found for group $\times$ moment.

apre $\mathrm{CO} 2 \square$ post $\mathrm{CO} 2$

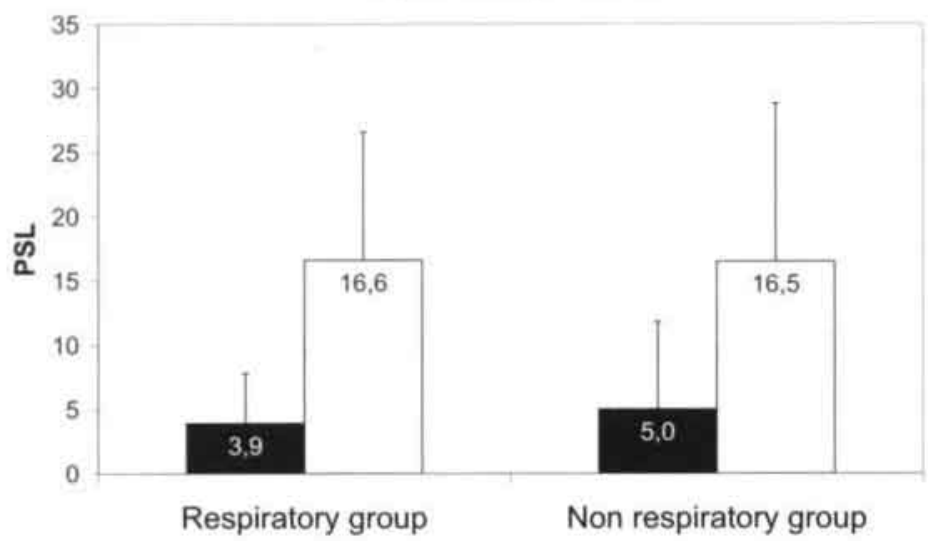

Figure 8.2 Scores (+SD) on the Panic Symptom List (PSL) on the $35 \% \mathrm{CO}_{2}$ challenge in panic disorder patients with (Respiratory) and without a history of respiratory disorders (Non respiratory)

\section{$\mathrm{CO}_{2}$-induced panic attacks}

Forty-eight PD patients with a history of respiratory disorders $(84.2 \%)$ and 28 PD patients without a history of respiratory disorders $(82.4 \%)$ had a $\mathrm{CO}_{2}$-induced panic attack. No significant difference was found in $\mathrm{CO}_{2}$-induced panic attacks between the two groups.

\section{Discussion}

The results of the present study do not support the idea that PD patients with a history of respiratory disorders are more vulnerable to the $\mathrm{CO}_{2}$ challenge than patients without such a history. The groups differed neither on $\mathrm{CO}_{2}$-induced anxiety, nor on experimental panic symptoms, and nor on $\mathrm{CO}_{2}$-induced panic attacks.

There have been other attempts to link either current respiratory symptoms or past pulmonary diseases with the higher than usual $\mathrm{CO}_{2}$ vulnerability in PD. Biber and Alkin (1999) classified 51 PD patients according to the symptom profile of 
their natural panic attacks. This was based on the way subjects experienced their symptoms. Those reporting strong respiratory symptomatology were considered to represent a 'respiratory' subtype of PD. It was found that $79 \%$ of the 'respiratory' subtype had a $\mathrm{CO}_{2}$-induced panic attack versus only $48 \%$ of the 'non respiratory' subtype (Biber \& Alkin, 1999). However, there might be no relation at all between the current symptom profile of panic attacks and a past history of respiratory disorders. In a previous experiment in the Maastricht laboratory, PD patients were divided into 33 subjects with severe respiratory symptoms during panic attacks ('respiratory' subtype) and 49 patients with moderate or minor breathing complaints ('non respiratory' subtype). This classification resembles Biber and Alkin's procedure. There was no relation between the two subtypes and history of respiratory diseases (Verburg et al., 1995b). Our present results suggest that, while a current 'respiratory' profile of real life panic attacks may indicate a higher $\mathrm{CO}_{2}$ vulnerability, a lifetime history of respiratory diseases does not.

There is an increased lifetime prevalence of respiratory disorders in PD (Perna et al., 1994; Spinhoven et al., 1994; Zandbergen et al., 1991) and a history of respiratory disorders has been linked to a higher probability of developing PD in subjects with familial predisposition to PD (Perna et al., 1997). On the other hand, $\mathrm{CO}_{2}$ vulnerability is a specific marker of panic (Verburg et al., 1998). It runs in families (Bellodi et al., 1998; Perna et al., 1995; Van Beek \& Griez, 2000) and apparently identifies those individuals at risk for PD (Coryell, 1997). However, results of the present study suggest that respiratory pathology early in life is not directly linked to an increased $\mathrm{CO}_{2}$ vulnerability. Present $\mathrm{CO}_{2}$ vulnerability does not merely result from past respiratory diseases, neither do past respiratory disorders add to present $\mathrm{CO}_{2}$ vulnerability. Hence, even though they may have suffered from more respiratory pathology than others, adult PD patients have no grossly disturbed ventilatory physiology (Gorman et al., 2001). PD patients showed no impairments in their pulmonary function (Carr, Lehrer, \& Hochron, 1992; Verburg, De Leeuw, Pols, \& Griez, 1997) and only a proportion of PD patients had subclinical impairments in lung function (Perna et al., 1994). The relation between history of pulmonary pathology, $\mathrm{CO}_{2}$ vulnerability, and $\mathrm{PD}$ may be more complex than a simple causal sequence.

Alternative explanations are possible. It is conceivable that both the propensity to early respiratory disorders and increased vulnerability to $\mathrm{CO}_{2}$ are linked to a third factor governing the development of PD in adulthood. Alternatively, the role 
of respiratory pathology in increasing the possible risk of developing PD may be less specific than once thought. A high prevalence of PD was not only found in respiratory patients: PD is also highly prevalent in fibromyalgia (Malt, Berle, Olafsson, Lund, \& Ursin, 2000) and cardiovascular patients (Fleet et al., 2000; Griez et al., 2000). While a high prevalence of PD was expectedly found in patients with asthma, these subjects also reported an increased frequency of social phobia, generalized anxiety disorder, and depression (Nascimento et al., 2002).

Notwithstanding, and even though the exact link between respiratory pathology and PD is not clear, special mention should be made of asthma. In a large sample of 3032 adults in the general population, a composite measure of the selfreported diseases asthma, chronic bronchitis or emphysema was associated with an increased likelihood of panic attacks. This specific association to panic attacks persisted after adjusting for differences in sociodemographic characteristics, physical illnesses, and comorbid mental disorders (Goodwin \& Pine, 2002). Other investigators have also found a specific relation between panic attacks and asthma (Carr, 1999; Perna et al., 1997). In light of a specific association between asthma and $\mathrm{PD}$, it should be interesting to investigate the $\mathrm{CO}_{2}$ vulnerability of $\mathrm{PD}$ patients with a history of asthma compared to PD patients with a history of other respiratory disorders.

The most obvious limitation of the present study lies in the retrospective character of the obtained data of the patient. It is possible, that there is a considerable time-gap between the actual respiratory disorder and the data collection. Since this data gathering was based on self-report, a recollection bias cannot be excluded. Being aware of this problem, we refrained from further refined diagnosis. This obviously introduced another limitation, preventing more refined analysis on basis of specific respiratory disorders.

To conclude, our findings indicate that PD patients with a history of respiratory disorders are not more vulnerable to the $35 \% \mathrm{CO}_{2}$ challenge than $\mathrm{PD}$ patients without such a history, suggesting that there is no simple direct causal link between lifetime respiratory pathology and the observed $\mathrm{CO}_{2}$ vulnerability in adult PD patients. 


\section{Chapter 9}

\section{Concluding remarks}

The objective of this thesis was to investigate a number of vulnerability factors in PD patients and their first-degree relatives. After having offered a general introduction about $\mathrm{PD}$, the factor $\mathrm{CO}_{2}$ sensitivity was examined empirically in the second chapter. Cognitive as well as physiological factors may enter into play to explain this $\mathrm{CO}_{2}$ sensitivity. The cognitive factor anxiety sensitivity (AS) was studied in the first part of the thesis. The last chapters addressed some issues related to the role of respiratory pathophysiology. In the current chapter, the main findings will be discussed and some directions for future research will be proposed.

\section{Main results}

- First-degree relatives of $\mathrm{PD}$ patients were more reactive to a $35 \% \mathrm{CO}_{2}$ challenge than healthy control participants.

- AS, which has been proposed as a risk factor for the development of PD, was higher in first-degree relatives of PD patients than in healthy control participants, but not as high as in PD patients.

- However, and specifically, young children of PD patients were not more anxiety sensitive compared to children of healthy parents.

- AS levels of PD patients decreased after a SSRI treatment of 6 weeks.

- First-degree relatives of PD patients have a significantly higher prevalence of COPD, asthma in particular, than first-degree relatives of other anxiety disorder patients.

- PD patients with a history of respiratory disorders were not more reactive to a $35 \% \mathrm{CO}_{2}$ challenge than those without such a history. 


\section{$\mathrm{CO}_{2}$ and anxiety sensitivity}

It has been established that the $35 \% \mathrm{CO}_{2}$ challenge is a valid laboratory model for panic attacks. The results of the study described in Chapter 2 revealed that healthy first-degree relatives of PD patients were more vulnerable to the $35 \% \mathrm{CO}_{2}$ challenge than healthy control participants. The cognitive factor AS may explain this vulnerability to $\mathrm{CO}_{2}$. The $\mathrm{CO}_{2}$ challenge may provoke sensations feared by highly anxiety sensitive first-degree relatives. Therefore, we first examined in Chapter 4 if first-degree relatives of PD patients have elevated AS levels at all. Results showed that first-degree relatives of PD patients without lifetime panic attacks indeed did have significantly higher levels of AS than control subjects. It has been proposed that high AS is a risk factor for the development of PD. Yet, increased AS is not a sufficient condition to develop a PD, since these first-degree relatives, all of whom never had PD, had a mean age of 50, well above the peak of onset for PD, and therefore were not likely to develop a PD anymore.

In Chapter 5 a subset of first-degree relatives of PD patients was examined with regard to AS. Somewhat unexpectedly, children of PD patients, who are likely to be more at risk for developing PD than older first-degree relatives, were not more anxiety sensitive than children of healthy parents. Thus, parental PD pathology does not seem to lead to high AS in their young children. Nevertheless, it may be the case that learning experiences may strengthen or weaken the level of AS in a person. It might therefore be possible that the level of AS in children can increase over time. In line with this, other investigators have found in a prospective study that ASI scores in adolescents did indeed increase over time (Weems et al., 2002). Thus, results from Chapter 5 suggest that AS might be a developing vulnerability factor in children of PD patients that may increase towards late adolescence or early adulthood. Only prospective studies could demonstrate whether in children of PD patients AS levels do escalate. Whatsoever, the putative mechanisms underlying an increased AS level over time warrant more investigation.

High levels of AS have been repeatedly found in subjects who have developed a PD. AS scores seem to be subject to change. Conceivably, if AS levels can increase over time, it can decrease as well. Therefore, we studied whether treatment with citalopram, a SSRI, has an effect on AS levels in PD patients. Results showed a significant decrease of AS levels after pharmacological treatment in these patients (Chapter 6). 
The provisory conclusion from the preceding studies may run as follows. Being a first-degree relative of a patient with $\mathrm{PD}$ is, in itself, an important factor in $\mathrm{CO}_{2}$ vulnerability, even in the absence of any lifetime history of panic. This strongly suggests that $\mathrm{CO}_{2}$ vulnerability may be a marker of a familial vulnerability to PD. AS may run in PD families as well. It is conceivable that an elevated AS level in first-degree relatives of $\mathrm{PD}$ patients is a vulnerability factor for both $\mathrm{CO}_{2}$ sensitivity and the development of PD. If so, AS is a risk factor that slowly develops over time. Primary prevention might be adjusted to counter this development.

\section{$\mathrm{CO}_{2}$ and respiratory pathology}

The literature already abounds in evidence suggesting an association between respiratory disorders and PD. Respiratory disorders and panic attacks each are leading causes of disability and heath-care utilization among youth and adults in the community (Kouzis \& Eaton, 2000; Steerenberg et al., 2000). It is possible that treatment of one can prevent exacerbation of the other. Consequently, improving our understanding of the possible relation between respiratory diseases and PD is important. Therefore in Chapter 7, the prevalence of respiratory disorders in PD families was investigated. We found the first-degree relatives of PD patients to report more COPD, asthma in specific, than those of other anxiety disorder patients. Given the fact that both PD and asthma run in families, our findings may suggest a specific association between asthma and PD. The mechanism of this observed link still remains unclear. Besides the factor of smoking, which has been discussed earlier, it might be the case that high AS plays a role in this association we have seen. High AS runs in PD families (Chapter 4), and is related to subsequent development of panic attacks (Schmidt et al., 1999). Strikingly, asthmatic patients reported significantly higher ASI scores than healthy control subjects (Caccappolo-van Vliet, Kelly-McNeil, Natelson, Kipen, \& Fiedler, 2002). It is therefore conceivable that AS as well may act as a moderating variable in the association between PD and asthma. Whether in particular first-degree relatives of PD patients with asthma display higher AS levels than others, requires however further investigation.

In our most recent study presented in Chapter 8 , the link between respiratory pathology and PD has been further examined. The hypothesis was tested whether PD patients with a history of respiratory disorders are more vulnerable to a $35 \%$ $\mathrm{CO}_{2}$ challenge than those without such a history. The results did not yield any evi- 
dence for a different response of PD patients with a history of respiratory disorders to the $\mathrm{CO}_{2}$ challenge. We can conclude from this study that a history of respiratory disorders is not a crucial factor in $\mathrm{CO}_{2}$ vulnerability in PD patients. Despite its suspected link with respiratory pathology, PD is in itself the most important factor for a high $\mathrm{CO}_{2}$ vulnerability.

\section{Conclusion}

To conclude, $\mathrm{CO}_{2}$ sensitivity appears to be a marker of a vulnerability to PD. Both AS and respiratory pathology, asthma in particular, might mediate this $\mathrm{CO}_{2}$ sensitivity and seem to be vulnerability factors in risk for PD. Apparently, all these factors interact in complex ways over time. Future studies that examine the relation between $\mathrm{CO}_{2}$ vulnerability, $\mathrm{AS}$, and respiratory pathology in persons at risk for PD may prove useful in determining possible underlying mechanisms. 


\section{References}

American Psychiatric Association. (1994). Diagnostic and statistical manual of mental disorders (DSM-IV) (4th ed.). Washington, DC: American Psychiatric Association.

Argyle, N., Deltito, J., Allerup, P., Albus, M., Nutziger, D., Rasmussen, S., Ayuso, J., \& Bech, P. (1991). The Panic-Associated Symptoms Scale: measuring the severity of PD. Acta Psychiatrica Scandinavica, 83, 20-26.

Asmundson, G., Norton, G., Lanthier, N., \& Cox, B. (1996). Fear of anxiety: do current measures assess unique aspects of the construct? Personality and Individual Differences, 20(5), 607-612.

Asmundson, G., \& Stein, M. (1994). Selective processing of social threat in patients with generalized social phobia: evaluation using a dot-probe paradigm. Journal of Anxiety Disorders, 8(2), 107-117.

Baer, L. (1996). Behavior therapy: endogenous serotonin therapy? Journal of Clinical Psychiatry, 57, 33-35.

Ball, S., Otto, M., Pollack, M., Uccello, R., \& Rosenbaum, J. (1995). Differentiating social phobia and panic disorder: a test of core beliefs. Cognitive Therapy and Research, 19(4), 473-482.

Balon, R., Jordan, M., Pohl, R., \& Yergani, V. (1989). Family history of anxiety disorders in control subjects with lactate-induced panic attacks. American Journal of Psychiatry, 146, 1304-1306.

Battaglia, M., \& Perna, G. (1995). The $35 \% \mathrm{CO}_{2}$ challenge in panic disorder: optimization by receiver operating characteristic (ROC) analysis. Journal of Psychiatric Research, 29(2), 111-119.

Bellodi, L., Perna, G., Caldirola, D., Arancio, C., Bertani, A., \& Di Bella, D. (1998). $\mathrm{CO}_{2}$-induced panic attacks: a twin study. American Journal of Psychiatry, 155, 1184-1188. 
Bertani, A., Caldirola, D., Bussi, R., Bellodi, L., \& Perna, G. (2001). The 35\% $\mathrm{CO}_{2}$ hyperactivity and clinical symptomatology in patients with $\mathrm{PD}$ after one week of treatment with citalopram: an open study. Journal of Clinical Psychopharmacology, 21, 262-267.

Biber, B., \& Alkin, T. (1999). Panic disorder subtypes: differential responses to $\mathrm{CO}_{2}$ challenge. American Journal of Psychiatry, 156(5), 739-744.

Birmaher, B., Khetarpal, S., Brent, D., Cully, M., Balach, L., Kaufman, J., \& Neer, S. M. (1997). The screen for child anxiety related emotional disorders (SCARED): scale construction and psychometric characteristics. Journal of the American Academy of Child and Adolescent Psychiatry, 36(4), 545-553.

Breslau, N., \& Klein, D. (1999). Smoking and panic attacks: an epidemiological investigation. Archives of General Psychiatry, 56, 1141-1147.

Caccappolo-van Vliet, E., Kelly-McNeil, K., Natelson, B., Kipen, H., \& Fiedler, N. (2002). Anxiety sensitivity and depression in multiple chemical sensitivities and asthma. Journal of Occupational and Environmental Medicine, 44(10), 890-901.

Calamari, J., Hale, L., Heffelfinger, S., Janeck, A., Lau, J., Weerts, M., Taglione, P., \& Schisler, R. (2001). Relations between anxiety sensitivity and panic symptoms in nonreferred children and adolescents. Journal of Behavior Therapy and Experimental Psychiatry, 32, 117-136.

Caldirola, D., Perna, G., Arancio, C., Bertani, A., \& Bellodi, L. (1997). The $35 \% \mathrm{CO}_{2}$ challenge test in patients with social phobia. Psychiatry Research, $71(1), 41-48$.

Carr, R. (1998). Panic disorder and asthma: causes, effects and research implications. Journal of Psychosomatic Research, 44(1), 43-52.

Carr, R. (1999). Panic disorder and asthma. Journal of Asthma, 36(2), 143-152.

Carr, R., Lehrer, P., \& Hochron, S. (1992). Panic symptoms in asthma and panic disorder: a preliminary test of the dyspnea-fear theory. Behaviour Research and Therapy, 30, 251-261.

Chambless, D., Caputo, C., Bright, P., \& Gallagher, R. (1984). Assessment of fear of fear in agoraphobics: the body sensations questionnaire and the agoraphobic cognitons questionnaire. Journal of Consulting and Clinical Psychology, 52(6), 1090-1097.

Clark, D. (1986). A cognitive approach to panic. Behaviour Research and Therapy, 24, 461-470. 
Clark, D., Salkovski, P., Hackmann, A., Middleton, H., Anastasiades, P., \& Gelder, M. (1994). A comparison of cognitive therapy, applied relaxation and imipramine in the treatment of PD. British Journal of Psychiatry, 164, 759769.

Coplan, J., Gorman, J., \& Klein, D. (1992). Serotonin-related function in PD: a critical overview. Neuropsychopharmacology, 6, 189-200.

Coryell, W. (1997). Hypersensitivity to carbon dioxide as a disease-specific trait marker. Biological Psychiatry, 41, 259-263.

Craske, M., Poulton, R., Tsao, J., \& Plotkin, D. (2001). Paths to panic disorder/agoraphobia: an exploratory analysis from age 3 to 21 in an unselected birth cohort. Journal of American Acadamy of Child and Adolescent Psychiatry, 40(5), 556-563.

Crowe, R. R., Noyes, R., Pauls, D. L., \& Slymen, D. (1983). A family study of panic disorder. Archives of General Psychiatry, 40(10), 1065-1069.

Donnell, C., \& McNally, R. (1990). Anxiety sensitivity and panic attacks in a nonclinical population. Behaviour Research and Therapy, 28(1), 83-85.

Ehlers, A. (1993). Somatic symptoms and panic attacks: a retrospective study on learning experiences. Behaviour Research and Therapy, 31(3), 269-278.

Ehlers, A. (1995). A one-year prospective study of panic attacks: clinical course and factors associated with maintenance. Journal of Abnormal Psychology, 104, 164-172.

Fleet, R., Lavoie, K., \& Beitman, B. (2000). Is panic disorder associated with coronary artery disease? A critical review of the literature. Journal of Psychosomatic Research, 48, 347-356.

Forsyth, J., Palav, A., \& Duff, K. (1999). The absence of relation between anxiety sensitivity and fear conditioning using $20 \%$ versus $13 \% \mathrm{CO}_{2}$-enriched air as unconditioned stimuli. Behaviour Research and Therapy, 37, 143-153.

Fyer, A. (1995). Schedule for Affective Disorders and Schizophrenia lifetime version. modified for the study of anxiety disorders (updated for DSM-IV). New York State Psychiatric Institute: Anxiety Family Study Unit, Dept. of Therapeutics.

Fyer, M., Uy, J., Martinez, J., Goetz, R., Klein, D., Fyer, A., Liebowitz, M., \& Gorman, J. (1987). $\mathrm{CO}_{2}$ challenge of patients with panic disorder. American Journal of Psychiatry, 144, 1080-1082.

Ginsburg, G., \& Drake, K. (2002). Anxiety sensitivity and panic attack symp- 
tomatology among low-income African-American adolescents. Journal of Anxiety Disorders, 16, 83-96.

Goisman, R., Warshaw, M., Peterson, L., Rogers, M., Cuneo, P., Hunt, M., Tomlin-Albanese, J., Kazim, A., Gollan, J., Epstein-Kaye, T., \& al et. (1994). Panic, agoraphobia, and panic disorder with agoraphobia. Data from a multicenter anxiety disorders study. Journal of Nervous and Mental Disease, 182(2), 72-79.

Goldstein, A., \& Chambless, D. (1978). A reanalysis of agoraphobia. Behavior Therapy, 9, 47-59.

Goldstein, R., Weissman, M., Adams, P., Horwath, E., Lish, J., Charney, D., Woods, S., Sobin, C., \& Wickramaratne, P. (1994). Psychiatric disorders in relatives of probands with panic disorder and/or major depression. Archives of General Psychiatry, 51, 383-394.

Goldstein, R., Wickramaratne, P., Horwath, E., \& Weissmann, M. (1997). Familial aggregation and phenomenology of 'early'-onset (at or before age 20 years) panic disorder. Archives of General Psychiatry, 54, 271-278.

Goodwin, R., \& Pine, D. (2002). Respiratory disease and panic attacks among adults in the United States. Chest, 122, 645-650.

Gorman, J., Askanazi, J., Liebowitz, M., Fyer, A., Stein, J., Kinney, J., \& Klein, D. (1984). Response to hyperventilation in a group of pateints with panic disorder. American Journal of Psychiatry, 141, 857-861.

Gorman, J., Fyer, M., Goetz, R., Askanazi, J., Liebowitz, M., Fyer, A., Kinney, J., \& Klein, D. (1988). Ventilatory physiology of patients with panic disorder. Archives of General Psychiatry, 45, 31-39.

Gorman, J., Kent, J., Martinez, J., Browne, S., Coplan, J., \& Papp, L. (2001). Physiological changes during carbon dioxide inhalation in patients with panic disoder, major depression, and premenstrual dysphoric disoder. Archives of General Psychiatry, 58, 125-131.

Gorman, J., Kent, J., Sullivan, G., \& Coplan, J. (2000). Neuroanatomical hypothesis of panic disorder, revised. American Journal of Psychiatry, 157(4), 493-505.

Gorman, J., Papp, L., Martinez, J., Goetz, R., Hollander, E., Liebowitz, M., \& Jordan, F. (1990). High-dose carbon dioxide challenge test in anxiety disorder patients. Biological Psychiatry, 28, 743-757.

Griez, E., De Loof, C., Pols, H., Zandbergen, J., \& Lousberg, H. (1990). Spe- 
cific sensitivity of patients with panic attacks to carbon dioxide inhalation. Psychiatry Research, 31, 193-199.

Griez, E., Lousberg, H., Van den Hout, M., \& Van der Molen, G. (1987). $\mathrm{CO}_{2}$ vulnerabiltiy in panic disorder. Psychiatric Research, 20, 87-95.

Griez, E., Mammar, N., Loirat, J., Djega, N., Trochut, J., \& Bouhour, J. (2000). Panic disorder and idiopathic cardiomyopathy. Journal of Psychosomatic Research, 48, 585-587.

Griez, E., \& Schruers, K. (1998). Experimental pathophysiology of panic. Journal of Psychosomatic Research, 45(6), 493-503.

Griez, E., \& Verburg, C. (1995). Angst, paniek en ademhaling. In J. Den Boer \& H. Westenberg (Eds.), Leerboek angststoornissen. Een neurobiologische benadering (pp. 199-216). Utrecht: De Tijdstroom.

Griez, E., Zandbergen, J., Lousberg, H., \& Van den Hout, M. (1988). Effects of low pulmonary $\mathrm{CO}_{2}$ on panic anxiety. Comprehensive Psychiatry, 29, 490-497.

Griez, E., Zandbergen, J., Pols, H., \& De Loof, C. (1990). Response to $35 \% \mathrm{CO}_{2}$ as a marker of panic in severe anxiety. American Journal of Psychiatry, 147 , 796-797.

Hayward, C., Killen, J., Kraemer, H., \& Taylor, C. (2000). Predictors of panic attacks in adolescents. Journal of American Academy of Child and Adolescent Psychiatry, 39(2), 207-214.

Herjanic, B., \& Campbell, W. (1977). Differentiating psychiatrically disturbed children on the basis of a structured interview. Journal of Abnormal Child Psychology, 5, 127-134.

Hettema, J. M., Neale, M. C., \& Kendler, K. S. (2001). A review and metaanalysis of the genetic epidemiology of anxiety disorders. American Journal of Psychiatry, 158(10), 1568-1578.

Hopper, J., Hannah, M., Macaskill, G., \& Mathews, J. (1990). Twin concordance for a binary trait: III. A bivariate analysis of hay fever and asthma. Genetic Epidemiology, 7, 277-289.

Hornsveld, H., Garssen, B., Fieldeldij Dop, M., Van Spiegel, P., \& De Haes, J. (1996). Double-blind placebo-controlled study of the hyperventilation provocation test and the validility of the hyperventilation syndrome. The Lancet, 348, 154-158.

Horwath, E., Adams, P., Wickramaratne, P., Pine, D., \& Weissman, M. M. (1997). 
Panic disorder with smothering symptoms: evidence for increased risk in first-degree relatives. Depression and Anxiety, 6(4), 147-153.

Imber, S., Pilkonis, P., Sotsky, S., Elkin, I., Watkins, J., Collins, J., Shea, M., Leber, W., \& Glass, D. (1990). Mode-specific effects among three treatments for depression. Journal of Consult of Clinical Psychology, 58, 352-359.

Johnson, J., Cohen, P., Pine, D., Klein, D., Kasen, S., \& Brook, J. (2000). Association between cigarette smoking and anxiety disorders during adolescence and early adulthood. Journal of the Amercian Medical Association, 284, 2348-2351.

Karajgi, B., Rifkin, A., Doddi, S., \& Kolli, R. (1990). The prevalence of anxiety disorders in patients with chronic obstructive pulmonary disease. American Journal of Psychiatry, 147, 200-201.

Kearney, C., Albano, A., Eisen, A., Allan, W., \& Barlow, D. (1997). The phenomenology of panic disorder in youngsters: an empirical study of a clinical sample. Journal of Anxiety Disorders, 11(1), 49-62.

Kendler, K., Heath, A., Martin, M., \& Eaves, L. (1986). Symptoms of anxiety and depression in a volunteer twin population: the etiologic role of genetic and environmental factors. Archives of General Psychiatry, 43, 213-221.

Kent, J., Coplan, J., \& Gorman, J. (1998). Clinical utility of the selective serotonin reuptake inhibitors in the spectrum of anxiety. Biological Psychiatry, 44, 812-824.

Klein, D. (1993). False suffocation alarms, spontanous panics, and related conditions. An integrative hypothesis. Archives of General Psychiatry, 50, $307-$ 317.

Koszycki, D., \& Bradwejn, J. (2001). Anxiety sensitivity does not predict fearful responding to $35 \%$ carbon dioxide in patients with panic disorder. Psychiatry Research, 101(2), 137-143.

Kouzis, A., \& Eaton, W. (2000). Psychopathology and the initiation of disability payments. Psychiatric Services, 51(7), 908-913.

Kovalenko, P., Hoven, C., Wu, P., Wicks, J., Mandell, D., \& Tiet, Q. (2001). Association between allergy and anxiety disorders in youth. Australian and New Zealand Journal of Psychiatry, 35, 815-821.

Lau, J., Calamari, J., \& Waraczynski, M. (1996). Panic attack symptomatology and anxiety sensitivity in adolescents. Journal of Anxiety Disorders, 10(5), 355-364. 
Lecrubier, Y., Sheehan, D., Weiller, E., Amorim, P., Bonora, I., Harnett Sheehan, K., Janavs, J., \& Dunbar, G. (1997). The International Neuropsychiatric Interview (MINI). A short diagnostic structured interview: reliability and validity according to the CIDI. European Psychiatry, 12, 224-231.

Leinonen, E., Lepola, U., Turtonen, I., Wade, A., \& Letho, H. (1990). Citalopram controls phobic symptoms in patients with PD: randomized, controlled trial. Journal of Psychiatry and Neuroscience, 25, 24-32.

Lepola, U., Leinonen, E., \& Turtoten, J. (1994). The effect of citalopram in PD and agoraphobia: a pilot study. Nordic Journal of Psychiatry, 48, 13-17.

Lepola, U., Wade, A., Leinonen, E., Koponen, H., Frazer, J., Sjodin, I., Penttinen, I., Pedersen, T., \& Letho, H. (1998). A controlled, prospective, one-year trial of citalopram in the treatment of PD. Journal of Clinical Psychiatry, $59,528-534$.

Maier, W., Lichtermann, D., Minges, J., Oehrlein, A., \& Franke, P. (1993). A controlled family study in panic disorder. Journal of Psychiatry Research, $27,79-87$.

Maller, R., \& Reiss, S. (1992). Anxiety sensitivity in 1984 and panic attacks in 1987. Journal of Anxiety Disorders, 6, 241-247.

Malt, E., Berle, J., Olafsson, S., Lund, A., \& Ursin, H. (2000). Fibromyalgia is associated with panic disorder and functional dyspepsia with mood disorders. a study of women with random sample population controls. Journal of Psychosomatic Research, 49, 285-289.

Mannuzza, S., Klein, R., Moulton, J., Scarfone, N., Malloy, P., Vosburg, S., \& Klein, D. (2002). Anxiety sensitivity among children of parents with anxiety disorders: a controlled high-risk study. Journal of Anxiety Disorders, 16, 135-148.

Marks, I., \& Mathews, A. (1979). Brief standard self-rating for phobic patients. Behavior Research and Therapy, 17, 263-267.

Mavissakalian, M., Perel, J., Talbott-Green, M., \& Sloan, C. (1998). Gauging the effectiveness of extended imipramine treatment for PD with agoraphobia. Biological Psychiatry, 43, 848-854.

McNally, R. (1994). Panic disorder: a critical analysis. New York: Guilford Press.

McNally, R. (1996). Anxiety sensitivity is distinguishable from trait anxiety. In R. Rapee (Ed.), Current controversies in anxiety disorders research (pp. 
214-227). New York: Guilford Press.

McNally, R. (1999). Theoretical approaches to the fear of anxiety. In S. Taylor (Ed.), Anxiety sensitivity: theory, research, and treatment of the fear of anxiety. Mahwah, New Jersey: Lawrence Erlbaum Associates.

McNally, R. (2002). Anxiety sensitivity and panic disorder. Biological Psychiatry, $52,938-946$.

McNally, R., \& Lorenz, M. (1987). Anxiety sensitivity in agoraphobics. Journal of Behavior Therapy \& Experimental Psychiatry, 18(1), 3-11.

Mohlman, J., \& Zinbarg, R. (2000). The structure and correlates of anxiety sensitivity in older adults. Psychological Assessment, 12(4), 440-446.

Muris, P., Merckelbach, H., Schmidt, H., \& Mayer, B. (1999). The revised version of the Screen for Child Anxiety Related Emotional Disorders (SCAREDR): factor structure in normal children. Personality and Individual Differences, 26, 99-112.

Muris, P., Schmidt, H., Merckelbach, H., \& Schouten, E. (2001). Anxiety sensitivity in adolescents: factor structure and relationships to trait anxiety and symptoms of anxiety disorders and depression. Behaviour Research and Therapy, 39, 89-100.

Nascimento, I., Nardi, A., Valenca, A., Lopes, F., Mezzasalma, M., Nascentes, R., \& Zin, W. (2002). Psychiatric disorders in asthmatic outpatients. Psychiatry Research, 110, 73-80.

Newman, D., Moffitt, T., Caspi, A., Magdol, L., Silva, P., \& Stanton, W. (1996). Psychiatric disorder in a birth cohort of young adults: prevalence, comorbidity, clinical significance, and new case incidence from ages 11 to 21 . Journal of Consulting and Clinical Psychology, 64(3), 552-562.

Otto, M., Pollack, M., Sachs, G., Rosenbaum, J., \& Fava, M. (1991). Anxiety sensitivity as a diathesis for PD: results from a naturalistic, longitudinal study. (Paper presented at the 147th Annual Meeting of the American Psychiatric Association, Philadelphia)

Overbeek, T., Vermetten, E., \& Griez, E. (2001). Epidemiology of anxiety disorders. In E. Griez, C. Faravelli, D. Nutt, \& J. Zohar (Eds.), Anxiety disorders: an introduction to clinical management and research (pp. 3-23). Chichester: John Wiley and Sons, Ltd.

Owens, K., Hadjistavropoulos, T., \& Asmundson, G. (2000). Addressing the need for appropriate norms when measuring anxiety in seniors. Aging and Mental 
Health, 4(4), 309-314.

Papp, L. A., Klein, D. F., Martinez, J., Schneier, F., Cole, R., Liebowitz, M. R., Hollander, E., Fyer, A. J., Jordan, F., \& Gorman, J. M. (1993). Diagnostic and substance specificity of carbon-dioxide-induced panic. American Journal of Psychiatry, 150(2), 250-257.

Perna, G., Barbini, B., Cocchi, S., Bertani, A., \& Gasperini, M. (1995). 35\% $\mathrm{CO}_{2}$ challenge in panic and mood disorder. Journal of Affective Disorders, 33, 189-194.

Perna, G., Battaglia, M., Gaberi, A., Arancio, C., Bertani, A., \& Bellodi, L. (1994).

Carbon dioxide/oxygen test in panic disorder. Psychiatry Research, 52, 159171.

Perna, G., Bertani, A., Arancio, C., Ronchi, P., \& Bellodi, L. (1995). Laboratory response of patients with panic and obsessive compulsive disorders to $35 \%$ $\mathrm{CO}_{2}$ challenges. American Journal of Psychiatry, 152, 85-89.

Perna, G., Bertani, A., Caldirola, D., \& Bellodi, L. (1996). Family history of panic disorder and hypersensitivity to $\mathrm{CO}_{2}$ in patients with panic disorder. American Journal of Psychiatry, 153, 1060-1064.

Perna, G., Bertani, A., Caldirola, D., Smeraldi, E., \& Bellodi, L. (2001). A comparison of citalopram and paroxetine in the treatment of PD: a randomized, single-blind study. Pharmacopsychiatry, 34, 85-90.

Perna, G., Bertani, A., Diaferia, G., Arancie, C., \& Bellodi, L. (1994). Prevalence of respiratory diseases in patients with panic and obsessive compulsive disorders. Anxiety, 1(2), 100-101.

Perna, G., Bertani, A., Politi, E., Colombo, G., \& Bellodi, L. (1997). Asthma and panic attacks. Society of Biological Psychiatry, 42, 625-630.

Perna, G., Cocchi, S., Bertani, A., Arancio, C., \& Bellodi, L. (1995). Sensitivity to $35 \% \mathrm{CO}_{2}$ in healthy first-degree relatives of patients with panic disorder. American Journal of Psychiatry, 152, 623-625.

Perna, G., Gabriele, A., Caldirola, D., \& Bellodi, L. (1995). Hypersensitivity to inhalation of carbon dioxide and panic attacks. Psychiatry Research, 57(3), 267-273.

Perna, G., Marconi, C., Battaglia, M., Bertani, A., Panzacchi, A., \& Bellodi, L. (1994). Subclinical impairment of lung airways in patients with panic disorder. Biological Psychiatry, 36, 601-605.

Peterson, R., \& Reiss, S. (1987). Test manual for the Anxiety Sensitivity Index. 
Worthington: $\mathrm{OH}$ : International Diagnostic System.

Peterson, R., \& Reiss, S. (1992). Anxiety Sensitivity Index Manual (2 ed.). Worthington: $\mathrm{OH}$ : International Diagnostic Systems.

Pine, D., Cohen, P., Gurley, D., Brook, J., \& Ma, Y. (1998). The risk for earlyadulthood anxiety and depressive disorders in adolescents with anxiety and depressive disorders. Archives of General Psychiatry, 55(1), 56-64.

Pollack, M., Kradin, R., Otto, M., Worthington, J., Gould, R., Sabatino, S., \& Rosenbaum, J. (1996). Prevalence of panic in patients refered for pulmonary function testing at a major medical center. American Journal of Psychiatry, $153,110-113$.

Pols, H., Verburg, K., \& Griez, E. (1994). Carbon-dioxide-induced panic. American Journal of Psychiatry, 151(2), 292-293.

Pols, H., Verburg, K., Hauzer, R., Meijer, J., \& Griez, E. (1996). Alprazolam premedication and $35 \%$ carbon dioxide vulnerability in panic patients. Biological Psychiatry, 40, 913-917.

Pols, H., Zandbergen, J., De Loof, C., \& Griez, E. (1991). Attenuation of carbon dioxide-induced panic after clonazepam treatment. Acta Psychiatrica Scandinavica, 84, 585-586.

Postma, D., \& Kips, J. (1999). Klinische aspecten en onderzoekingen bij astma. In M. Demedts, J. Dijkman, C. Hilvering, \& D. Postma (Eds.), Longziekten (pp. 639-648). Assen: Van Gorcum.

Rabian, B., Peterson, R., Richters, J., \& Jensen, P. (1993). Anxiety sensitivity among anxious children. Journal of Clinical Child Psychology, 22(4), 441446.

Rapee, R., \& Medoro, L. (1994). Fear of physical sensations and trait anxiety as mediators of the response to hyperventilation in non clinical subjects. Journal of Abnormal Psychology, 103, 693-699.

Reiss, S. (1987). Theoretical perspectives on the fear of anxiety. Clinical Psychology Review, 7, 585-596.

Reiss, S. (1991). Expectancy model of fear, anxiety, and panic. Clinical Psychology Review, 11, 141-153.

Reiss, S. (1997). Trait anxiety: it's not what you think it is. Journal of Anxiety Disorders, 11, 201-214.

Reiss, S., \& McNally, R. (1985). Expectancy model of fear. In S. Reiss \& R. Bootzin (Eds.), Theoretical issues in behavior therapy (pp. 107-121). 
New York: Academic Press.

Reiss, S., Peterson, R., Gursky, M., \& McNally, R. (1986). Anxiety sensitivity, anxiety frequency and the prediction of fearfulness. Behaviour Research and Therapy, 24(1), 1-8.

Rijcken, B., Schouten, J., \& Kerkhof, M. (1999). Astma en COPD. In M. Demedts, J. Dijkman, C. Hilvering, \& D. Postma (Eds.), Longziekten (pp. 566-569). Assen: Van Gorcum.

Roy-Byrne, P., \& Cowley, D. (1998). Search for pathophysiology of PD. Lancet, $352,1646-1647$.

Sanderson, W., Rapee, R., \& Barlow, D. (1989). The influence of an illusion of control on panic attacks induced via inhalation of $5.5 \%$ carbon dioxideenriched air. Archives of General Psychiatry, 46, 157-162.

Saviotti, F., Grandi, M., Savron, G., Ermentini, R., Bartolucci, G., Conti, S., \& Fava, G. (1991). Characterological traits of recovered patients with PD and agoraphobia. Journal of Affective Disorders, 23, 113-117.

Schmidt, N., \& Koselka, M. (2000). Gender differences in patients with panic disorder: evaluating cognitive mediation of phobic avoidance. Cognitive Therapy and Research, 24(5), 533-550.

Schmidt, N., Lerew, D., \& Jackson, R. (1997). The role of anxiety sensitivity in the pathogenesis of panic: prospective evaluation of spontaneous panic attacks during acute stress. Journal of Abnormal Psychology, 106, 355-364.

Schmidt, N., Lerew, D., \& Jackson, R. (1999). Prospective evaluation of anxiety sensitivity in the pathogenesis of panic: replication and extension. Journal of Abnormal Psychology, 108, 532-537.

Schmidt, N., Lerew, D., \& Joiner, T. (1998). Anxiety sensitivity and the pathogenesis of anxiety and depression: evidence for symptom specificity. Behaviour Research and Therapy, 36, 165-177.

Schmidt, N., Lerew, D., \& Joiner, T. J. (2000). Prospective evaluation of the etiology of anxiety sensitivity: test of a scar model. Behaviour Research and Therapy, 38, 1083-1095.

Schmidt, N. B., \& Cook, J. H. (1999). Effects of anxiety sensitivity on anxiety and pain during a cold pressor challenge in patients with panic disorder. Behaviour Research and Therapy, 37(4), 313-323.

Shear, M., Pilkonis, P., Cloitre, M., \& Leon, A. C. (1994). Cognitive behavioral treatment compared with nonprescriptive treatment of panic disorder. 
Archives of General Psychiatry, 51(5), 395-401.

Sheehan, D., Lecrubier, Y., Harnett, K., Janavs, J., Weiller, E., Keskiner, A., Schinka, J., Knapp, E., Sheehan, M., \& Dunbar, C. (1997). The validity of the International Neuropsychiatric Interview (MINI) according to the SCID-P and its reliability. European Psychiatry, 12, 232-241.

Sheehan, D., Lecrubier, Y., Janavs, J., Knapp, E., Weiler, E., Bonora, P., Sheedan, M., Amorim, P., Baker, R., Sheehan, K., \& Lepine, J. (1994). Mini International Neuropsychiatric Interview.

Shipherd, J. C., Beck, J. G., \& Ohtake, P. J. (2001). Relationships between the anxiety sensitivity index, the suffocation fear scale, and responses to $\mathrm{CO}_{2}$ inhalation. Journal of Anxiety Disorders, 15(3), 247-258.

Silverman, W., Fleisig, W., Rabian, B., \& Peterson, R. (1991). Childhood anxiety sensitivity index. Journal of Clinical Child Psychology, 20(2), 162-168.

Simons, A., Garfield, S., \& Murphy, G. (1984). The process of change in cognitive therapy and pharmacotherapy for depression. changes in mood and cognition. Archives of General Psychiatry, 41, 45-51.

Skre, I., Onstad, S., Torgersen, S., Lygren, S., \& Kringlen, E. (1993). A twin study of DSM-III-R anxiety disorders. Acta Psychiatrica Scandinavica, $88,85-92$.

Slattery, M., Klein, D., Manuzza, S., Moulton, J., Pine, D., \& Klein, R. (2002). Relationship between seperation anxiety disorder, parental panic disorder, and atopic disorders in children: a controlled high-risk study. Journal of American Academy of Child and Adolescent Psychiatry, 41 (8), 947-954.

Smoller, J., Pollack, M., Otto, M., Rosenbaum, J., \& Kradin, R. (1996). Panic anxiety, dyspnea, and respiratory disease. Theoretical and clinical considerations. American Journal of Respiratory and Critical Care Medicine, 154, 6-17.

Spielberger, C., Gorsuch, R., \& Lushere, R. (1970). STAI manual for the StaitTrait Anxiety Inventory. Palo Alto, California: Consulting Psychologist Press.

Spinhoven, P., Ros, M., Westgeest, A., \& Van der Does, A. (1994). The prevalence of respiratory disorders in panic disorder, major depressive disorder and Vcode patients. Behaviour Research and Therapy, 32, 647-649.

Steerenberg, P., van Loveren, H., Vandebriel, R., Vos, J., Opperhuizen, A., \& van Amsterdam, J. (2000). The prevalence of asthma and allergy increases: a 
world-wide problem. Bilthoven: National Institute of Public Health and the Environment.

Stein, M. B., Jang, K. L., \& Livesley, W. (1999). Heritability of anxiety sensitivity: a twin study. American Journal of Psychiatry, 156(2), 246-251.

Stewart, S., Taylor, S., \& Baker, J. (1997). Gender differences in dimensions of anxiety sensitivity. Journal of Anxiety Disorders, 11(2), 179-200.

Taylor, S. (1996). Nature and measurement of anxiety sensitivity: reply to Lilienfeld, Turner, and Jacob (1996). Journal of Anxiety Disorders, 10(5), 425451 .

Taylor, S. (1999). Anxiety sensitivity: theory, research, and treatment of fear of anxiety. Mahwah, New Jersey: Laurence Erlbaum Associates.

Taylor, S., \& Cox, B. (1998). Anxiety sensitivity: multiple dimensions and hierarchic structure. Behaviour Research and Therapy, 36, 37-51.

Taylor, S., Koch, W., \& McNally, R. (1992). How does anxiety sensitivity vary across the anxiety disorders? Journal of Anxiety Disorders, 6, 249-259.

Taylor, S., Koch, W., Woody, S., \& McLean, P. (1996). Sensitivity and depression: how are they related? Journal of Abnormal Psychology, 105(3), 474-479.

Telch, M., Lucas, J., Schmidt, N., Hanna, H., Jaimez, T., \& Lucas, R. (1993). Group cognitive-behavioral treatment of panic disorder. Behaviour Research and Therapy, 31, 279-287.

Torgersen, S. (1983). Genetic factors in anxiety disorders. Archives of General Psychiatry, 40, 1085-1089.

Torgersen, S. (1988). Genetics. In C. Last \& M. Hersen (Eds.), Handbook of anxiety disorders (pp. 159-170). New York: Pergamon Press.

Turner, S., Beidel, D., \& Costello, A. (1987). Psychopathology in the offspring of anxiety disorders patients. Journal of Consulting and Clinical Psychology, 55(2), 229-235.

Unnewehr, S., Schneider, S., Florin, I., \& Margraf, J. (1998). Psychopathology in children of patients with panic disorder or animal phobia. Psychopathology, 3I(2), 69-84.

Van den Hout, M., \& Griez, E. (1984). Panic symptoms after inhalation of carbon dioxide. British Journal of Psychiatry, 144, 503-507.

Van Widenfelt, B., Siebelink, B., Goedhart, A., \& Treffers, P. (2002). The Dutch Childhood Anxiety Sensitivity Index: psychometric properties and factor structure. Journal of Clinical Child and Adolescent Psychology, 3I(1), 90- 
100.

Van Beek, N., \& Griez, E. (2000). Reactivity to a $35 \% \mathrm{CO}_{2}$ challenge in healthy first-degree relatives of patients with panic disorder. Biological Psychiatry, 47, 830-835.

Van Beek, N., \& Griez, E. (2003). Anxiety sensitivity in first-degree relatives of patients with panic disorder. Behaviour Research and Therapy, 4l(8), 949-957.

Van Beek, N., Schruers, K., \& Griez, E. (submitted for publication). Does age or sex influence anxiety sensitivity.

Vasey, M., Daleiden, E., Williams, L., \& Brown, L. (1995). Biased attention in childhood anxiety disorders: a preliminary study. Journal of Abnormal Child Psychology, 23(2), 267-279.

Verburg, C., Griez, E., \& Meijer, J. (1994). A 35\% carbon dioxide challenge in simple phobias. Acta Psychiatrica Scandinavica, 90(6), 420-423.

Verburg, K., De Leeuw, M., Pols, H., \& Griez, E. (1997). No dynamic lung function abnormalities in panic disorder patients. Biological Psychiatry, 41, 834-836.

Verburg, K., Griez, E., Meijer, J., \& Pols, H. (1995a). Discrimination between panic disorder and generalized anxiety disorder by $35 \%$ carbon dioxide challenge. American Journal of Psychiatry, 152, 1081-1083.

Verburg, K., Griez, E., Meijer, J., \& Pols, H. (1995b). Respiratory disorders as a possible predisposing factor for panic disorder. Journal of Affective Disorders, 33(2), 129-134.

Verburg, K., Perna, G., Bellodi, L., \& Griez, E. (1998). The $35 \% \mathrm{CO}_{2}$ panic provocation challenge as a diagnostic test for panic disorder. In L. Bellodi \& G. Perna (Eds.), The panic respiration connection (pp. 51-68). Milan, Italy: MDM Medical Media.

Verburg, K., Perna, G., \& Griez, E. (2001). A case study of the $35 \% \mathrm{CO}_{2}$ challenge. In E. Griez, C. Faravelli, D. Nutt, \& J. Zohar (Eds.), Anxiety disorders: an introduction to clinical management and research (pp. 341-357). Chichester: John Wiley \& Sons, Ltd.

Watt, M., Stewart, S., \& Cox, B. (1998). A retrospective study of the learning history origins of anxiety sensitivity. Behaviour Research and Therapy, 36 , $505-525$.

Weems, C., Hayward, C., Killen, J., \& Taylor, C. (2002). A longitudinal investiga- 
tion of anxiety sensitivity in adolescence. Journal of Abnormal Psychology, 111(3), 471-477.

Weems, C. F., Hammond-Laurence, K., Silverman, W. K., \& Ginsburg, G. S. (1998). Testing the utility of the anxiety sensitivity construct in children and adolescents referred for anxiety disorders. Journal of Clinical Child Psychology, 27(1), 69-77.

Weissman, M. (1993). Family genetic studies of panic disorder. Journal of Psychiatric Research, 27(1), 69-78.

Weissman, M. M., Bland, R. C., Canino, G. J., Faravelli, C., Greenwald, S., Hwu, H. G., Joyce, P. R., Karam, E. G., Lee, C. K., Lellouch, J., Lepine, J. P., Newman, S. C., Oakley-Browne, M. A., Rubio-Stipec, M., Wells, J. E., Wickramaratne, P. J., Wittchen, H. U., \& Yeh, E. K. (1997). The crossnational epidemiology of panic disorder. Archives of General Psychiatry, 54(4), 305-309.

Welkowitz, L., Papp, L., Martinez, J., Browne, S., \& Gorman, J. (1999). Instructional set and physiological response to $\mathrm{CO}_{2}$ inhalation. American Journal of Psychiatry, 156(5), 745-748.

Wittchen, H., \& Essau, C. (1993). Epidemiology of panic disorder: progress and unresolved issues. Journal of Psychiatric Research, 27(Suppl 1), 47-68.

Woods, S., Charney, D., Delgado, P., \& Heninger, G. (1990). The effect of longterm imipramine treatment on carbon dioxide-induced anxiety in panic disorder patients. Journal of Clinical Psychiatry, 51, 505-507.

Yellowlees, P., Alpers, J., Bowden, J., Bryant, G., \& Ruffin, R. (1987). Psychiatric morbidity in patients with chronic airflow obstruction. The Medical Journal of Australia, 146, 305-307.

Yellowlees, P., Haynes, S., Potts, N., \& Ruffin, R. (1988). Psychiatric morbidity in patients with life-threatening asthma: initial report of a controlled study. The Medical Journal of Australia, 149, 246-249.

Zandbergen, J., Bright, M., Pols, H., Fernandez, I., De Loof, C., \& Griez, E. (1991). Higher life-time prevalence of respiratory diseases in panic disorder? American Journal of Psychiatry, 148(1583-1585).

Zandbergen, J., Lousberg, H., Pols, H., De Loof, C., \& Griez, E. (1990). Hypercarbia versus hypocarbia in panic disorder. Journal of Affective Disorder, $18,75-81$.

Zinbarg, R., Barlow, D., \& Brown, T. (1997). Hierarchical structure and general 
factor saturation of the anxiety sensitivity index: evidence and implications. Psychological Assessment, 9, 277-284.

Zvolensky, M., McNeil, D., Porter, C., \& Stewart, S. (2001). Assessment of anxiety sensitivity in young American Indians and Alaska Natives. Behaviour Research and Therapy, 39, 477-493.

Zvolensky, M., Schmidt, N., \& Stewart, S. (2003). Panic disorder and smoking. Clinical Psychology: Science and Practice, 10, 29-51. 


\section{Summary}

Individuals suffering from panic disorder experience recurrent and unexpected panic attacks. Panic attacks are marked by fear and symptoms such as palpitations and dyspnea. It has been established that genetic and familial influences play an important role in the development of panic disorder. The objective of the present thesis was to investigate a number of vulnerability factors in panic disorder patients and their first-degree relatives. The factor $\mathrm{CO}_{2}$ sensitivity may identify subjects with a predisposition to develop a panic disorder. Hence, we examined whether $\mathrm{CO}_{2}$ sensitivity is a marker of a vulnerability to panic disorder. Furthermore, cognitive as well as physiological factors may play a role in explaining the $\mathrm{CO}_{2}$ sensitivity. They were hypothesized to be important factors that might be transmitted in panic disorder families. Accordingly, the role of anxiety sensitivity and respiratory pathophysiology as vulnerability factors were investigated.

The $35 \% \mathrm{CO}_{2}$ challenge is used to provoke panic-like symptoms in the laboratory. A considerable amount of previous research has shown that panic disorder patients are more vulnerable to $35 \% \mathrm{CO}_{2}$ than other populations (see Introduction Chapter 1). In Chapter 2, results showed that first-degree relatives of panic disorder patients, who had never experienced a panic attack, were also more reactive to the $35 \% \mathrm{CO}_{2}$ challenge than healthy control participants. This suggests that $\mathrm{CO}_{2}$ hypersensitivity may be a marker of a familial vulnerability to panic disorder.

The nature of the $\mathrm{CO}_{2}$ vulnerability, however, remains unclear. The cognitive factor anxiety sensitivity may explain this vulnerability to $\mathrm{CO}_{2}$. Anxiety sensitivity refers to individual differences in the fear of anxiety-related sensations and the expectations that such sensations can have harmful consequences. The $\mathrm{CO}_{2}$ challenge may provoke sensations, feared by highly anxiety sensitive first-degree relatives of panic disorder patients. Hence, it would be important to establish if these first-degree relatives have elevated AS levels at all (Chapter 4). The results 
pointed out that first-degree relatives of panic disorder patients were more anxiety sensitive than control participants, suggesting that anxiety sensitivity runs in families.

As a methodological side issue, the influence of age and sex on anxiety sensitivity levels was examined in Chapter 3 . We found that neither age nor sex has a clear influence on anxiety sensitivity in this particular sample of panic disorder patients.

In Chapter 5, a study on a sub sample of first-degree relatives of panic disorder patients, namely children, was presented. Children of panic disorder patients are most likely to be more at risk of developing panic disorder than older firstdegree relatives. Under the assumption that anxiety sensitivity is a risk factor for the development of panic disorder, we studied whether they display higher levels of anxiety sensitivity than control children. Somewhat unexpectedly, children of panic disorder patients did not differ in anxiety sensitivity from control children. Nevertheless, the possibility remains that anxiety sensitivity might be a developing vulnerability factor in children of panic disorder patients, that may increase towards late adolescence or early adulthood.

We further elaborated on the theme of anxiety sensitivity in Chapter 6. Results of this study showed a significant reduction of anxiety sensitivity levels in panic disorder patients after treatment of a SSRI.

Research has repeatedly demonstrated an association between respiratory disorders and panic. In Chapter 7, a study was presented on the prevalence of respiratory disorders in panic disorder families. We found that first-degree relatives of panic disorder patients reported significantly more chronic obstructive pulmonary diseases in general and asthma in particular, than those of other anxiety disorder patients. Given the fact that both asthma and panic disorder run in families, our findings may suggest a specific association between the two disorders.

The link between respiratory pathology and panic disorder has been further investigated in Chapter 8 . The increased $\mathrm{CO}_{2}$ vulnerability displayed by panic disorder patients may be related to lifetime respiratory pathology. Our results revealed that panic disorder patients with a history of respiratory disorders were not more anxious, did not show more panic symptoms, and did not have more panic attacks after the $\mathrm{CO}_{2}$ challenge than panic disorder patients without such a history. It was concluded that a history of respiratory disorders is not a crucial factor in $\mathrm{CO}_{2}$ vulnerability in panic disorder patients. This supports the idea that having a 
panic disorder is in itself an important factor in $\mathrm{CO}_{2}$ vulnerability.

The results of the studies in the present thesis indicate that $\mathrm{CO}_{2}$ sensitivity seems to be a marker of a vulnerability to panic disorder. Furthermore, anxiety sensitivity as well as respiratory pathology appear to be vulnerability factors in risk for panic disorder. Apparently, all these factors interact in complex ways over time (see Concluding remarks Chapter 9). 



\section{Samenvatting}

Mensen die lijden aan een paniekstoornis ervaren terugkerende en onverwachte paniekaanvallen. Angst en symptomen, zoals palpitaties en dyspneu zijn kenmerken van een paniekaanval. Het is aangetoond dat genetische en familiale invloeden een belangrijke rol spelen in de ontwikkeling van een paniekstoornis. Het doel van dit proefschrift was om een aantal kwetsbaarheidsfactoren in paniekpatiënten en hun eerstegraads familieleden te onderzoeken. De factor $\mathrm{CO}_{2}$-gevoeligheid kan mogelijk personen met een predispositie om een paniekstoornis te ontwikkelen, identificeren. Vandaar dat we onderzocht hebben of $\mathrm{CO}_{2}$-sensitiviteit een marker is van een kwetsbaarheid voor een paniekstoornis. Verder kunnen zowel cognitieve als fysiologische factoren een rol spelen in het verklaren van deze $\mathrm{CO}_{2}$-gevoeligheid. Deze factoren worden verondersfeld belangrijke elementen te zijn die doorgegeven kunnen worden in families waarin paniekstoornissen voorkomen. Hiermee in overeenstemming werden de rol van angstgevoeligheid (anxiety sensitivity) en respiratoire pathofysiologie als kwetsbaarheidsfactoren onderzocht.

De $35 \% \mathrm{CO}_{2}$-provocatietest wordt gebruikt om paniekachtige symptomen in het laboratorium op te wekken. Een aanzienlijke hoeveelheid aan onderzoek heeft aangetoond dat paniekpatiënten gevoeliger zijn voor $35 \% \mathrm{CO}_{2}$ dan andere populaties (zie Introductie Hoofdstuk 1). In Hoofdstuk 2 laten resultaten van een experiment zien dat eerstegraads verwanten van paniekpatiënten, die nooit een paniekaanval hebben ervaren, ook meer reageren op de $35 \% \mathrm{CO}_{2}$-provocatietest dan gezonde controledeelnemers. Dit suggereert dat het zeer gevoelig zijn voor $35 \% \mathrm{CO}_{2}$ een marker kan zijn voor een familiale kwetsbaarheid voor een paniekstoornis.

Echter de aard van de $\mathrm{CO}_{2}$-gevoeligheid blijft onduidelijk. De cognitieve factor angstgevoeligheid kan deze kwetsbaarheid voor $\mathrm{CO}_{2}$ misschien verklaren. 
Angstgevoeligheid verwijst naar individuele verschillen in de vrees voor angstgerelateerde sensaties en de verwachtingen dat zulke sensaties schadelijke consequenties hebben. De $\mathrm{CO}_{2}$-provocatietest kan sensaties opwekken die hoogangstige eerstegraads familieleden van paniekpatiënten vrezen. Daarom is het belangrijk om eerst vast te stellen of eerstegraads verwanten überhaupt een verhoogd niveau van angstgevoeligheid hebben (Hoofdstuk 4). De resultaten tonen aan dat eerstegraads verwanten van paniekpatiënten angstgevoeliger zijn dan controledeelnemers. Dit suggereert dat angstgevoeligheid in de familie zit.

In Hoofdstuk 3 wordt de invloed van leeftijd en geslacht op angstgevoeligheid onderzocht in een methodologisch georiënteerde studie. In deze steekproef van paniekpatiënten werd gevonden dat noch leeftijd, noch geslacht een duidelijke invloed op angstgevoeligheid heeft.

In Hoofdstuk 5 wordt een studie beschreven over een subgroep van eerstegraads familieleden van paniekpatiënten, namelijk kinderen. Kinderen van paniekpatiënten hebben waarschijnlijk een hoger risico op het ontwikkelen van een paniekstoornis dan oudere eerstegraads familieleden. Uitgaande van de assumptie dat angstgevoeligheid een risicofactor is voor de ontwikkeling van een paniekstoornis, onderzochten we of deze kinderen angstgevoeliger waren dan controlekinderen. Enigszins onverwacht verschilden de kinderen van paniekpatiënten niet in angstgevoeligheid van de controlekinderen. Desondanks blijft de mogelijkheid bestaan dat angstgevoeligheid een kwetsbaarheidsfactor is die zich nog ten volle kan ontwikkelen in de late adolescentie en vroege volwassenheid bij kinderen van paniekpatiënten.

De factor angstgevoeligheid wordt verder bestudeerd in Hoofdstuk 6. Resultaten van deze studie laten zien dat de angstgevoeligheid reduceert bij paniekpatiënten na behandeling met een SSRI.

Het is al herhaaldelijk aangetoond dat er een associatie bestaat tussen respiratoire aandoeningen en paniek. Een studie over de prevalentie van respiratoire aandoeningen in families met een paniekstoornis wordt in Hoofdstuk 7 beschreven. We hebben gevonden dat eerstegraads verwanten van paniekpatiënten in het algemeen significant meer chronisch obstructieve longaandoeningen, en specifiek astma, hebben dan familieleden van patiënten met een andere angststoornis. Gegeven het feit dat zowel astma als de paniekstoornis familiaal is, suggereren deze bevindingen een specifieke associatie tussen beide aandoeningen.

De relatie tussen respiratoire pathologie en de paniekstoornis wordt verder on- 
derzocht in Hoofdstuk 8. De verhoogde $\mathrm{CO}_{2}$-gevoeligheid die paniekpatiënten vertonen kan gerelateerd zijn aan de respiratoire pathologie gedurende hun leven. Onze resultaten laten zien dat paniekpatiënten met een geschiedenis van respiratoire aandoeningen niet angstiger reageren, niet meer panieksymptomen rapporteren, en niet meer paniekaanvallen hebben na een $\mathrm{CO}_{2}$-provocatietest dan paniekpatiënten zonder dergelijke geschiedenis. We kunnen hieruit concluderen dat een geschiedenis van respiratoire aandoeningen geen cruciale factor is in de $\mathrm{CO}_{2}$-gevoeligheid van paniekpatiënten. Dit ondersteunt het idee dat het hebben van een paniekstoornis op zichzelf een belangrijke factor is in $\mathrm{CO}_{2}$-gevoeligheid.

De resultaten van de studies in dit proefschrift tonen dat $\mathrm{CO}_{2}$-gevoeligheid een marker kan zijn van een kwetsbaarheid voor een paniekstoornis. Daarenboven lijken zowel angstgevoeligheid als respiratoire aandoeningen kwetsbaarheidsfactoren te zijn voor het risico op een paniekstoornis. Echter, alle eerdergenoemde factoren staan vermoedelijk op complexe wijze met elkaar in wisselwerking (zie Afsluitende opmerkingen Hoofdstuk 9). 



\section{Dankwoord}

\section{De trein}

De trein vertrok vanuit Maastricht, station Academisch Angstcentrum (AAC), PMS Vijverdal. Geleidelijk aan vulde de trein zich met medereizigers. Als eerste ben ik alle deelnemers zeer dankbaar dat ze zich voor onderzoek in wilden zetten. Want bovenal, zonder deze passagiers had de trein geen bestemming. Ik waardeer het zeer dat met name de patiënten op deze manier bij wilden dragen aan de kennis over de paniekstoornis waaraan zij zelf leden.

Niet alleen de proefpersonen hebben meegewerkt aan dit proefschrift, want zonder machinist komt een trein niet vooruit. Professor Griez, Eric, van u heb ik het vak wetenschappelijk onderzoeker geleerd. Ik wil ú bedanken voor uw inspirerende kijk op onderzoek. Ik ben blij dat ik van u geleerd heb om eerst de ruwe data te visualiseren in grafieken alvorens statistische analyses erop los te laten. Ook vond ik uw wetenschappelijke schrijfadviezen zeer waardevol. U gaf me de ruimte om plannen te ontwikkelen en uit te voeren. Ik heb meer dan alleen wetenschap geleerd. Ik vond het prettig dat $\mathrm{u}$ me de gelegenheid gaf om onderzoek te doen in Italië. Bij deze wil ik dan ook Giampaolo Perna en zijn gastvrije team bedanken. Grazie!

Op een trein hoort ook een co-machinist en tijdens de reis, stapte dr. Schruers op de rijdende trein. Koen, bedankt dat je mijn co-promotor en, zelfs in een hectische tijd, tijdelijk mijn duurste onderzoeksassistent ooit ;-) wilde zijn. Ik waardeer het dat ik mijn mening bij je kwijt kon.

De trein bolderde verder en af en toe stopte hij bij een tussenstation. Inmiddels waren een aantal (ex)-collega's van het AAC ingestapt die ik graag bij naam vernoem. Mark Ahsmann, Marjan Böhm, Denise Cobben, Klara de Cort, Ann Goorts, Marie-Jeanne Haack, Louis Kersten, Femmie Kruizinga, Jamie Luermans, Rudy 
Nijssen, Thea Overbeek, Julien Peeters, Henk Pols, Nicole Theunissen, Mariette Ubaghs, Marlies van Duinen, Marijke van Kempen, Manuela Walraeven-Nix en François Wilms, bedankt voor jullie medewerking en collegialiteit. Het zijn de therapeuten en artsen die ervoor zorgdragen dat patiënten weer met de trein durven reizen. In het bijzonder wil ik Inge Leclaire en Nicolette Bongaerts bedanken voor hun praktische assistentie bij de reis. Zonder jullie hulp zouden de studies in dit proefschrift heel wat moeizamer tot stand zijn gekomen. En met dit over de jaren heen uitgebreide team is er nog meer vlaai om van te smullen.

De trein werd steeds voller, want ook de onmisbare secretaresses van de capaciteitsgroep en collega's van de universiteitsgang reisden mee. Met name Lea Esten, Jolanda Koch, Ine Kusters en vooral Leni Noteborn, bedankt voor jullie altijd vriendelijke service. Rob van Diest, bedankt voor het opzetten van onze internetfaciliteiten. Gelukkig was jij, als vrijwilliger, bereid de gang hiermee steeds weer behulpzaam te zijn. Ik zal het geroep op de gang "wie zit er op het net" nog bijna gaan missen.

Deze treinreis was een bijzondere periode in mijn leven en ik bedank mijn vrienden die op de perrons voor me klaar stonden. In het bijzonder wil ik mijn paranimfen Heidi Rijnen en Machteld Ouwens bedanken. Heidi, onze afspraken, met name het zwemmen, deden en doen me altijd erg goed. Machteld, ik ben blij dat ik al een hele tijd je vriendin mag zijn. Mijn ouders ben ik zeer dankbaar voor hun onvoorwaardelijke steun vanaf het prille begin. Ingrid, zonder jou was deze treinreis vast niet zo gezellig geweest. En, ik ben blij dat er telefoon bestaat.

Stephan, deze reis verliep een stuk vlotter met jou erbij. Ik waardeer het zeer dat ik zoveel steun van je mocht ontvangen. Is de lay-out van dit boekje niet prachtig...

De trein vermindert vaart. De bestemming is bereikt. 


\section{Curriculum vitae}

Nicole van Beek werd in 1974 in Maarheeze geboren. Na het behalen van haar VWO-diploma aan het Mill-Hillcollege te Goirle, vertrok zij als au pair naar Groot-Brittannië. Daarna ging zij in 1993 Gezondheidswetenschappen studeren aan de Universiteit Maastricht. In 1994 behaalde zij het propedeutisch examen en voltooide de afstudeerrichting Geestelijke Gezondheidkunde in 1998. Aansluitend volgde de aanstelling als Assistent In Opleiding (AIO) bij het Academisch Angtscentrum in het Psychomedisch Streekcentrum Vijverdal en de capaciteitsgroep Psychiatrie en Neuropsychologie van de Universiteit Maastricht. In deze functie heeft zij gedurende drie maanden onderzoek verricht in het het San Raffaele Hospital te Milaan in Italië. De AIO-aanstelling heeft in voorliggend proefschrift geresulteerd. Parallel aan het AIO-schap startte zij in 2000 met de opleiding tot gedragstherapeut van de Vereniging voor Gedragstherapie en Cognitieve Therapie (VGCt). In 2001 voldeed zij aan het aspirant lidmaatschap van de VGCt. 


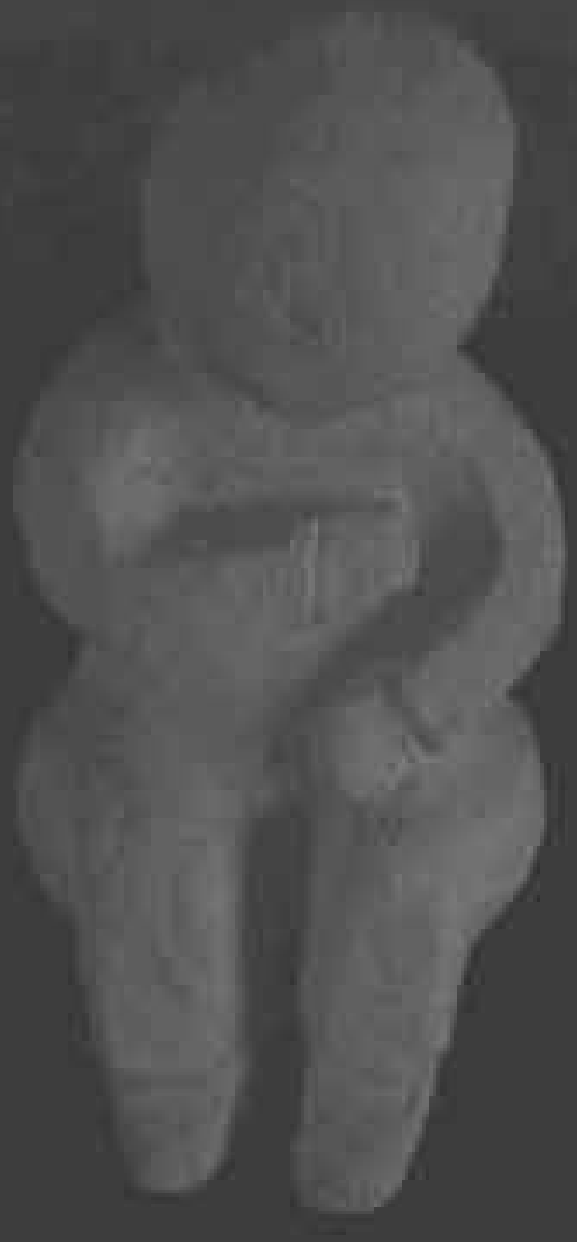

